\title{
Digitizing the Pyrates: Making a Digital Critical Edition of Captain Charles Johnson's A General History of the Pyrates (1724-1726)
}

by

Ingrid Reiche

A thesis submitted to the Faculty of Graduate and Postdoctoral Affairs in partial fulfillment of requirements for the degree of

Master of Arts

in

English Specialization in Digital Humanities

Carleton University

Ottawa, Ontario

(C) 2016, Ingrid Reiche 


\begin{abstract}
Critical editing in a digital environment has changed how bibliographic practices are employed. This thesis investigates how digital critical editing impacts eighteenthcentury literary studies. The way scholars examine questions of author attribution and employ bibliography practices has changed with the advent of digital tools. Since the mid nineteen-nineties, digital editing has taken on various forms, from hypermedia archives to crowdsourced projects. A critical apparatus that provides a high-level of interactivity to elucidate the intricacies of a text over its production in a given time is often overlooked in these projects. By producing a digital edition that compares the first four editions of $A$ General History of the Pyrates (1724-26) using the Versioning Machine V.4.0 and conducting a user experience survey regarding the edition's functionality (both are at http://ingridreiche.com/Resume/Thesis.html), the goal of this project has been to show how eighteenth-century print culture was a highly collaborative space where authorship was unstable.
\end{abstract}




\section{Acknowledgments}

Dedicated to Eric and Mary Ann Reiche for all their encouragement, support, hours of reading and helping to iron out my ideas.

With special thanks to Professor Brian Greenspan for his editorial diligence, insight and patience, and for motivating me to always look beyond my original goals.

To Professor Julie Murray for her editorial input, knowledge and advice about the world of eighteenth-century print culture.

To Professors Shawn Graham and Travis DeCook for being supportive members of my committee.

To the Faculty of English Language and Literature, those who teach in the Digital Humanities Program at Carleton University, and all my colleagues for listening to talk about bibliography and piracy for two years.

To the team who made the Versioning Machine for facilitating my work.

To all those who took the time to participate in my survey in particular: Paul Henke, Rebecca Oatman, and Michael Reiche. 


\section{Table of Contents}

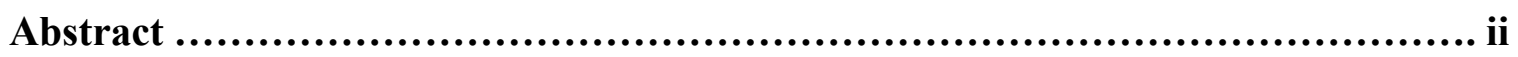

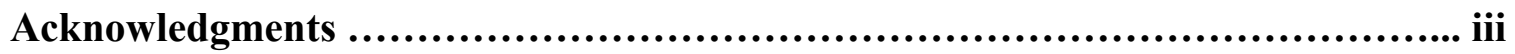

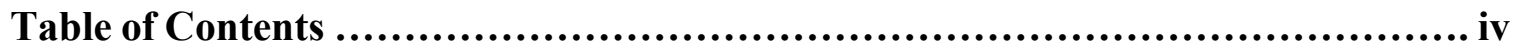

List of Appendices .................................................................. vi

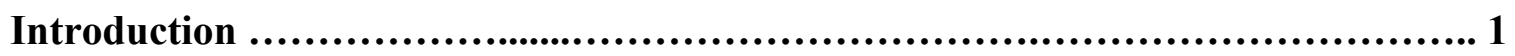

Introduction to the Book .............................................. 6

Chapter 1: Literature Review ...................................................... 8

1.1 A Background to A General History of the Pyrates and its Authorship ...... 17

1.2 Of Captain Charles Johnson ..................................... 18

1.3 Of J.R. Moore: Attribution to Defoe ................................ 20

1.4 The Contestation of Moore's Findings and his Attribution to Defoe .......... 30

Chapter 2: Bibliographic Theory and Digital Editions ........................... 42

2.1 The Copy-Text: Does Digitization Illuminate the Need for Selection? ....... 47

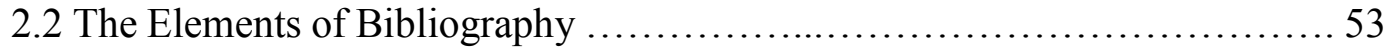

2.3 Types of Scholarly Editions ....................................... 56

Chapter 3: The Long History of the Short Era in Digital Critical Editing ............ 65

3.1 The Materiality of Digital Texts ................................... 68

3.2 Hypertext Theory and Methodology in Digital Critical Editions ............ 71

3.3 The Lens Through Which Digital Editions Can Be Seen .................. 73

3.4 What Text Encoding does to Digital Critical Editions .................... 77

Chapter 4: Making the Digital Critical Edition of $A$ General History of the Pyrates. 84 


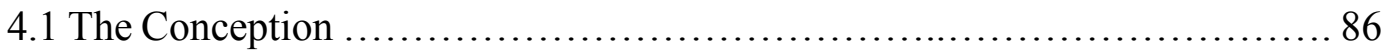

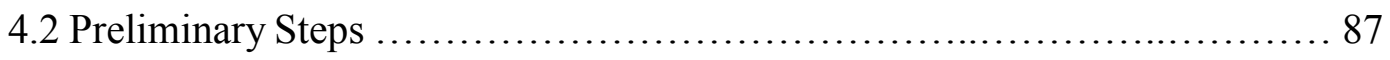

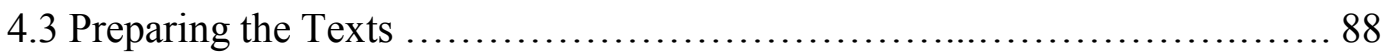

4.4 The Versioning Machine and TEI.................................. 92

4.5 The User Experience Survey_-Its Goals and Results .................. 100

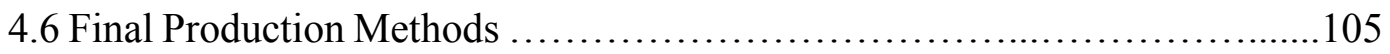

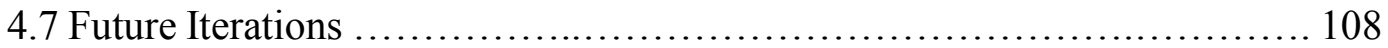

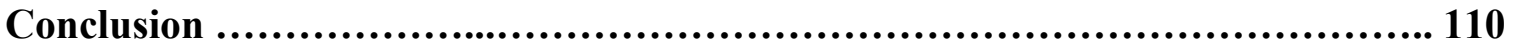

\section{Appendices}

Appendix A ......................................................... 117

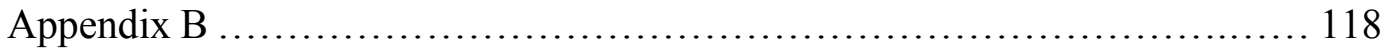

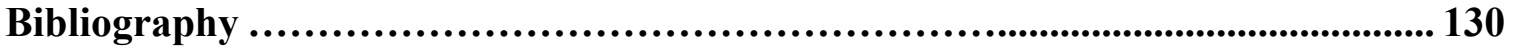


Reiche vi

\section{List of Appendices}

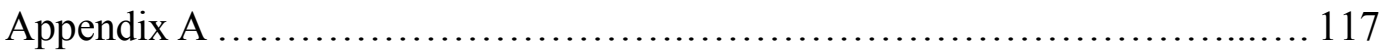

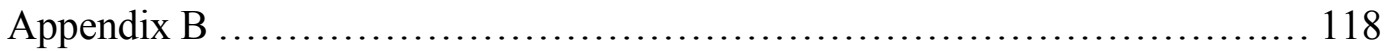




\section{Introduction}

The critical edition is a staple in literary scholarship. Undergraduate students of literature are familiar with the critical editions that are typically reserved for canonical works from the fifteenth to nineteenth century, such as those of Chaucer or Shakespeare, in which editorial notes help contemporary readers understand texts written in Old or Middle English. This type of edition has also been used for poetical works, such as those of Walt Whitman and many others, where significant revisions have been made to the original work. Notes in critical editions of poetry often explain the changes made to a text, or literary devices employed and their significance at the time of publication. Notes in critical editions also often attempt to explain an author's relation to the text, or how the text relates to some personal event in his or her life.

Since the introduction of the World Wide Web in 1990, editors have been producing and exploring ways to apply digital media in editorial practice. This transition from print-based texts to digital texts has changed "the way scholarly editors were dealing with not only the practicalities of critical text editing but also, in a deeper way, with various conceptions about the nature of texts and their transmission" (Apollon, Belisle and Régnier vii). In the process of producing a digital critical edition for Captain Charles Johnson's eighteenth-century book A General History of the Pyrates (1724-26), both the practicalities and the transmission of editing a scholarly edition have been of utmost concern. Decisions about what type of software to use, the presentation, user experience, and how to incorporate a critical apparatus, while at the same time doing due diligence to the historical circumstances under which the original work was produced, have all been issues that I grappled with in the process. Aside from these concerns, there have been a few 
voices asking the other pertinent question: Why make a digital critical edition of this work at all?

In short, the answer to this question is the very reason for this paper, and is because the practices of digital editing change and inform the way one looks at the production of eighteenth-century literature. However, there is also a larger threefold explanation. First, the practice of digital editing changes one's view about the relationship between authors, booksellers and printers, and the production of eighteenth-century literature, forcing one to notice the large and small changes made to a work over the course of its printing history, and how one finds it presented today. Producing a digital critical edition of $A$ General History of the Pyrates was initially inspired by the inquiry into its authorship. In 1932, John Robert Moore, a scholar of eighteenth-century literature and a bibliographer who specialized in the works of Daniel Defoe, attributed the book to Daniel Defoe, though this attribution remains contested. Second, this leads to larger questions about the concept of authorship in that period, as well as the process of author-attribution in the twentiethcentury. The discussion about that process is based from both primary sources from the eighteenth-century, such as those of Edward Young and William Duff who wrote about literature and individual "genius," as well as twentieth-century scholars and bibliographers of Defoe's work, such as J.R. Moore, P.N. Furbank and W.R. Owens, who discuss the question of author-attribution as it applies to this work. Third, alongside this discussion are scholarly writings that address broader questions about the climate of authorship and printing in the eighteenth-century, and help contextualize literary commerce at that time. These discussions are, in many ways, prefatory material that could not be incorporated into the digital critical edition, but which provide a backdrop for the production of the text and 
familiarise readers with eighteenth-century print culture, and the development of and changes to concepts of authorship between the eighteenth and twentieth-centuries.

The process of making/editing a digital critical edition of $A$ General History of the Pyrates, necessitated the incorporation of certain practical considerations. Traditional print critical editions provide readers with a singular reading text, based on all available information, alongside substantial footnotes and introductory material. However, this project uses The Versioning Machine V.4 (hereafter VM 4.0), a software program developed by Susan Schreibman, a scholar of digital editing, which allows for a comparative parallel-text reading of the four editions examined for this thesis. The decision to produce this type of digital edition was based on numerous factors. First, there was the desire to apply traditional principles of descriptive bibliography and include information about the collation, pagination, signatures, and the contents of the source texts, which could be accomplished using the VM 4.0 "Bibliographic Information" pane that allows the editor to add whatever information is deemed important. The second chapter of this thesis provides a thorough discussion of the bibliographic principles developed over the course of the twentieth-century by W.W. Greg, Fredson Bowers, Thomas Tanselle and Ronald McKerrow, and how they have been applied to this project. Thankfully, the VM 4.0 also allows for a "Critical Introduction," which has been written for each section of $A$ General History of the Pyrates included in the digital edition that accompanies this work. Finally, and most importantly, the VM 4.0 allows editors to create a parallel-text reading that provides readers/users with multiple versions (known as witnesses) of the text, instead of producing a singular reading text. However, readers/users may choose to look at any single version as a reading text. This approach to creating a digital critical edition allows 
readers/users to compare the changes throughout the versions an editor has chosen by using interactive highlighting, underlining (which was customized to display as text in a different colour, for the final production of the critical edition accompanying this thesis) and notes to mark the changes and explain them. In this project the first four editions of $A$ General History of the Pyrates were chosen for comparison. A brief discussion of each edition immediately follows this section of the introduction.

What emerged from the work of creating this edition was a vastly improved understanding of the process of encoding a text using extensible mark-up language (XML) in accordance with the Text Encoding Initiative (hereafter TEI) Guidelines, in order to document and make the changes visible to readers/users. A more in-depth discussion of the theories and methodologies of digital editing and encoding a digital edition will be elaborated in Chapter Three and Four of this thesis. The process of encoding led to two realizations. First, by having to document and mark-up each change in the four editions, so users could view these changes, and by providing explanatory notes about each variant in the texts, it became evident, that a substantial amount of material was added to the work in three years. What was more intriguing were the minute changes made to the typesetting, capitalization, spelling, punctuation and wording, which were more numerous than the additions to the text itself. Second, there were numerous ways to encode these differences for transmission to the audience, which begged the question of what was most appealing to the audience. In order to answer this second question, a user experience survey was created and circulated to participants from four different, but sometimes overlapping, fields: scholars in English literature, scholars of the digital humanities, scholars of library and information science, and the general public (being people who may or may not be 
active in academia but are not generally familiar with digital editing platforms). The results of this survey are discussed in Chapter Four of this thesis, and informed the encoding methodology that was employed for the final iteration of the digital edition.

Research into the construction of authorship, the attribution of A General History to Defoe, bibliographic theory, its application in a digital environment, the practice of encoding the work in XML, and the results from the user experience survey and its impact on the final encoding methodology used in the digital critical edition amounted to a firm justification for producing a digital critical edition of $A$ General History. The justification is not because it might help resolve issues surrounding the authorship of the book, or answer questions of author-attribution. It is rather because the practice of encoding the work and producing a digital edition informs questions about eighteenth-century print culture and how the relationship between authors (known or unknown), booksellers, and printers made up the editorial practices of that era. Through writings from the eighteenthcentury, one comes to understand the construction of authorship in that era. From modern and contemporary scholars, and the application of bibliographic principles, one sees how author attribution combined with careful examination of texts, demonstrates that the production of literature in the eighteenth-century was much more of a collaborative process, and that a single individual rarely, if ever, had control over the changes made to a book. As works travelled from one bookseller to another, and from one printer to the next, small changes became apparent and the culmination of all these little changes results, in this case, in a significant expansion of $A$ General History. From whence these changes and expansions came remains elusive, but they are the result of many hands, not one. Changes in typesetting may be from printers, while additional material may have come from the 
author, or may have been added at the request of a bookseller and written by a different hand. Revisions were plentiful, and while some were of little consequence, others, such as additional chapters, changes to the organization, layout and continuity of a work, were of more significance.

Introduction to the Book

A General History of The Pyrates was first printed at the end of what is seen as "the great age of piracy, which began in 1650 and was brought to an abrupt end around 1725" (Cordingly XVII). This great age of piracy "reaches its peak around 1720, when some two thousand pirates were terrorizing ships on both sides of the Atlantic and seriously threatening the trade of the American colonies" (Cordingly XVII). During the end of this period many pirate leaders met their death in public "mass hangings" (Cordingly XVI). So it is not surprising that the first printing of this book was in 1724, just as the "great age of piracy" was coming to a close. This first printing was for Charles Rivington under the title, A General History of the Robberies and Murders of the most Notorious Pyrates, and also Their Policies, Discipline and Government, From Their first Rise and Settlement in the Island of Providence, in 1717, to the present Year 1724. The Title Page names one Captain Charles Johnson as its author, as do the subsequent three editions.

The first edition contained fourteen chapters about thirteen different pirate Captains (the second chapter, titled the "Rise of the Pyrates," was not about any particular Captain) (Johnson ed.1: Title Page). In the following two years, three more editions were published. The second edition, printed for T. Warner, appeared later in 1724 under the title, A General History of the Pyrates, From Their first Rise and Settlement in the Island of Providence, to the present Time (ed.2: Title Page). This edition included three additional chapters about 
pirate Captains, renamed "The Rise of Pyrates" to the "Introduction," and renamed one "Captain Thatch" as "Captain Teach" (ed.1: Title Page; ed.2: Title Page). The third edition, bearing the same title as the second, was also printed for T. Warner in 1725, and added one more chapter about "Captain Smith," so that the book now contained a total of seventeen chapters about sixteen pirates (ed.3: Title Page). That same year, a smaller work of seventyfive pages was printed for Edward Midwinter bearing the title, The General History and Lives of all the most Notorious Pirates, and Their Crews (anon.). This work does not name any author, and its Title Page does contain the names of Captains John Gow and his lieutenant James Williams. Captain Gow mentioned in this smaller work is actually the same Captain added to the third edition of A General History, under the alias Captain Smith.

Finally, in 1726 a fourth edition appeared in two volumes, though the second volume may have been published in 1728 , as will be discussed later in Chapter One. This fourth edition was printed for T. Woodward, and the Title Page of its first volume is identical to the one of the third edition with the exception of it having "The Fourth EDITION. | VOL. I.," as well a different place of printing and a different person for whom it was printed (ed.4: Title Page). The second volume, however, lists fifteen totally new pirate Captains, one of whom is Captain Williams, mentioned on the Title Page of the work printed for Edward Midwinter in 1725. Its Title Page is significantly different from the first three editions and that of Volume I. First, its title is The History of The Pyrates; second, there are no chapter numbers; third, it has two lengthy paragraphs regarding a "Description of Magadoxa in Ethiopia" and "An Appendix, which compleats the Lives of the first Volume"; fourth, the author's title of Captain is abbreviated to "Capt." (ed.4: Title Page). 
Between these four editions, A General History of the Pyrates grew from its original 326 pages to 882 in the two volumes printed in 1726(28). Volume I of the fourth edition was 452 pages, meaning that an additional 126 pages were added to the original single book, and Volume II contained 430 pages of totally new work; one begins to wonder where all the information about the additional pirates came from. Many theories have been suggested, including that the author may have been a careful revisionist who desperately wanted his work to sell; that the printers may have commissioned the additional material; and that someone else entirely could have written Volume II in hopes of making money off the book. There have also been numerous debates about the authorship of this book, which will provide some insight into both the history of the book and the additional material found in editions two through four. Though the controversy over authorship is not the main focus of this thesis, by engaging in a discussion surrounding the question of $A$ General History of the Pyrates authorship and by using digital tool to track the changes to the work over time, what did become apparent is that the concept authorship and the production of literature in the eighteenth century was a collaborative space and diverged greatly from its construction by modernist scholars of the twentieth-century.

\section{Chapter 1: Literature Review}

Among the debates about the authorship of A General History of the Pyrates the most prevalent is that Defoe is the author, as claimed by John Robert Moore at the Modern Language Association's conference in 1932. This attribution was more fully developed in his work Defoe in the Pillory and Other Studies (1939). Moore's claim and the many works that contest it are discussed later in this chapter. Before an in-depth discussion and analysis 
of the author-attribution question that has been the source of much debate, it is important to understand that the twentieth-century construction of Defoe and his canon was "not only a recent construction but also one of dubious validity" (Marshall 1). Ashley Marshall's essay, "Fabricating Defoes" (2012) states that modernist "constructions of Defoe have much to do with the canon on which they are based" (2-3). Moore's writings about Defoe from the mid-twentieth-century have much to do with the idea of the author as an independent genius, which emerged in the nineteenth-century, but had begun to take form as early as the eighteenth-century, in the writings of numerous poets, novelists, and critics, including those of William Duff and Edward Young.

In the twentieth-century it became common for critics to assume that one could look "for the author in his or her writings" and that "that the writer's life can be traced in his or her works, and even that we can go to the works for evidence about his or her life (Griffin, Authorship 10). It is this type of logic that Moore applies in his attribution of $A$ General History of the Pyrates to Defoe, primarily because this was a common practice in the attempt to ascertain author-attribution. Moore's work is rigorous in the parallels he draws between A General History of the Pyrates and the many works he believes are attributed to Defoe. But his work also stems largely from what Marshall describes as "the desire to turn Defoe into a 'Great Author' [which] has meant assuming literary aspirations, privileging a small number of not-very-representative texts, and attempting to derive a picture of the man on the basis of the works" (3). This approach is how many bibliographers of the mid-twentieth-century devised authorial attributions to eighteenth-century writers, and one that is problematic. However, Moore did draw on an extremely vast number of 
works, stacking one work on top of another in a circular method of bibliographical practice that will be discussed in Chapter Two.

Part of Moore's construction of Defoe's authorship can be viewed as an extension of "the rise of the independent author" and the application of "the master narrative of liberation" that was cemented by "nineteenth-century historians" (Griffin, Authorship 5). As Griffin argues in Authorship in the Long Eighteenth-Century (2014), this idea is a "fiction" whereby authors were freed from patronage and the subscription system and "gained both dignity and economic power" (5). Griffin goes on to discuss how authors in the nineteenth-century, such as Thomas Babington Macaulay, wrote at a time when "writers could support themselves comfortably with the fruits of their writing" and whose “account of the eighteenth-century literary culture validates his [Macaulay's] celebration of a more perfect present" in the nineteenth century (6). This fiction of liberation endured well into the twentieth-century, and it resonates in Moore's work and his celebration of Defoe. The narrative of the rise of the independent author has its roots in eighteenth-century writings not only about the commerce of writers by figures such as Samuel Johnson and Defoe, but also in the growth of works about the independent literary "genius" that can be found throughout the eighteenth century. Though the ideas of independent literary genius in the eighteenth and nineteenth centuries were construed to some degree as freeing writers from the subscriptions system, "[t]he eighteenth century witnessed momentous changes in the production, distribution and consumption of art. .. [L]iterature was the first among the arts to undergo the changes" (Woodmansee 22). It should also be noted that as the subscription system fell, the rise of the market economy took its place. 
In The Author, Art and the Market, Martha Woodmansee discusses the eighteenthcentury German critics of aesthetics, Karl Philipp Moritz and Johann Wolfgang Goethe. She points out that of "[t]he vast majority of writers, many of them [were] succumbing to the commercial pressures depicted here, churned out imitations and variations on proven popular themes with unprecedented rapidity. Those who did not - the 'true artists' of Goethe and of Moritz-sold poorly" (27). In turn this often brought a propensity and "condemnation of elitist writers" who would "lash out at the hacks and at the unscrupulous publishers and book dealers for thinking of nothing but their own selfish 'interests"' (29). Much in the same manner that Pope would criticize Defoe, the propensity to publish what some considered pulp became a driving force to feed the ever growing demand of "middle class" readers, who desired novels and travelogues. In fact, Defoe and Moritz shared many of the same interests: "In addition to the novels Anton Reiser and Andreas Harknopf for which he is best known today, Moritz wrote travelogues and books and essays on topics ranging from history, philosophy, language, and aesthetics to psychology and mythology; he also edited a number of periodicals" (30). Furthermore, "[t]he pressing need for money caused Moritz to take on three or four projects at a time... [t]he end results of the different projects, completed in such extreme haste because of the urgently needed honoraria, frequently exhibit striking similarities to one another. Moritz was a shameless recycler of his ideas" (30). These conditions demonstrate that the book trade was experiencing similar circumstances in Germany as in England. Some of these factors speak to the manner in which A General History was written: the numerous editions printed so closely together, the restructured format in each edition, the changes to the first pages of each chapter, and the other materials that J.R. Moore believes to have been written by Defoe and that bear a 
striking similarity to the book, and some of which may even have been incorporated into the work.

Duff writes at length about the topic and composition of genius in his works Essays on Original Genius (1767), and its sequel, Critical Observations on the Writings of the Most Celebrated Original Genius in Poetry (1770). In the first of these works Duff introduces the reader to how the product of genius is expressed in science and art when he states:

to invent the designs, and perfect the productions of Art, is the province of Genius alone ... the attainment of these ends can only fall within the compass of the few enlightened, penetrating and capacious minds, that seem destined by Providence. ... The bulk of the literary part of mankind must be contented to follow the path marked out by such illustrious leaders. (5) Ideas such as these speak to the concept of genius and the independent literary writer who acts alone in the mid-eighteenth-century to produce a masterpiece. Duff goes on to state that there are three essential qualities of genius, "IMAGINATION, JUDGMENT and TASTE," and that in the right proportion, almost like an alchemical equation, they will act together in the mind of genius to produce a literary work or artistic product that is "universally acknowledged" (6). Edward Young provides a more direct correlation between writing, genius and originality in Conjectures on Original Composition (1757). Young states that brilliant writers are those "who write with vigour, and success, to the world's delight, and their own renown. These are the glorious fruits where genius prevails" (9). Unlike Duff, Young does not limit himself to telling his audience what comprises 
"genius," but he also implies that the product of a genius will bring success, fame and popularity.

In Young one also finds two other popular topics in a discussion of originality and imitation in eighteenth-century literature. He writes, “An Original . . rises spontaneously from the root of genius; ... Imitations are often a sort of manufacture wrought up by those mechanics, art, and labour, out of pre-existent materials not their own" (12). The concepts of originality and imitation outlined by Young speak not only to the sentiments about literary "genius" in his day, but also to Defoe's position as an eighteenth-century writer and one that contradicts J.R. Moore's praises. For in Young we find praise of "Milton's genius" and "Pope's Iliad," yet nowhere is there mention of Defoe (59-61). To Young Milton's work is to be placed above Pope's, because Milton was an original, whereas Pope's Illiad "is a Translation still; which differs as much from an Original, as the moon from the sun" (61). In his day, Defoe was often called an imitator, a literary pirate and a "sloppy and incautious Grub Street hack" by his contemporaries, and recognized more as a journalist and pamphleteer, than a member of the elite class of author or poet (Marshall 4). Young's work differentiates between the author as an original, and the writer as an imitator, stating that "an author; that is, One (to speak of accurately) thinks and composes; while other invaders of the press, how voluminous, and learned soever (with due respect be it spoken) only read, and write" (54). Both Pope and Swift make references to Defoe that place him in a category of writer that writes for money, below their class of the literary elite. Swift says “"the Fellow that was pilloryed, I have forgot his Name,' who is so grave, sententious, dogmatical a Rogue, that there is no enduring him," refusing to even name Defoe, and belittling him to a point that implies he is not even worth mentioning (qtd. in 
Marshall 4). In response to Defoe's The Shortest Way (1702), for which he stood in the pillory, Pope describes him as "Earless on High' and 'un-abash'd"” in his poem The Dunciad Vavriorum (1729) (qtd. in Marshall 4).

It is without a doubt that the climate of eighteenth-century literature and print culture in general varied as much as the seasons. The construction of "[a]uthorship in the eighteenth century is contested ground, a struggle for literary authority involving authors, patrons, booksellers, critics, and readers." (Griffin, "Fictions" 192). Ideas about originality, imitation, plagiarism and piracy all ebbed and flowed with tides. While Defoe may have been seen as a grub street hack, he was also an active participant in debates surrounding the author's ownership of literary property. As debates and copyright laws were in the midst of changing, he wrote in a 1710 issue of the Review:

A book is the Author's Property, 'tis the Child of his Invention, the Brat of his Brain; if he sells his Property, it becomes the Right of the Purchaser, if not, 'tis as much his own as his Wife and Children are his own — But behold in this Christian Nation, these Children of our Heads are seiz'd, captivated, spirited away, and carry'd into Captivity, and there is none to redeem them. (Defoe, Review, Vol. VI. Num. 129, 2 February 1710 qtd. in David 291)

The Statute of Anne, passed in 1710, was the first statute that provided for the government to regulate copyright instead of private parties. It stated:

[t]hat the author of any book or books already composed, and not printed and published, or that shall hereafter be composed, and his assignee or assigns, shall have the sole liberty of printing and reprinting such book and 
books for the term of fourteen years, to commence from the day of the first publishing. (Anne C 19)

How authors distributed their works in the eighteenth century varied dramatically from today. The Statute of Anne "placed copyright in possession of the author for limited periods of time to be arranged through negotiation with booksellers and publishers. The writer thus became an active participant in the literary marketplace. [Yet] for the next three centuries ... the author became an increasingly contested figure" (David 291). Authors were caught between the spheres of creativity and the often dubious literary marketplace.

It must be reiterated that the goal of this thesis is primarily to investigate editorial practice in the contemporary digital era and how it can shed light on the production of literature in the eighteenth-century, not to decipher authorial attribution. Unlike Moore, whose ideas of author-attribution were based largely on a growing interest in establishing a canon, the present moment has allowed for a different sort of investigation into the history of eighteenth-century print culture. "[W]ith the assistance of new data bases, from EBBO (Early English Books Online) and ECCO (Eighteenth Century Collections Online) to GoogleBooks, scholars are likely to assemble a base of quantitative data about authors and their writings" (Griffin, Authorship 12). The bibliographic practices within this paper and the following discussion of Moore's work have provided the opportunity to draw on a broader range of materials than were at Moore's disposal, many of them now available digitally at any time of day or night. This is not to say that the information in this thesis or the accompanying critical edition in any way surpasses that of Moore, for the motives behind this thesis are completely different. From a historical perspective, this thesis does not focus on the way in which a particular work may be attributed to an author, such as 
Defoe, through connection to his life or writing style, "[f]or many works [of] bibliographers who specialize in this period have often searched in vain for clues" that attempt to decipher this riddle of the ages (Snyder 133). Instead, this thesis focuses "on the writing life: a writer's interaction with booksellers, patrons, collaborators and correspondents, and how and why those interactions change over time," and shaped print culture in the eighteenthcentury (Griffin, Authorship 10). The digital critical edition of A General History of the Pyrates tracks the changes found in its first four editions in order to gather information about the people and circumstances that were at the root of these changes and editorial practices.

In no manner does this paper intend to explore Defoe's canon, except as a part of the history of the bibliographical practices that have been applied to A General History of the Pyrates. Moore's work is vastly more invested in practices of descriptive bibliography and a contribution to the canonisation of Daniel Defoe. As Ashley Marshall argues this "is not the place to rehearse the attributional sins of Defoe bibliographers from George Chalmers (1790) to John Robert Moore" (Marshall 2). This project merely aims to trace the evolution of $A$ General History of the Pyrates in the first four printed editions. While Chapter One and a large part of this thesis discusses the authorship of A General History of the Pyrates, to present the merit of producing a critical digital edition of the text, to inform the setting and background of the historical debates that surround this work, to understand eighteenth-century print culture, to show how digital critical editing informs and changes scholarly practices of editing, and in turn changes the way one investigates the question of author attribution, all of which are essential to the critical aspects of a critical edition. 
1.1 A Background to A General History of the Pyrates and its Contested Authorship

It is necessary to take some time to investigate the question of authorship and the additions to the text in order to fully comprehend the history of this book. While a digital critical edition (hereafter the DCE) will not necessarily help unravel these questions, nor does it aim to, it will allow one to see exactly where changes to the book have been made in these four editions, and to question whose hand made them. This study does not provide an exhaustive page by page comparison; instead, six features have been deemed important for determining when changes were made, who possibly made them, and where some of this material came from. In examining: the "Title Page;" "The Preface;" parts of "The Contents;" the first page of each chapter, including a page count of the entire chapter and its page numbers or place in the book; the back matter, which is usually advertisement; and the illustrations, the DCE will shed light on the changes and additions in this text. However, before delving into the advantages a DCE offers for the comparison of these features, some background information will help readers understand the origins and debates surrounding it.

The first edition of $A$ General History of the Pyrates was printed for Charles Rivington in "March or April 1724", naming one Captain Charles Johnson as its author (Bialuschewski 33). There has been much controversy over the author's name, beginning when John Robert Moore announced "at the 1932 meeting of the Modern Language Association" that Daniel Defoe was the true of author of this book (Furbank and Owens, Cannonisation 100). Seven years later, Moore's findings were published in Defoe in the Pillory and other Studies (1939), in which he discusses at length why he believes that 
Captain Charles Johnson is a pseudonym used by Daniel Defoe. He notes that only two works "published after 1710" bear Defoe's name as the author, and it is true that Defoe is known for having used over one-hundred pseudonyms (Moore 134). However, in The Canonisation of Daniel Defoe (1988), P.N. Furbank and W.R. Owens argue that Moore's hypothesis rests heavily on "exploited internal evidence" such as style and language (113). This rebuttal and Moore's study will be discussed in more depth later in this chapter. Finally, in "Daniel Defoe, Nathaniel Mist, and the General History of the Pyrates" (2004), Arne Bialuschewski agrees with Moore that Captain Charles Johnson was likely a pseudonym, but argues that there is also significant evidence that A General History was written by Nathaniel Mist. Mist was a sailor, "printer and a journalist" of the early eighteenth century, who also employed Defoe to work on the publication of Mist's Weekly Journal (22). Both Moore and Bialuschewski state that no person by the name of Captain Charles Johnson ever existed, and the name does not appear "in the contemporary records of the Royal Navy or of the East India Company"; however, there were numerous Charles Johnsons alive in late seventeenth and early eighteenth-century (Moore 129).

\subsection{Of Captain Charles Johnson}

In The History of Piracy (1934), Philip Gosse notes that one Captain Charles Johnson, R.N. "was employed by Sir Thomas Lynch to search for the pirate Hamlin of $L a$ Trompeuse and other Jamaican pirates in 1682" (185). As Gosse points out, this Johnson's age would have been approximately sixty-eight in 1724 when $A$ General History was first published (185). After taking a little time to scour through all the records of the Royal 
Navy, I have failed to find such a record, and Gosse fails to provide readers with a note or citation explaining where exactly he found this evidence.

There was also one Charles Johnson (1679?-1748) who, though not a Captain, was an eighteenth-century poet and playwright. One particularly notable fact is that he wrote a poorly received play titled The Successful Pyrate about the pirate Henry Avery in 1712 (Kelley). The play is even referred to in the beginning of $A$ General History "as an example of the interest in Captain Avery" (Moore 132; Johnson ed.1: 25). While I do believe this is a coincidence worth noting, I tend to agree with J.R. Moore that it is rather unlikely he wrote $A$ General History.

The Captain Charles Johnson who wrote A General History is also mentioned in the Oxford Dictionary of National Biographies but here again we find mention that the writer's "name is probably an assumed one" (Tedder). Another point of interest regarding Johnson from the entry is that his name also appears on the Title Page of A General History of the Lives and Adventures of the Most Famous Highwaymen, Murderers, Street-Robbers, $\& c$. (1734). The first edition of this book was published "in seventy-two weekly twopenny numbers" and includes much of the content seen in A General History, but also reprinted Alexander Smith's A Complete History of the Lives and Robberies of the Most Notorious Highwaymen from 1714 (Tedder). I have examined the second edition of this work, from 1742 in the Thomas Fisher Library at the University of Toronto, and used it in previous bibliographical comparisons. However, it will not be included in the critical edition, as the book varies too dramatically from the editions included herein, which makes it impossible for a parallel-text comparison. More than half of its contents come from Smith's 1714 work, and are about thieves and various other criminals, not pirates. Its format and collation 
are also dramatically different. Johnson and Smith's compilation is a large folio measuring $35.6 \times 22.7 \mathrm{~cm}$, with text in two columns, and it contains over seventy plates, whereas $A$ General History was published as an octavo, without columns, and its first edition contained only two plates. Defoe died in 1731, three years before Johnson and Smith's first edition of The Most Famous Highwaymen, in 1734, and more than a decade before the printing of Johnson and Smith's second edition in 1742, meaning any changes found in either of these two editions were the work of Smith or another editor or compiler, and certainly not those of Defoe. The chapters about pirates also vary quite dramatically in their content, and with its additional material, it proves to be out of place in this type of bibliographical comparison. Interestingly, Alexander Smith is also most likely a pseudonym, according to Moore and the entry for him Oxford Dictionary of National Biographies (Rogers). Whoever Captain Charles Johnson was, he was a literary pirate who had a hand in plagiarism.

\subsection{Of J.R. Moore: Attribution to Defoe}

If one looks at most contemporary editions of $A$ General History, such as Manuel Schonhorn's edition from 1972, which was re-edited in 1999, or any number of library catalogue records of this work, most bear the name of Daniel Defoe either as the author or as an added author. Though it is uncertain in my opinion whether Defoe wrote the book or whether he had any part in its making, John Robert Moore was very certain that the work was indeed Defoe's. It is also his work that has caused so many libraries to add Defoe's name to their catalogues. Moore's claims and understanding of Defoe as an author was founded on a desire to entrench the works of Defoe in the literary canon. As previously 
mentioned, the construction of Defoe as a "Great Author" is a modernist construction that meant something very different in the early and mid-eighteenth-century, and did not exist in the way many conceive of it today. Moore's understanding of eighteenth-century print culture is based largely on the ideas of the author as a genius that had roots in the writings of the eighteenth-century, but grew significantly in the nineteenth century and were in full bloom by the early twentieth-century. This view of authorship does not reflect the collaborative space of eighteenth-century print culture; rather, it reflects the "imposition of a distinctly literary viewpoint" of the twentieth-century (Marshall 12). Moore's position as a scholar who was trying to establish Defoe's canon and his view of eighteenth-century literature, are among the reasons why his argument is being investigated herein.

After making the announcement that A General History was the work of Daniel Defoe at the MLA's 1932 meeting, Moore said that he took up a "'minute study of the relationship of The History to Defoe's previously accepted writings"' and other works that he believed to be Defoe's (qtd. in Furbank and Owens Cannonisation 100). Over the next two decades, he developed his Checklist of the Writings of Daniel Defoe (1960), containing 120 new attributions, which grew to 140 in the second edition (1971), and include a total of 570 items (Furbank and Owens Cannonisation 117; Marshall 3). In order to secure his attributions to Defoe's canon, he contacted numerous libraries in the United States and Britain and offered to "lend them a copy of his bibliography in draft, to help them in the revising of their Defoe catalogue entry" (Furbank and Owens Cannonisation 117). Among these libraries were "the Huntington Library, the William Andrews Clark Memorial Library, the Indiana University Library, the Boston Public Library, the Bodleian and the British Museum” (Furbank and Owens Cannonisation 117). In 1953, the British Museum 
issued a new Defoe catalogue entry, though it was a separate publication from their main catalogue (Furbank and Owens Cannonisation 117). It was after this point that $A$ General History was listed with Defoe's name attached to it, and it remains so today, even though there has been much debate surrounding its attributions. Furbank and Owens' The Canonisation of Daniel Defoe (1988), was the first work to seriously contest Moore's attribution, based on Moore's lack of external evidence. More recently, Arne Bialuschewski's, "Daniel Defoe, Nathaniel Mist, and the General History of the Pyrates" (2004) suggested that Nathaniel Mist may be the author.

Moore's findings of his "“minute study"” are published in Defoe in the Pillory and Other Studies (1939) and are based largely on internal evidence about A General History's resemblance in style, language and content to other works he regards to be Defoe's. There are numerous similarities to other works, and five in particular that Moore believes to be crucial. In the chapter "The Authorship of A General History of the Pirates," Moore claims that $A$ General History belongs to a period when Defoe's writing was making a "transition from romance to history" and that therefore readers should expect two things to be true:

1, that the subject-matter is more closely related to Defoe's later writing on piracy (the account of Gow, The Four Years' Voyages of Capt. George Roberts and Robert Drury's Journal) than to The King of Pirates and the earlier romances; and

2, that although it is less readable than the best of Defoe's earlier romances, it excels them in historical accuracy (sic). (147)

Yet Moore begins his comparative analysis with Defoe's earlier works, by discussing the life of Captain Avery. He stars by writing that less was known about Captain Avery than 
many of the other pirates in The History, but that there were many stories regarding him (154). He then goes on to chart these numerous references to Avery. The first reference is to an article Defoe wrote in 1707 for the Review, which has little or no significance aside from the fact that Defoe wrote it. Then Moore moves on to discuss The King of Pirates and Captain Singleton (1719) and their similarities to A General History. He observes "the typical Defoe allusion to the origin of Rome" in both The King of Pirates and A General History, "which recurs so often in Defoe's known works and 'Johnson's' History" (Moore 155). He also writes that "the passages are typical of Defoe in thought and in style" (156). However, if Moore is arguing that the King of Pirates and Captain Singleton are less likely to resemble Defoe's style in A General History than his later writings, the attempt to draw similarities between these early works and A General History proves contradictory to Moore's initial argument. In comparing the passages from A General History with those from the King of Pirates and Captain Singleton one will not find two passages that are an exact copy. Furthermore, Moore's argument that Defoe employed allusions to Rome, which are common in eighteenth-century literature, does little to strengthen his argument.

Philip Ayres's Classical Culture and the Idea of Rome in Eighteenth-Century England (1997) examines "the aristocratic adoption of Roman ideals in eighteenth-century English culture and thought. . . . [T]he propensity to adopt the self-image of virtuous Romans was the attempt of a newly empowered oligarchy to dignify and vindicate itself by association with an idealised image of republican Rome" (Epigraph). Comparisons to Rome date back at least as far as the sixteenth century, and eighteenth-century writing also reflected England's political climate and its construction of national identity. Throughout this time, in England there was a "continuing respect for classical literature and values" of 
the Roman Empire, as England had been expanding its empire through colonisation in the Americas and elsewhere, much as Rome had expanded its empire across Europe (Ayres 2). Defoe did make allusions to Rome in A New Satyr on the Parliament (1701), in which he writes:

Blest Patriots who Liberty employ, T'elude thy Laws and Liberty destroy! Where is the Noble Roman Spirit fled, Which once inspir'd thy ancient Patriots dead?

(qtd. in Ayres 8)

Throughout the chapter "Literary Personae: Pope, Swift, Johnson, Thomson, Fielding, Burke," Ayres goes through numerous examples of how the literary works of these authors used analogies of Rome to depict, for better or worse, eighteenth-century Britain. One of the many examples from these authors in Ayres' book are lines 53-62 of Alexander Pope's "Epistle to Mr Addison, Occasioned by his Dialogues on Medals" where Pope writes:

Oh when shall Britain, conscious of her claim

Stand emulous of Greek and Roman fame?

How Plato's, Bacon's, Newton's looks agree;

Or in fair series laurelled Bards be shown,

A Virgil there and here an Addison. (qtd. in Ayres 14)

Allusions to Rome were clearly not the provenance of Defoe alone, but a common theme in writings of the day. 
According to Moore, there are many Defoe-like phrases in “'Johnson's' life of Avery" that are found in other of Defoe's writings such as The King of Pirates, but again none are perfect matches, and often do not even present two consecutive words that are the same (157). One significant disconnect between The King of Pirates and A General History involves the spelling of the word Pirate/Pyrate. If Defoe is the writer of $A$ General History and/or The King of Pirates (which lists no author on its title page), the decision to go from the more contemporary spelling of Pirate to the older form of Pyrate (from the French spelling) at a later date, when it was falling out of fashion and usage in Britain, only distances these two works to a greater degree. Perhaps the author purposefully wanted to create a disconnect between A General History and The King of Pirates, or merely wanted to appear antiquarian.

Moore then moves on to a lengthy two-page comparison of the fortified dwellings described in The King of Pirates, Robinson Crusoe, Captain Singleton, Robert Drury's Journal and A General History. While there are certain similarities concerning the protective wood surrounding the hut, the thorns, winding pathways and ladders used to access the dwelling in these books, it is possible that some other author had read any of the above mentioned titles and constructed a similar description. However, addressing the passage in this fashion and denouncing that they are the work of Defoe is as speculative as Moore's own reasoning.

Next Moore moves on to the Life of Captain John Gow, which he mentioned should bear more similarities to A General History than the King of Pirates, as it was published later and closer to the time that Gow appears in A General History. For some clarification, John Gow appears in the third edition published in 1725 under the name Smith, and as 
Smith's alias Gow, and in the fourth edition. Here there are indeed some striking similarities. The text Moore is comparing is a tract about the hanging of John Gow published in Applebee's Journal (11 June 1725). Moore says it has been recognized for 70 years as the work of Defoe, but here again he back-pedals, writing that "the original pamphlet had to be cut down more than three-fourths for inclusion . . . had to be recast, so that at first sight it would appear to be an entirely new life" (161). Moore states that there are two important similarities. First, that the story is in many ways turned inside out and that some of the content is moved "from the last page to the first page and a number of other details halfway across the story" (161). Second, that Defoe leaves numerous blanks in the pamphlet that are filled in by Johnson in the fourth edition and that certain phrases are identical.

Three examples of such phrases are "pretending to be bound to -----,", which becomes "pretending to be bound to the West Indies"; and the "New England ship, ----Cross, commander," which becomes the "New England ship, Benjamin Cross, commander"; and the phrase, "being greatly disappointed and in want of water and wine" (Aitken 301; Johnson 325 qtd. in Moore 162). These are some glaring similarities, but Moore then goes on to quote numerous passages in their entirety, though he omits sentences or often cuts out paragraphs from how they appear in Johnson's fourth edition of $A$ General History. He concludes his analysis of this chapter by writing that, “[u]nless 'Johnson' was a very demon of skilful revision, he [Defoe] must have been the author of the original pamphlet on the life of Gow," a rather erroneous explanation (168). The pamphlet Moore discussed does not appear to be the same one printed by Edward Midwinter, which I have personally examined. The chapter regarding Gow in this pamphlet is seven pages long and 
does not contain the blanks Moore refers to, though is it dated 1725. In the third and fourth editions of $A$ General History, printed in 1725 and 1726 respectively, this chapter was enlarged to twelve pages. This makes one wonder who requested the printing and revision of yet another version of an account of the life of John Gow, and it seems just as possible that whoever added this chapter, be it Defoe or someone else, was indeed a master at revision.

Moore then investigates the life of Captain George Roberts and compares it to Robinson Crusoe, Robert Drury's Journal and The Four Years' Voyages and Travels. Here again Moore gives numerous examples that compare different parts of these texts with $A$ General History, and writes that they contain "the usual Defoe touches to give verisimilitude, such as 'I forget the Gentleman's Name at the present'” (qtd. in Moore 171). Statements such as these run through this chapter, and Moore concludes: "It may be urged by one who is only superficially acquainted with Defoe's method of composition [that] these multitudinous likenesses are due to 'borrowing"' (180). Frankly, Moore's case rests largely on his own assumption and internal evidence from his Checklist of Defoe's works. His arguments do bring to light some impressive evidence, but do little to disprove that by borrowing and plagiarism, editors or printers may have compiled A General History from the numerous sources Moore mentions and other newspaper articles to create a book.

He then goes on to state that, from the similarities in the stories told throughout the half-dozen works he compares to A General History and that he has attributed to Defoe, there is also another body of evidence that Defoe penned A General History. Here he discusses Defoe's numerous interests that crop up in A General History, such as bookkeeping, shipbuilding, cockfighting, his encouragement of trade with Africa, trade and 
colonization in general, and his interest in languages. Furthermore, he returns to Defoe's “'use of idiomatic language,' for which many considered him illiterate, and his loose sentences held together by 'say' or his favorite abbreviations such as nem. con. viz. and etc." (Moore 187). Here again I might interject that the above mentioned topics would have been of interest to many people in the early eighteenth-century. Piracy, both on the high seas and in the book trade was at its height, shipbuilding played a major factor in colonization and trade, and knowledge of lands distant from Britain was increasing as was an interest in language. All were tools necessary for building a colonial empire and a national identity for Britain.

The passing of the "Statute of Anne" in 1710, also titled as "An Act for The Encouragement of Authors," was "the first modern copyright act and the first to insert the word 'author' into the law of ownership of literary property" (Temple 3). Though the "Statute" did not require authors to print their names on the title page, it did push English authors "to make more exaggerated claims for the value of individualized authorship than their actual production processes, quite dependant on collaboration, borrowing, and collecting, could support" (Temple 3). From the time the "Statute of Anne" was first introduced to the late eighteenth-century, the construction of authorship was in flux. "[S]pectacles involving Irish book piracy, Scottish and English forgery, copyright thieves, and the show trials surrounding slave narratives" were plentiful, and what was once "seen as trivial Grub Street disputes between printers or between literary rivals became important markers of the national ethos and national authorship. ... crucial to the development of national identity" (Temple 4). This entangling of national and individual identity gained force as the eighteenth century progressed, but it also shows that borrowing and plagiarism 
were very much still a part of the writing world, particularly in the first half of the century. During the "first half of the eighteenth century the 'author' was an unstable marriage of two distinct concepts" (Woodmansee 36). These were the notions of the writer as craftsman, on the one hand, and as inspired genius, on the other. The "craftsman ... master of a body of rules, or techniques preserved and handed down in rhetoric and poetics" (Woodmansee 36). Yet if "a writer managed to rise above the requirements of the occasion to achieve something higher, much more than craftsmanship seemed to be involved. . . . the writer was said to been inspired-by some muse, or even by God" (Woodmansee 36). This dichotomy harkens back to the previous discussions of William Duff's Essays on Original Genius and Edward Young's Conjectures on Original Composition. For Young, whether a writer's work was seen as an original or an imitation when pen is put to paper, "[b]oth these are happy in this, that by fixing their attention on objects most important, they escape numberless little anxieties, that tedium vitce [sic] which often hangs so heavy on its evening hours" (8-9). Though writing was separated into the two categories of craftsmanship and inspired original genius, it was in the latter "that the inspired work was made peculiarly and distinctively the product-and the property-of the writer" (Woodmansee 37). This was the foundation upon which authors (be they "genius" or "mere craftsman") began to be viewed as the creators, originators and owners of their works.

While the idea of the author as an inspired originator was central to the eighteenth century, it became a more grounded idea a century later. In the nineteenth century businessmen such as Robert Macfie, and lawyers such as William Hindmarch, who was studying patent law in England, would draw an analogy to copyright law, and see authors as the sole creators/owners of a literary work and as a product of individual genius. In 
Observation on the Defects of Patent Laws (1851), Hindmarch argued "that imaginative works alone were the unique creations of individual genius", stating: "A work of the imagination, whether in literature or the fine arts . . is actually created by its author"' (Hindmarch qtd. in Coulter 81). Similarly, Macfie would say that " there can be no rival claimant to the authorship of any particular book"' (Macfie qtd. in Coulter 86). It is from these nineteenth-century ideas of independent authorship and through the stabilization of copyright law that Moore conceives authorship and Defoe's works as that of a sole individual, independent writer.

Moore validates Defoe's authorship by stating that "[t]hroughout The History there are many such detailed ideas and phrases which cannot be the result of plagiarism or of mere coincidence" (Moore 181). But Moore gives no reason why such similarities could not be plagiarism. Might some printer or compiler not have lifted these texts from the multitude of sources, perhaps changed the typesetting, moved passages around or re-wrote various episodes and added information from additional sources? Or Moore could be correct, and Defoe may very well have written A General History, or some part of it, perhaps even reusing his own work.

\subsection{The Contestation of Moore's Findings and his Attribution to Defoe}

Considering Moore's evidence alone may lead one to believe that A General History is indeed Daniel Defoe's, and he does raise some interesting parallels between it and other texts. However, as P.N. Furbank and W.R. Owens have noted in the two chapters "Principles of Author-Attribution" and "John Robert Moore" from The Canonisation of Daniel Defoe, when most bibliographers of Defoe's canon discuss their principles, it is 
"rare for them to say much about authority" (38). Furbank and Owens discuss David Foxon, who seems to be an exception to this rule, and who believes that it is impossible to investigate an author's canon in depth based solely on "biographical research or by internal evidence of style," which is exactly what Moore does (qtd. in Furbank and Owens 38). Furthermore, Foxon discusses his "'rule of thumb" regarding "“cumulative authority", with which I wholeheartedly agree, that when attribution is based on the "unsupported statement of a catalogue of a library or modern bookseller" it should not be regarded as evidence that a work belongs to the named author (qtd. in Furbank and Owens 38).However, Foxon "does give weight to cumulative authority - even though . . succesive editors can be shown to be united in a misjudgment" (qtd. in Furbank and Owens 38).For Foxon this means that he accepts $A$ hymn to the mob, as Defoe's because "it has been in the cannon for a century though external evidence is lacking, while I [Foxon] reject $A$ hymn to the funeral sermon because it rests on the authority of the late J.R. Moore alone" (qtd. in Furbank and Owens 38-9). Furbank and Owens also address Moore (and other Defoe bibliographers such as Lee, Crossley and Trent) who used "oracular phraseology" and statements such as “'unquestionable', 'indisputably' or 'beyond a shadow of doubt' by Defoe" as a basis for attribution (Furbank and Owens 39). Statements such as these are deeply misleading and problematic as they give credence to a bibliographer's own findings without relying on any external evidence to support them.

In Defoe in the Pillory and Other Studies, Moore states that his method for ascribing author-attribution to works he believes to be Defoe's has arisen out of "a sharp personal response to Defoe's style and his ideas — a style so distinct that . . . it seems to be recognizable by its rhythm alone, and ideas so individualistic that (taken in combination) 
they set Defoe apart from any other writer who has used the English language" (Moore 70). Moore himself admits that his primary basis of attribution is style and his personal ideas about how he sees Defoe's writings. Moore attempts to "discover unmistakable traces of the Defoe who is known to us in his other books" (71). But the problem is some of these other books are not attributed to Defoe by anyone except Moore. Moore was obviously a dedicated scholar of Defoe, his contribution to Defoe's canon is substantial, and the study of his works is meticulous. For example, he notes that the Worcester affair is "inserted in the narrative of Captain John Bowen as a 2,200 word digression, introduced by 'I shall leave them awhile to relate an unfortunate history' and closing with 'to return to Captain Bowen, ...'” (149). But it is not Defoe's account of the Worcester affair that is reproduced, but Captain Thomas Bowrey's “proposal for an Act of Parliament which would enable the Worcester to recoup their losses" that is inserted into A General History (148). Moore acknowledges that Defoe and Bowrey had become acquainted in 1709 when Bowrey wrote his proposal, but this only proves that if Defoe wrote the General History, he lifted Bowrey's work, not that it was Defoe's (148). In order to fully understand this it is necessary to look at the endnotes, as Moore's account of this insertion left this author with the impression that it was Defoe's account of the Worcester affair that had been inserted (230). Thus, it does nothing to prove that Defoe wrote $A$ General History, merely that if he was involved with its production, he used other writers' work to compose it, which goes to show that the Defoe portrayed by Moore was a literary pirate of sorts, and that whoever wrote this book drew on many other works to write it. This brief sketch of the collaborative world of eighteenth-century print culture raises issues with a singular authorship of $A$ General History. 
Moore also rests much of his evidence on other bibliographers' statements. For example, his whole discussion of $A$ General History's chapter "Of Captain Avery" is based on a comparison to The King of Pirates (1719), a pamphlet that the nineteenth-century bibliographer William Lee had attributed to Daniel Defoe. Moore uses Lee's attributions and draws a number of parallels between the two in regard to their "habits of thought and expression" (Furbank and Owens Cannonisation 100). Similarly, Moore's discussion of Captain Smith, alias Gow, is based again on the attribution of An Account of the Conduct and Proceedings of the Late John Gow (1725) that Lee had also attributed to Defoe. As noted above, and supported by Furbank and Owens, there are some passages in A General History that appear to be directly copied from this pamphlet, but Moore resorts to lines of inquiry that are problematic. Furbank and Owens discuss Moore's logic in the passage below which ends with a quote from Moore and where Moore argues that:

if the two accounts are by different authors, then it is a matter not of borrowing but of theft ... if on the other hand, he says, the accounts are both Defoe, and Defoe has rewritten and revised his earlier pamphlet for the purposes of the History, then 'we have indisputable evidence for Defoe's hand in the History' (qtd. in Furbank and Owens 103).

Furbank and Owens point out that building a link between these two works on 'if' statements about Defoe having written the pamphlet and revising it to prove that he wrote A General History depends on a very circular logic that does not hold any real proof that Defoe is in fact the author. In addition to this circular logic, Moore follows a similar line of inquiry when he draws parallels between the three works he believes account for a large portion of A General History: these are Robert Drury's Journal, An Account of the late 
John Gow, and The Four Years Voyage of Capt. George Roberts. By attributing all these works to Defoe, he stacks one on top of the other to build his case.

According to Furbank and Owens, this stacking is the most problematic in the case of A General History and its link to Robert Drury's Journal. William Lee, another bibliographer, had considered that the Journal might have been written by Defoe, but "after much reflection rejected the idea" (Furbank and Owens 109). In 1890, Pasefiled Oliver sensed Defoe's style or someone who was imitating him and finally, in 1912, W.P Trent included the work in a bibliography of Defoe published by The Cambridge History of English Literature. Moore, on the other hand, skewed this evidence and stated "that no 'journal' by Drury had ever existed or could have existed and that the book was purely a romance by Defoe" (Furbank and Owens 109). Moore builds his case on those who are somewhat uncertain of this attribution. In fact, Furbank and Owens even point out that the Journal was not even published until 1729, after A General History had been written. This statement was made in another chapter of Defoe in the Pillory and Other Studies and caused some serious controversy in Moore's career. The Journal which was said to be authentic, though edited for its publication, is based on a certain amount of fact. Drury claimed to have left home at age fourteen, disregarding his parents' concern, and boarded the Degrave, whose mate was "John Bendow, son of the famous Admiral Bendow," and sailed for Madagascar where they were taken captive and massacred, though Drury escaped (Furbank and Owens Cannonisation 110). There was a ship named the Degrave and its crew did indeed get massacred in Madagascar. These events appeared in a London newspaper in March of 1705. Additionally, the keeper of the Cape of Good Hope archives published an account including the "discovery of John Bendow in Madagascar in December of 1707" 
(Furbank and Owens Cannonisation 113). This evidence definitively contradicts Moore's argument that the Journal was merely a story made up by Defoe.

Much of Furbank and Owens' argument sheds light on some of the very troubling ways Moore goes about attributing Defoe as author of $A$ General History, but they do not discount this possibility completely. Rather, they question the manner in which Moore goes about making a case for Defoe. They point to Moore's "silent manner of its introduction and the collusion, or at least questionable alliance between Moore the biographer and Moore the bibliographer" (Furbank and Owens Cannonisation 120). On top of this, as Furbank and Owens, as well as Foxon who pointed out earlier that basing authorial attribution on internal evidence such as a stylistic comparison of works that are in their own right questionably attributed to Defoe, or on biographical evidence that he enjoyed certain subjects, does not amount to a solid foundation for bibliographical analysis. What would amount to a solid foundation for bibliographical analysis is in part outlined in Chapter Two of this thesis, "Bibliographic Theory and Digital Editions," but for now it is sufficient to say that the lack of thorough descriptive bibliographical practice that was standard in Moore's day, when one would examine numerous copies of an editions, is evidence that would have strengthened Moore's argument. P.N. Furbank and W.R. Owens' later work A Critical Bibliography of Daniel Defoe (1998), outlines three principles “[f]or an authorial canon to be soundly based" (XXV). These are introduced in their earlier work The Canonisation of Daniel Defoe, but are more precisely laid out in their later work. They are:

1- In arguing for an ascription, one should not 'forge chains' of attribution, that is to say base any part of one's argument on some merely probable 
attribution, but should draw solely upon works indisputably by the author in question.

2- If making a new ascription, one should always explain one's reasons.

3- One should not regard the fact that an ascription seems plausible - i.e. comparable with the author's known style or interests etc. - as in itself sufficient reason for making it; nor should one be tempted to include a work in the canon provisionally. (XXV)

Furbank and Owens' also note that of the 570 works Moore lists as Defoe's 'fifteen are marked with an asterisk to indicate that the attribution is not certain" (Canonisation 2).

Arne Bialuschewski offers another perspective on A General History, one that also contests Defoe's authorship, but which goes on to hypothesize that the author is in fact Nathaniel Mist. Bialuschewski's argument rests quite literally on the paper trail that Mist left behind as a printer and through his numerous encounters with the law. Mist was a Tory and Jacobite who was closely tied to Daniel Defoe, as well as a former sailor and journalist. In "Daniel Defoe, Nathaniel Mist, and the General History of the Pyrates" Bialuschewski argues that there is strong evidence that points to Mist as the author. Mist published The Weekly Journal: or Saturday's Post beginning on 15 December 1716 and in "the spring or summer of 1717 the Earl of Sunderland, a prominent Whig who had recently become Secretary of State, secretly employed Defoe to write for Mist's paper and tone down its anti-government propaganda" (Bialuschewski 23). In 1718 Defoe was discovered to have been writing treasonable essays for both Mist's Weekly Journal and the Whig Whitehall Evening Post, as well as supplying Mist with paper. He then temporarily cut all ties to Mist (Bialuschewski 23). However, in early 1719 he went back to the Weekly Journal until 
November, when Mist published articles "that criticized the King's support for the Protestants in the Palatine," and which landed Mist before the House of Lords and led to his prosecution on 2 June 1720. After this, Defoe ceased any further collaboration with him. (Bialuschewski 23).

Over the following years Mist continued to gain the attention of the law. In 1721, "he was sentenced to stand in the pillory twice, to three months in prison, pay a fine of $£ 50$ and give sureties for his good behaviour for seven years" (Bialuschewski 27). Mist's sentence at the King's Bench Prison in Southwark was prolonged because his creditors "filed legal action for a debt of $£ 500$," as they feared they might lose their money (Bialuschewski 27-8). While Mist's brushes with the authorities were placing a significant financial burden on him, his income from the Weekly Journal also began to diminish as the London Journal started to gain popularity and reduced his readership.

Bialuschewski believes that under these circumstances, it is possible Mist decided to write a book about piracy in order to supplement his income. As both the "author and printer of the General History, Mist had every prospect of making a handsome profit," as all he needed to do was find a bookseller to organize and distribute the book (Bialuschewski 27). Charles Rivington, who printed and sold the first edition of the work, often placed advertisements in the Weekly Journal, and “Rivington's shop opposite St. Paul's Cathedral [was] only a few yards from Mist's house in Carter Lane” (Bialuschewski 33). Furthermore, between May and June of 1724 Mist published several prominent advertisements for the work and dedicated "two lengthy lead essays in his paper to $A$ General History" (Bialuschewski 24). 
Mist had been a sailor on the Spanish Seas and had knowledge of the West Indies prior to entering the newspaper business. In 1717, he began printing "news of raids.... He obtained some reports from correspondents in America, while others he simply copied from colonial newspapers" (Bialuschewski 25). Bialuschewski therefore believes he had both the knowledge and literary skills to be the author of A General History. Furthermore, beginning in the sixteenth-century, the Stationers' Company started to keep records of the books published by its members, and A General History of the Pyrates "was registered with the Stationers' Company on 24 June 1724 'for Nathaniel Mist' by his foreman John Wolfe" (Bialuschewski 26). Additionally, and perhaps in order to further disguise his affiliations with the book Mist did not print the book himself but instead got other wellknown printers to whom he had ties to distribute and sell the work.

There are also two letters in the Stationers' Company Archive that are communications between Mist and one Capt. Charles Johnson in 1728, though the second of these Bialuschewski believes to be fiction, and the existence of a Capt. Charles Johnson is much debated (Bialuschewski). There is also a note that appeared in 1730, which instructed the "Under Secretary Charles Delafaye who usually dealt with the press on behalf of the ministry" to ask Charles Viscount Townsend to send one Mr. Watson to locate Mist. This note states:

The Sheets of the Lives of $y^{\mathrm{e}}$ Pyrates

My Lord Townsend desires you would

please to examine him, Mr. Watson, where Mr. Mist is, Watson corrects it for Mist. (PRO SP 35/29 pt.1, fol.226 qtd. in Bialuschewski 26-7) 
In August of the same year the second edition of $A$ General History with three additional chapters was printed for "Thomas Warner, another long-term associate of Mist who was also responsible for the distribution of the Weekly Journal" (Bialuschewski 35). This edition also rose in price from "four to five shillings," which would have increased Mist's profits (Bialuschewski 35). In May of 1725 the pirate John Gow was captured on the Scottish coast and tried by the High Court and sentenced to hang in June. The account of Gow's hanging was published in newspapers, and when the third edition of $A$ General History came out later the same year it contained an additional chapter about Gow, as well as the same content as the second edition. But despite efforts to promote the second and third edition of $A$ General History, it did not sell as well as intended. In 1733 Warner died and, according to Bialuschewski and A Catalogue of the Stock of Mr. Thomas Warner published in London in 1734, "an auction was organized, and the remaining copies were offered for sale in quires (bundles of 24 or 25 unbound books)"; however, there is no record of who bought these sheets (qtd. in Bialuschewski 36). In 1726 a fourth edition of $A$ General History was printed for Thomas Woodward and contained no alteration to its content (though numerous changes in typesetting and particularly line-endings) aside from its Title Page which announced it as "The FOURTH Edition | VOL. I | Printed for T. Woodward ..." (ed.4: Title Page).

Bialuschewski hypothesizes that "Woodward bought the sheets from Mist, whilst in return receiving a promise to handle the publication of a future second volume, which, however, did not appear before July 1728 " when a series of advertisements appeared in the Weekly Journal (Bialuschewski 36). The Title Page of the second volume is not dated; therefore, it is impossible to tell exactly when it was printed. Aside from these 
advertisements, Bialuschewski offers no other record about its time of printing, nor any evidence that Mist bought the sheets from Warner's auction and sold them to Woodward. In 1727, Mist was once again facing legal trouble for a libelous article, and took refuge in France to avoid serving another and more lengthy imprisonment (Bialuschewski). Mist's flight and his legal troubles could be the reason the second volume did not appear for two years. His personal situation and the fact that piracy on the high seas had almost disappeared by 1726 could also explain the lack of continuity between the first and second volume of the fourth edition. The second volume was comprised partially of Robert Drury's Journal, or some adaptation of it, that recounts the events of a sailor who was held captive "by the indigenous population of the east coast of Africa" (Bialuschewski 36). It also contained the life of Captain Mission, his description of Madagascar, and his attempt to set up a utopian colony of pirates called "Libertalia." However, Bialuschewski seems to believe that Mist was not the author of this story, but "received the tale from another, possibly a French writer" (Bialuschewski 36).

While many arguments have been made concerning the authorship of $A$ General History of the Pyrates, and it does seem reasonable that Defoe and Mist could have had a hand in its writing, this paper will not present any definitive conclusion about its attribution; however, a discussion of these issues is pertinent as part of the historical and scholarly aspect of a critical edition. Additionally, by examining the changes throughout the four editions it becomes apparent that the twentieth-century notions of authorship Moore applied do not accurately reflect the collaborative, divergent and indeterminate nature of authorship in the eighteenth-century. One potential hypothesis is that Defoe and Mist may have written and edited parts of the book. Defoe had previously published works 
about piracy that are arguably attributed to him by Moore. Nathaniel Mist was in contact with Defoe and had access to some of his writings, as well as other newspaper articles regarding pirates. It is possible that Mist stole Defoe's work, often word for word, or edited his works and others, to various degrees, and added additional material, be it from previous works or through his own writing. Eventually, he may have written and compiled Volume II of the fourth edition of $A$ General History under the name of Captain Charles Johnson in order to avoid further conflict with both with Defoe and the law. I will not hazard a guess, as to whether Defoe or Mist wrote the previous editions, because it would only amount to a tentative argument that would require further research and is something that, at this point, seems unlikely to result in a grounded conclusion. Though the need to determine authorship is something that should be considered, it is more useful and much more ascertainable to examine this question by looking at the relationship between the people involved in creating this eighteenth-century text.

Both Defoe and Mist have many links to each other and to the printers of $A$ General History of the Pyrates, Charles Rivington and Thomas Warner. In examining P.N. Furbank and W.R. Owens' later work, A Critical Bibliography of Daniel Defoe (1998), these connections become apparent. Of the two hundred works they attribute to Defoe, Charles Rivington, who printed the first edition, also printed six other works by Defoe. One of these was advertised in Mist's Weekly Journal. Thomas Warner, who printed the second and third editions, also printed eighteen other works by Defoe. Four were advertised in either Mist's Weekly Journal or Mist's Journal. An additional seven of Defoe's works by other printers were also advertised in Mist's Journal or Mist's Weekly Journal. This demonstrates that Defoe, Mist, Rivington and Warner had relationships in the world of eighteenth- 
century print culture and had produced other works together. This approach may help to explain the 'who, what, where and why' of the changes made in each edition.

For this reason, this project aims to create a DCE that compares the first four editions of $A$ General History to determine where additional material was added or when certain sections were expanded. Though the goal of this thesis and the DCE that accompanies it is by no means to decipher this three-hundred year old question of authorship, it is a necessary discussion in order to familiarize the reader with the material and the controversies of authorial attribution that surround this work. In doing, so it may be possible at a later date to examine some of the materials mentioned by Moore, Furbank and Owens, and Bialuschewski to ascertain A General History's correlation to these works, and explain where the additional materials came from. It would only be at that point that an investigation into its authorial attribution would even begin to be possible.

\section{Chapter 2: Bibliographic Theory and Digital Editions}

Before exploring the advantages and limitations of digital critical editions, it is necessary to examine some of the historical background of bibliographic principles and theories that form its foundations. The production of the DCE that accompanies this thesis documents the changes in the first four editions of the text, and also provides a critical and historical context for the making this DCE. As will be shown in this chapter, a print critical edition most often offers readers a single reading text based on all the available evidence with substantial notes and introductory material. However, to date, digital critical editions rarely provide a single reading text, but instead offer multiple ways for readers to access various versions of a text. Unfortunately, what has often been lacking in digital critical 
editions is the critical element, which is why the first two chapters of this thesis dedicate a significant portion to examining the historical, authorial and bibliographical aspects surrounding A General History. The goal of making the DCE is to present readers/users with a critical commentary to aid in demonstrating the relation between the changes made to the four editions (or the history of the books' production) by those involved in its production, without providing an overt commentary on who may have made the changes. This will be accomplished by using a critical apparatus that points to the different types of changes made to the text through the four types of notes used in the DCE ( $g$ for gloss notes about changes in spelling or capitalizing; $p$ for notes about changes to the physical layout of the text; $c$ for critical notes about additions and critical changes made to the text; and $n$ for general notes that do not fit into the above three categories). By performing an analysis of traditional bibliographic principles, it will become evident which elements of bibliography are not possible to transpose in a digital edition; in doing so, I will also shed light on the limitations of digital editions before examining their advantages.

Fredson Bowers' Principles of Bibliographic Description (1962) outlines comprehensive methodological approaches to various types of bibliography, including enumerative, descriptive and analytical bibliography. Bowers' also emphasizes the importance of selecting a copy-text, which was viewed as one of the main components of a bibliography prior to the advent of digital tools and hypertext.

According to Bowers, descriptive bibliography is an outgrowth of the catalogue (1). By catalogue, Bowers is referring to lists of books in a particular collection, be it a library catalogue, books of a certain period or subject, or books by an individual author (Bowers).He also notes that a checklist is synonymous to a catalogue or should be regarded as such. 
In this light, Moore's Checklist of Defoe's work can be seen as an exercise in bibliography. In particular, the Checklist is a practice of enumerative bibliography: that is, a list of works grouped by the unifying principle of author that states the title, the creator(s), publication date and place of publication. However, this type of bibliography is merely the tidal pool of a much larger sea. As W.W. Greg notes, the "belief that bibliography consists of the compilation of bibliographies" is comparable to saying that "geography means mapmaking" (77).This is not the type of bibliographic practice that will be undertaken in the present project. Rather, descriptive bibliography is the branch of this field that is the foundation of this project, though further sub genres of comparative, analytical and critical bibliography are all at play within the present work.

The four editions examined in this project are prefaced in the digital edition with what Bowers refers to as a bibliographic catalogue of the editions (which are otherwise known as witnesses), used for the location-referenced method as denoted by the TEI and which is employed by the VM 4.0, the software used to create this project. The locationreferenced method, enables editors to encode multiple versions (editions/witnesses) of a text in one document. This method when paired with the $V M$ 4.0, allows editors to create a single display of all the encoded texts on one webpage; it also facilitates line-by-line comparison and helps readers/users visualize the location of changes through interactive cues such as highlighting, notes, underlines (which have been changed to a colour in the DCE). For the present project the six chosen elements, mentioned in the previous chapter, will be the focus of these comparisons. According to Bowers, such a catalogue contains a full or quasi-facsimile transcription of the Title Pages, collation statements and indications of "variations in signing and numbering; and copies in prominent libraries are listed" (4). 
However, as pointed out by Bowers, such a catalogue does not discuss the "historical, textual or bibliographic questions raised by a book" (4). However, the DCE submitted along with this thesis aims to accomplish both, by providing readers/users with a historical account of the debates surrounding A General History, its contested authorship, its place in eighteenth-century print culture, as well as providing a descriptive and parallel-text reading of the diplomatic editions covered.

The reader must be familiar with some terminology in order to understand the bibliographic practices at hand in this project and to assess its value. The definitions used in this section come from Fredson Bowers; though they are over half a century old, they remain the same for printed books, however, Mathew Kirschenbaum has also elaborated and reframed the for digital texts. The first are the definitions of edition, issue, and state in hand-printed books of the eighteenth-century. Bowers describes an edition as "the whole number of copies of a book printed at any time or times from substantially the same setting of type pages (and) includes all issues and variant states existing within its basic typesetting" (39). An issue, on the other hand, is the "whole number of copies of a form of an edition put on sale at any time or times as a consciously planned printing unit and varying only in relation to the form of an ideal copy of this unit" (40). A re-issue is some special form of the original issue of an edition that was printed and sold at another time containing most of the original sheets with a different title page (Bowers). A separate issue is one in which "type-pages have undergone re-imposition or a minor substitution or addition of new settings of type or new headlines, direction-lines or ornaments as part of a new impression" (40). It must also have occurred after the time of the original printing. A state is the narrowest form of variations to the text, and "can be applied to any part of a book exhibiting 
variations in typesetting" (41). All the books I examine in this study are editions, though their issues and states are unknown without comparison to other copies of the same edition (with the exception of the second edition where two states of the same issue, as digital facsimiles were examined).

These definition have been adapted to digital texts by Matt Kirschenbaum in his book Text Editing, Print and the Digital World. In this work Kirschenbaum defines five levels of the digital text. The layer, the object, the state, the instances, and the copy. Where a layer "comprise[s] all elements of an electronic work that are computationally compatible and functionally integrated" (70). If one were talking about the DCE this would amount to the entire DCE as displayed for any given section. An object on the other hand is "a 'generic identifier for some discrete digital entity, such as a file"” (70). Again in the DCE this would mean just one of the XML files, or any of the other files including the CSS, JS, and the JPEG's). A state "'refers to the computational composition of an object in some particular format" (70). This could be regarded as XSLT style sheet that interprets the XML and translates it to the HTML display. An instances "refers to an object in a particular state as presented in a particular software environment. The state of the DCE would be its HTML. Finally, a copy 'refers to one particular instances of one particular state of an object', rather like copies of an impression", this would amount to every time someone accesses the DCE on their computer through the Internet (71).

The final aim of descriptive bibliography, according to Bowers, is to arrange an edition in its "correct and logical relationship to other editions," which is precisely the goal of this project (6). Bowers argues that this can only be accomplished after examining “every available copy of an edition of a book in order to describe in bibliographical terms 
the characteristics of an ideal copy of this edition" (6). This particular step of comparing multiple copies of the same edition will be bypassed in this project because the aim is not to ascertain an ideal copy of each edition, but to examine where the variants, and additional materials in the text occur after the first edition. To this end, the project takes the first edition not as an ideal copy, but as the copy to be used as the basis for comparison.

\subsection{The Copy-Text: Does Digitization Illuminate the Need for Selection?}

The use of an ideal copy or copy-text was needed when editors and authors had to publish their work in printed form, as it was impossible to reprint every variant witness of an edition. Ronald McKerrow, one of the forefathers of bibliographical theory, introduced the term copy-text in his 1904 study The Works of Thomas Nashe Edited From the Original Texts, defining it simply as "the text used in each particular case as the basis of mine" (xi). The term is often "used in a general sense to indicate that early text of a work which an editor selected as the basis of his own" (Greg 374). Later in his career, McKerrow changed this definition to a more definitive argument of a "text which embodies the author's latest corrections should, as a general rule, be given decisive weight in questions of reading," provided they are not printers' errors (McKerrow 220). The debate over the rationale in choosing a copy-text continued among bibliographers for over seventy years.

In "The Rationale of Copy-Text” (1950), W. W. Greg put forward:

that significant, or "substantive readings of the text, those namely that affect the author's meaning or the essence of his expression, and others, such in general as spelling, punctuation, word-division, and the like, affecting 
mainly its formal presentation, which may be regarded as the accidents ... or 'accidentals', of the text" should be used of a copy-text. (376)

For Greg this meant that a copy-text should look to the oldest text and retain some of the author's original spelling, and "preserve the spelling of the period" by reproducing the accidentals, yet could vary in wording (376). It also meant that the editor should be allowed to take the same liberties as classical editors and be able to choose their own substantive reading or copy-text (Greg). This meant that editors were no longer bound to one particular text as their copy-text. Following Greg's rationale subsequent bibliographers such as Fredson Bowers and G. Thomas Tanselle also used Greg's method, adding their own explanations and justifications for its defense.

Bowers addresses the two primary objections to Greg's method in the Current Theories of Copy-Text (1950). The first is that if editors become uneasy with the idea that they must "distinguish between readings which are authoritative and unauthoritative," they risk disengaging from their responsibility and "duty to judge the validity of altered readings in a revised state" (279). Bowers' opposition to Greg's theory of copy-text is a matter that editors still debate when engaging in the production of critical editions. According to Bowers, a critical edition "is supposed to represent the best detailed text of an author in a form as close to his intentions as can be managed" (279). Bowers' second objection to Greg's theory of a copy-text is that it "will result in an amalgamated, or bastardized text in effect, the conflation of two or more editions" (279). However, Bowers eventually agrees with Greg, that such an amalgamated edition will produce a text that is closest to the author's intentions (Bowers). This type of edition is often known as an eclectic edition. Bowers uses the example of an author's annotated copy to defend Greg's choice of 
choosing a revision or an amalgamated text. He notes that if an editor were to come across such an annotated copy, "no editor would print his critical text from the actual revised edition which was set from the marked copy" (280). Rather, an editor would use an earlier edition, particularly if it were a first edition, and add the "author's corrections in the same way that errata lists are incorporated" (280). Hence, a critical edition would provide textual criticism about changes to the work over time.

G. Thomas Tanselle has nicely summed up the selection, reliance and use of a copytext by editors as a "presumptive authority, a text to be relied on when one finds no basis for preferring one variant over another - an authority, it must be emphasized, that does not restrict one's freedom to choose variants from other texts when there is reason to do so" (303). The selection of a copy-text has been an issue of concern for a century of bibliographers, and continues to be a matter of debate when it comes to producing printed and digital editions. However, in a digital edition or hypertext edition some of the concern surrounding this selection can be mitigated by the fact that editors have the advantage of providing readers with multiple variants at the same time, rendering the hierarchical selection of a copy-text obsolete. In theory, presenting multiple variant revisions of text as witnesses might seem to eliminate the need for selecting a copy-text, but the reality is that even digital editions must decide what changes are to be noted and how to present the variations. In this sense, there is still a need for selecting a base-text which one uses for comparison of all further changes. Though the base-text, like the copy-text, is not free from an editor's notes, it acts, in the DCE, as a method to note where additions, changes or deletions have been made. The first edition of $A$ General History is in many ways the basis 
for all further comparison, but in it one will find remarks where content appears only in this edition.

This is not to say that consideration of authority and revision are left in the margins, but that editors can present multiple variant readings to the audience. There is nonetheless the need to inform readers of the elements of bibliography that are of interest to the editor, and what the goal of a particular type of digital edition is. First, let us examine the decisions that inform the present DCE. It is these decisions that form the rationale for selecting the six elements that are included in the edition. After an explanation of the decision and rationale used, I will then discuss what type of critical edition this work intends to be.

For hand-printed books, Bowers asserts that the "collation formula and the basic description of an edition should be that of an ideally perfect copy of the original issue" (113). Examining multiple copies of the same edition would offer insight into the issue or state of each edition, and would potentially result in variations of the signatures and gatherings in the collation statement, but it would not necessarily aid in the goal of documenting the additional material seen in this project. Furthermore, the editions of $A$ General History in this project have notable variations and inconsistency in collation, which will be presented in the bibliographic pane for each section or as critical notes, so that future scholars can compare multiple copies of the same edition to ascertain an idealcopy of each if they so desire. Bowers' first objective, which the project does fulfill, is "to give a detailed and accurate bibliographical description of the copy used" (F.R. Johnson qtd. in Bowers 6). For Bowers "the description of an ideally perfect copy is not based on a single copy, because an important purpose of the description is to set up a standard of reference whereby imperfections may be detected and properly analyzed when a copy of a 
book is checked against the bibliographic description" (113). Though the DCE uses a single copy of each edition for its description (with the exception of the second edition where two copies have been examined), it is not intended to provide an ideal description. If one were to pursue the question of attribution, it would be advised that further copies be examined. However, according to the English Short Title Catalogue, which has been cross referenced with WorldCat, there are approximately eighty-eight copies of all four editions included in the DCE, none of which were printed by any printers other than those identified in the four editions. This means that only a separate state or issue of editions would exists, and while comparing the various forms of the text could prove to have some bearing on the changes seen through the editions examined in the DCE, it is unlikely to have a significant effect on questions pertaining to authorship.

The description of each edition within the accompanying DCE will provide sufficient details for each edition to allow for its comparison to other copies. In this vein the DCE does not follow suit with Bowers' aim at providing a perfect description. By informing readers that a perfect description is not the goal, this author feels that every attempt has been made not to "misrepresent a book by describing only an imperfect individual copy" (113). Because only one copy of each edition has been examined, even if readers are informed of this, there is the risk that bibliographic scholars will criticize this departure from traditional bibliographic practice. However, by acknowledging that this project departs from traditional bibliography and does not describe the ideal copies of each edition, it leaves room for improvement and additional research into bibliographical editing in the digital realm. 
When notable errors in pagination or collation are seen in one edition, as in the copy of the second edition provided by the Internet Archive's scan of the Boston Public Library's copy of A General History, other digital copies were consulted, if they were available, to determine whether the digital facsimile has been collated with error, or whether the mistake is indeed seen in other copies of the text. The collation of digital facsimiles adds additional copies to the collection of an edition because every edition that has been scanned and digitized must also be compiled and collated for presentation online. Much like collating paper copies of the texts, collating digital facsimiles is subject to human error. Finally, any inference made about the editions used will be portrayed as such. This method also provides a platform for comparison that is accessible to all and will be published online. Criticism and revision is anticipated, welcomed and desired. The project aims to be a reference point that is open to all scholars and not kept in isolation behind the doors of any particular library.

However, by neglecting to examine multiple copies of all editions, if they are not digitally available and limiting comparison to only copies this author has had the chance of examining or to digitized versions of an edition, it will be impossible to completely satisfy all of Bowers goals in descriptive bibliography for an edition. Bowers's stipulation that "[i]n the collation formula line the correct signing and pagination would be given, with press-variants noted" from all copies examined (114-5). This will not be possible to attain in the current project, without having examined more than a single copy of each edition. Though as Bowers notes, bibliographies typically give "separate major headings only to editions," not to individual states, issues or impressions of a text (37). 


\subsection{The Elements of Bibliography}

Bowers lists seven elements or principles of bibliography for sixteenth, seventeenth and eighteenth-century books that have become the staple of descriptive bibliographies for the last century. Certain elements of these principles will not be discussed in this DCE, as is explained after introducing them, however, it is important to discuss each of these elements and inform readers/users why some of these elements will not be incorporated. These elements are as follows:

Digital critical transcripts of the title and imprint, special or section title, colophon or explicit, head title, and running-titles with variants; . . . the format and coalitional formula, a list of the contents, a statement of the signing, together with a statement of the pagination or foliation and a and a list of plates or inserts, a selection of catchwords, a note on typography, a list of copies examined, and finally a series of notes and annotations concerning the book. (124)

Additionally, binding and paper are usually described. It should be noted that the DCE uses two digital sources as primary texts (the second and third editions) and two sources from copies examined in rare book collections that have been scanned or photographed by the author. For this reason, and particularly when using a digital primary source, it is impossible to describe paper and binding, as these elements are not usually present in digital copies. Thus a description of binding, watermarks, countermarks, and chainlines is impossible for these editions, as it normally involves examining the source text under magnification and natural light. While this information has been documented for the copies examined by the author in libraries, it will not be included in the DCE, as it is not available 
for the two digital works, and would prove an inconsistency in the DCE. Similarly, an accurate description of typeface based on a measurement of twenty lines of type is also impossible when using digitized facsimiles as primary sources because an accurate measurement of ' $\mathrm{x}$ ' size or twenty lines of type is impossible to determine. Even if one were to print a page it would be necessary for one to know the exact size of a leaf in order to accurately determine the typeface. These are the primary limitations of a DCE and using digital texts for comparison.

Title pages, on the other hand, will be fully transcribed as in traditional descriptive bibliography. Traditional descriptive bibliography transcribes a title statement as follows: "A GENERAL | HISTORY | OF THE | Robberies and Murders | Of the molt notorious | PYRATES, | AND ALSO | Their Policies, Difcipline and Government, |," where line endings are demarked by “|” (ed.1: Title Page). However, in the DCE each line of the Title Page is transcribed as it appears, with line numbers at the interval of every fifth line, which are associated with the first edition. These line numbers can added and removed by checking or unchecking "Line Numbers" in the VM 4.0 menu. This approach proves a substantial improvement in readability in this author's opinion, as readers can examine each line and compare it to same line in other editions, both in location and its content (wording, capitalization, line-endings). Moreover, because this author uses TEI's locationreferenced method to encode the DCE with the $V M 4.0$, readers can click on any given line and see it become highlighted in all editions if the majority of the words match or if the content corresponds to the same location.

The DCE provides a full quasi-facsimile transcription for the "Title Page," "The Preface," the first page of each chapter and the back matter (including any colophons). The 
quasi-facsimile transcription of "The Preface", first page of each chapter, and back matter surpass Bowers's rules for descriptive bibliography, as he does not state that they ought to be in quasi-facsimile or diplomatic form, and they too will have all the same features of the "Title Page." The contents are listed for each edition, but are not fully transcribed due to the amount of variation between editions. This method adheres to Bowers' rule about fully transcribing the contents list, but not providing a quasi-facsimile transcription of contents (as this not part of Bowers' method, but was originally anticipated to be included in the DCE). By clicking on the link for each particular section of the work found on the webpage that hosts the DCE, readers/users will also be able to access a digital facsimile of each page image by clicking on the thumbnail that corresponds to each JPEG. Finally, by clicking on various parts of parallel-text transcriptions readers/users can compare the similarities and differences, as well as view critical and explanatory notes.

The "Bibliographic Information" pane included with each chapter provides readers/users with a collation statement, pagination, along with the signing, a page count, and the running-titles within the chapter. The "Critical Introduction" is also included with each chapter containing information about the type of notes, a glossary, and any other variations that occur. The default chosen by this author, is to set the notes as "Popup Notes" that appear when readers/users scrolls over a superscript letter that indicates the presence of a note. However, readers/users can also use the notes tab in the $V M 4.0$ 's menu to have the notes appear as "Inline Notes," that appear on the left side of the screen, similar to footnotes appear at the bottom of a page in a printed edition. Alternately, readers/users may choose to suppress all notes, using "Hide Notes" from the drop-down menu to provide an un-interrupted reading of any single edition, or all the editions in the DCE at once. The 
notes have also been appended or listed to correspond with the edition(s) the readers/users are examining. Plates and illustrations have also been inserted into the chapters in which they appear, as linked images that readers/users can examine as desired, though they have not been marked-up, as this feature was not available until the release of the VM 5.0 early in 2016. This approach allows readers/users to compare where additional illustrations have been inserted over the course of the first three years of A General History's publication, and the four editions used in the DCE (1724-1726).

\subsection{Types of Scholarly Editions}

The printed critical edition is portrayed as a form of textual or scholarly editing, it is distinguished from documentary editing, which usually involves "single rather than multiple documents, and [is] often associated therefore with historical rather than literary edition" (Greetham 8). Critical editions emphasize the "joint technical and critical skills involved in textual scholarship" (Greetham 9). Critical editions imply that the author will offer textual criticism along with the bibliographical practices seen in descriptive bibliography. Without entering into the debates about what makes up a critical edition, as this was and is a debated topic in textual and scholarly editing, one can say that "any edition that attempts to construct a work using all the available evidence is "critical", whatever its methodology" ("Types of Editions"). Though critical editions "require collation of different witnesses, and the construction of a reading text out of the results of that collation", they also use a base text which is reprinted "in one book as well as scholarly responses to it and other information useful to understanding the book" ("Types of Editions"; "Critical Editions"). 
Jerome McGann draws a more specific definition of a critical edition that includes the idea of eclectic editing, as proposed by the theories of Greg-Bowers-Tanselle:

Critical editing ... does not reproduce the text of a particular document but produces an eclectic text based on several texts and on editorial emendations. It assumes that though multiple texts of a work may vary in authority, no one text is entirely authoritative. ... A Critically edited text, when combined with an apparatus that presents the evidence used in the text's construction and that lists the variants of the authoritative states, is called a 'critical edition' (Williams and Abbott 56-57 qtd. in McGann, "Editing" 49).

In light of these definitions, the accompanying DCE is not eclectic as it does not present all the available evidence, or construct a reading text in this manner. However, as in the case of an eclectic edition, it does not take a single edition as the authoritative version. The DCE is also not a critical edition in that it lists variants from multiple editions, without examining numerous states of any one edition. The accompanying DCE does offer critical responses, but does not use one base text. Rather, it offers critical responses to all the editions within. The DCE is critical in its use of an apparatus and its demonstration of variants within the four states of editions it encompasses. The DCE is a variation of an eclectic comparative text of multiple diplomatic transcriptions, supplemented with facsimile images and a critical apparatus. This is not to say that the DCE is all these types of editions at their pinnacle. It could be said that the accompanying DCE does not use all the available evidence, as certain works have not been examined in their printed copies, and therefore information about paper and binding have been excluded. However, all the 
evidence available in the four digital editions included were consulted, and therefore the DCE is critical of this evidence, as well as the advantages and limitations of digital editions.

The DCE is also a diplomatic edition, or rather multiple diplomatic editions, presented in digital parallel-text reading. A diplomatic edition aims to reproduce, in print or online, all the textual content of the original, "the exact spelling, punctuation and capitalization (usually)," as well as the line division, marginalia, and rubrication (Greetham 350; "Types of Editions"). It also varies from a facsimile edition, which today refers to the reproduction of a work in digital images. All the works that have been transcribed for the DCE maintain the characteristics of a diplomatic edition mentioned above and also provide a facsimile image as part of the editions. Furthermore, diplomatic editions are not to be confused with type facsimiles, which "attempt to reproduce the actual physical appearance of the original in a different typesetting" (Greetham 350). Examples of some of the elements of a diplomatic edition that are evident in the DCE are the maintenance of the line division, exact spelling (with the exception of the long ' $\mathrm{s}$ ' ( $\left(\right.$ or $\left.\int\right)$, capitalization, and italicization, all of which allow readers/users to engage in a line-by-line comparison of the diplomatic transcription of all the editions featured in the DCE. Typefaces are not transcribed as they would be in a type facsimile.

A third type of edition, an extension of the diplomatic edition, is the parallel-text edition. Although this DCE employs facets of both critical and diplomatic editions, it most resembles a parallel-text edition. This type of edition "presents multiple versions of a text side-by-side," allowing scholars to perform a line-by-line comparison ("Types of Editions"). The two main applications of a parallel-text edition are identifying textual variants in context and source study, where one attempts to identify how closely an author 
has followed any given source ("Types of Editions"). These are the two main goals of this DCE. The VM 4.0 uses TEI's location-referenced method to allow users to compare two or more versions of the same text. Although today many parallel-text editions appear electronically, this type of edition was originally available in printed form. However, they were extremely cumbersome and in turn costly to produce, which is why very few of them were published, the bulk of these types of edition that are from the eighteenth-century texts are those that offer translations of a text from Latin to English, or English to French, etc. One such work is Joseph Warton's An Ode to evening. Translated into Latin verse (1749). In this short book, one finds no footnotes and two distinct manuscripts reproduced for comparison, which assumes a knowledge of Latin (which would have been more common in the eighteenth century) but it offers no critical apparatus, to help on understand the translation. Another such example, from a nineteenth-century text with endnotes, is the parallel-text edition of Wordsworth's Prelude, edited by J.C Maxwell (1971), that compares the 1805 and the 1850 edition of this poem, but leaves readers flipping from cover to cover to discern the changes By identifying textual variants in the context of each of the first four editions of $A$ General History, it is possible to identify where type has been reset and to what degree, and provide explanatory notes without distracting readers. It is known that whoever the author of A General History is, they have relied to some degree on accounts of real pirates, such as the account of John Gow's hanging, which appears in the 1725 issue and in the third and fourth editions, and perhaps on other texts about Captain Avery or Robert Drury's Journal.

A fourth type of edition that also encompasses this DCE is the hypertext edition. Broadly defined, any edition that uses digital media and contains a series of hyperlinks to 
various sources can be described as a hypertext. Hypertext editing generally attempts to present larger quantities of information than the printed page is capable of, providing access to information through popups, text-boxes, hyperlinks, and a choice of reading environments. In "The Rationale of Hypertext," Jerome McGann reiterates that "hyperediting should be seen as a nested series of operational possibilities (and problems)" ("Rationale" 58). At the time McGann wrote this chapter in Radiant Textuality he envisioned "a fully networked hypermedia archive" of Dante Gabriel Rossetti's pictorial and written works ("Rationale" 58). McGann saw the practice of hyperediting containing two elements:

(1) that the hyperediting design for a specific project be imagined in terms of the largest and most ambitious goals of the project (rather than in terms of immediate hardware or software options); and (2) that the design be structured in the most modular and flexible way, so that inevitable and fastbreaking changes in hardware and software will have a minimal effect on the work as it is being built. ("Rationale" 58)

Hypertext editions have also largely taken over parallel-text and diplomatic editions. $A$ General History's DCE can in some respect be seen as a hypertext edition, in that it employs such functions as popups and text boxes to provide the readers with notes about the textual variations, and manipulates the text to provide readers with divergent reading environments. But the DCE also has internal links to the digital facsimiles of the pages and this what McGann called a "hypermedia edition," as it incorporates "visual elements" and has higher level of interactivity, than print editions ("Rationale" 58). However, the DCE is also locked into the VM 4.0's software platform, which is in opposition to McGann's view 
that hyperediting should not rely on one immediate platform. The DCE is not a large scale project focused on the corpus of an author or artist, such as the Blake Archive or the Rossetti Archive, but it aims to show how a single work (or rather multiple editions of work) do employ theories of hypertext editing and hypermedia archives into the web page that hosts the DCE (http://ingridreiche.com/Resume/Thesis.html), in order to examine larger questions about eighteenth-century print culture, and debates about author attribution. The theories of hypertext and hypermedia will be further discussed in the next chapter along with the numerous methodological approaches to digital critical editing.

D. C. Greetham proposes that hypertext editions "might properly be called postcritical, in that the editor does not establish a text nor does he or she simply reproduce a previously existing text," but rather the editor provides the reader with numerous possible editions which, according to Greetham, this is drastically "different from the fixing of text usually associated with critical editions" (357). Two decades ago, in 1994 when Greetham's work Textual Scholarship: An Introduction was published, he noted that "reader designed critical editions are still in the planning stage" (360). Today they have indeed come to fruition, and can be seen on sites such as The Shakespeare Quartos Archive and Digital Thoreau. The Shakespeare Quartos Archive offers readers "cover to cover digital reproductions and transcriptions of thirty-two copies of the five earliest editions of the play Hamlet ("Introduction to the Archive"). Though it may not offer "all forms and states of a text forming that text's history," as Greetham proposed, it does provide coverage of the foundational versions that make up this text, and allows for a reader-design experience, as users can annotate the text, create an exhibition or character cue line lists, and download and print text and images, in effect potentially creating their own digital 
edition, if so desire. In theory, the DCE of A General History is therefore a post-critical edition that employs versions and elements of diplomatic editing to form a parallel-text edition with multiple readings and critical analysis of the editions it contains.

The hypertext edition also falls under the larger umbrella of a social editing theory. Newer forms of social edition will be discussed in the next chapter, but even before McGann was discussing hyperediting, he was looking at social theories of textual criticism, which are a major factor to any modern editor and crucial to the DCE. In the "Foreword" to the paperback edition of McGann's A Critique of Modern Textual Criticism, D.C. Greetham notes that according to McGann's view of social textual criticism "authority is no longer derived solely from the author but instead from the accumulated social history of the work and ... [t]his means that a later, derived text, if it can be shown to have a social and historical presence and influence, is also a primary text in the charting of that history of reception. (xviii). This is precisely the case in A General History, and a major factor that dissuades J.R. Moore's arguments for its authorial attribution. McGann's "argument for a 'social theory of text' (as it has been called) introduced new problems for the (technical, editorial) issues of 'authorial intentions," as it calls for "the necessity of grounding literary scholarship in a self-conscious study of material texts, their production and their distribution" (xxii). Such a self-conscious study is exactly what this thesis and the DCE illustrate: the modes of production and the players involved all had a hand in making the four similar, yet divergent editions of A General History.

As McGann mentions, "[m]any persons besides the author are engaged in these events, and the entire process constitutes the life of an important social institution at the center of which is the literary work itself" (Critique 52). As previously noted, the world of 
eighteenth-century print culture was a collaborative and social space, and one where "for an editor and textual critic the concept of authority has to be conceived in a more broadly social and cultural context" (Critique 84). Moore's reconstruction of "the dynamic social relations which always exist in literary production - the dialectic between the historically located individual author and the historical developing institutions of literary productiontends to become obscure in criticism" (Critique 81). Moore's analysis and his view that $A$ General History is undoubtedly the work of Defoe acknowledges the many other works that may have figured into the social construction of the text. However, he fails to recognize that the social context of the eighteenth century print world was muddied with plagiarism, rewritings, and the changing force of an emerging literary world—newly infused with copyright law—and the desire for individual ownership of one's work, which was at the same time fueled by the commercial forces of a book trade that had been unshackled from a system of patronage. At the same time, McGann does not hesitate to point out that "[a] theory of modernized nonspecialist editions is necessary to a full critical theory for precisely this reason: that the factor of the intended audience is easily seen in the modernized edition, whereas in the critical and scholarly edition it is buried under the critic's social and institutional ideology" (Critique 113).

In his later study, The Textual Condition, McGann reflects and elaborates on his earlier work, noting that "[c]orrelative with this position is the argument that no single editorial procedure — no single 'text' of a particular work—can be imagined or hypothesized as the 'correct' one" (Textual 62). This is where the eclectic edition, one that draws from many variant readings, comes from. As much as the eighteenth century was a collaborative space, so too is a social edition and critical editing. The "distinction between 
a work's bibliographical and its linguistic codes is fundamentally important for textual criticism and hence critical editing" (Textual 52). Much like printers and book sellers or the changes between editions, "when we edit we change, and even good editing ... involves fundamental departures from 'authorial intention"” and authorial attribution (53). It is "in this sense [that] literary texts and their meanings are collaborative events. . . [T] he most important 'collaboration' process is that which finds ways of marrying a linguistic to a bibliographical text" within the practice of critical editing (Textual 60-1). However, “[a]uthors' relation with their readers and editors, however, are highly interactive. The character of these interactions varies greatly from situation to situation. Because the critical editor's task is to expose and clarify those interactions," and to recognize one's own social and ideological position (Textual 61).

One point that must be discussed is the limitations and advantages of digital editions, be they eclectic or not. What a printed critical edition does well is provide a critical analysis of the text, and construct a reading text, from all witnesses examined. This reading text is often what is lacking in digital editions that provide readers with multiple readings but no singularly authoritative one. Linking, hypertext and versioning often end in a cumbersome exercise for readers that provides little critical analysis, and is wanting in its ability to incorporate "expert knowledge" that has been constructed through centuries of scholarship about a given text (O’Donnell 121). This is particularly difficult in true hypertext editions, where readers must jump from one source to the next and editors often neglect the construction of a reading-text. Furthermore, shedding over a century's worth of bibliographical theory for a myriad of possible reader constructed versions does little to acknowledge the work done by predecessors in the field of bibliography, for their work is 
also crucial to the construction of critical editorial work in the digital milieu. One ought not dismiss the selection criteria for a copy-text or a base-text or the making of a reading text in favour of mass amounts of the raw information afforded in digital editions, but instead ask oneself how the digital edition might construct a reading text of its own, given its ability to display such variant readings.

\section{Chapter 3: The Long History of the Short Era in Digital Critical Editing}

Digital critical editions and the production of such editions have existed for roughly twenty-five years, in the scope of critical editing in general this is quite a short period of time. One of the first editions of this type was The Wife of Bathe's Prologue, on CD-ROM, edited by Peter Robinson, which was conceived in 1990 and completed in 1996. However, within in the last twenty-five years the field has made significant advancements. In this chapter, the history of digital critical editions and their various permutations during this time will be examined to demonstrate how they have arrived at their current state. Their modes of transmission and presentation will be discussed from their early iterations up until the present day. Along the way, the problems digital editors have faced and the limitations and advantages digital editing have brought to textual analysis will be discussed. The theoretical frameworks and methodological practices of those who produce and critique such projects will also help elucidate the considerations of digital editors past and present.

There are two theoretical frameworks that will aid in analyzing the processes and practices of digital editions and digital critical editions. These two terms do have distinct connotations that differentiate them. First, Patrick Sahle's definition of and distinction 
between the digitized and the digital helps to demonstrate what a digital edition is. Sahle's points out that:

Digital scholarly editions are not just scholarly editions in digital media. I distinguish between digital and digitized. A digitized print edition is not a 'digital edition' in the strict sense used here. A digital edition can not be printed without a loss of information and/or functionality. The digital edition is guided by a different paradigm. If the paradigm of an edition is limited to the two-dimensional space of the 'page' and to typographic means of information representation, than it's not a digital edition. (Sahle qtd. in Pierazzo 22-3)

This difference is crucial in examining the many types of digital editions one finds today, and acts as a means to separate the oft confused idea of the digitized and the digital. In Sahle and Vogeler's "Preliminary Remarks" to the Criteria for Reviewing Scholarly Digital Editions the authors point out that "scholarly digital editions . . . are information systems which follow a methodology determined by a digital paradigm, just as traditional print editions follow a methodology determined by the paradigms of print culture. A scholarly edition is an information resource which offers a critical representation of (normally) historical documents or texts."

Early digital editions often referred to as hypertext editions, electronic editions, or the digitized edition, frequently involved a series of internal links to various aspects of an author's corpus. In these early stages of digital editing there was a movement towards "unediting," which is "reproducing the text in documentary form, typically in the form of facsimiles. In print this was a fairly expensive undertaking reserved for the most canonical 
authors" (Schreibman, "Scholarly Editing" par.19). However, while digital facsimile editions are much less expensive to produce than their print counterparts, it is also relevant to note that unediting is "fairly trivial in the digital form. Digital images are relatively inexpensive to create and store. Many projects choose to take this route rather than transcribe and encode text. But current technology can also make these editions clunky" (Schreibman, "Scholarly Editing" par. 20).

One project that takes this route is The William Blake Archive. Schreibman argues the Blake Archive is a work of "extreme editing" of a facsimile edition that results in "the creation of an image based scholarly edition," yet this does not make it a critical edition by any means (Schreibman, "Scholarly Editing" par. 20). The Archive is exactly what it calls itself — an archive. A digital archive, yes; a scholarly edition, yes; a critical edition, no. In "Ongoing Challenges for Digital Critical Editions," Philippe Régnier points out that the Blake Archive is a complete divergence from a critical edition, and functions instead as a "hypermedia database" (68). There is no doubt that as one of the early projects in digital image editing, which was first undertaken by the Institute for Advanced Studies in the Humanities at the University of Virginia in 1992, the Archive does exemplary work in providing access to Blake's work in a digital medium. It offers transcriptions, the ability to visually compare multiple images and/or transcriptions, a biography, glossary, chronology and critical articles, but it lacks any critical apparatus (Schreibman; Eaves, Essick, and Viscomi). The Archive is at "once a scholarly edition, a special library collection, a museum, and a research centre." (Régnier 68). A digital archive, or digital repository for the works of a particular author, should not be confused with digital critical editing. While 
archives do employ digital reproduction and transcription, they can lack the critical aspect that is so crucial to a critical edition.

The critique of digital repositories or archives, as missing a critical dynamic, is not an attempt to dismiss their presentation and reception. The William Blake Archive and the Rossetti Archive are two admirable examples, both of which are exceptional in their presentation, searchability, and the breadth and amount of information they contain, and are thus valuable tools for literary scholarship. But as some of the earlier incarnations of hypermedia, I would argue that they may not be editions, but more properly archives and/or databases that contain many works of an artist and/or writer.

\subsection{The Materiality of Digital Texts}

The material relationship between the critical edition and the hypermedia archive is likely much more reciprocal in that print texts mimic electronic texts and vice versa. According to Hayles' theory of materiality "media constantly engage in a recursive dynamic imitating each other, incorporating aspects of competing media into themselves while simultaneously flaunting the advantages that their own forms of mediation offer" (69). In the early 1990s many ambitious and highly talented scholars were forming collectives that articulated hypertext, hyperediting, and hypermedia theory and methodology. This theory and methodology is arguably primarily rooted in digital remediation, which begs the question, "[i]s digital technology simply a new means of gaining access to material existing in another medium, or does it bring radical changes in the representation of texts and documents" (Hillesund and Bélisle 114). The answer is both. Digital media does often reproduce existing material, like that in the Blake Archive; 
however, they also change reading, writing and editing practices, as well as the bibliographical practices behind the digital edition. Electronic texts are not immaterial if one thinks of "materiality as the interplay between a text's physical characteristics and its signifying strategies ... a dynamic quality that emerges from the interplay between the text as the physical artifact, its conceptual content, and the interpretative activities of reader and writers" (Hayles 72). This is so true that we see electronic texts constantly trying to mimic the printed book, both in presentation and representation. Often e-books have page turning functions, mimicking the way we would turn a page in a physical book, or have bookmarking options, that produce a little red bookmark, mimicking how one inserts a bookmark, or dog ears a page in a book. We do not see the tags which make paragraphs and lines in digital texts, unless we deliberately seek them out through the act of selecting something like "reveal code" or "view page source" in a web browser. Similarly, we do not see these devices printed in books; we see the white space they embody.

Printed books can also embody aspects of hypertext. In a broad definition of how printed texts can operate as hyperptext, Hayles proposes "that hypertext has at a minimum the following characteristics: multiple reading paths; some kind of linking mechanism; and chunked text ...." (72). She uses the encyclopedia as an example with its "multiple reading paths, a system of extensive cross-references that serve as linking mechanisms, and chunked text in entries separated typographical from one and other" (73). I might go as far as to argue that certain characteristics such as the footnote, the endnote, a table of contents, indexes, or the choose-your-own-adventure book are forms of hypertext that predate digital text, and that such devices are the precise points where one can see the recursive nature between the digital and the print. Furthermore, it is key to note that Hayles' point is not 
only to draw out parallels between these two mediums, but to demonstrate that the medium which a text embodies "interacts dynamically with linguistic, rhetorical, and literary practices to create the effects we call literature" (70).

In Bibliography and the Sociology of Texts (1999), D.F. Mckenzie suggests that at a time when the status of the text is being challenged by changes in its material transmission, from printed objects to digital ones, the practice of bibliography and in turn critical bibliography might better be defined as:

the discipline that studies texts as recorded forms, and the processes of their transmission, including their production and reception. . . . [and] that bibliographers should be concerned to show that forms effect meaning. Beyond that, it allows us to describe not only the technical but the social processes of their transmission. In those quite specific ways, it accounts for non-book texts, their physical forms, textual versions, technical transmission, institutional control, their perceived meanings, and social effects. $(12-13)$

With this turn in material transmission from print to digital, the change in transmission of a text is the remediation of the text and also of the critical edition. It means that a person is no longer bound to the institution of publishing. In the same way that the Gutenberg press unshackled the church's ability to disseminate and transcribe written documents, and allowed for texts to be distributed to a much larger population, so too has the digital era seemingly freed people from the confines of publishing houses and printers. On the other hand, it has also increased the work of scholars and has made printers, transcribers and often publishers of many more individuals. The day where one could pass an editor a hand- 
written draft, have it edited, and have someone type it up and prepare it for printing and publishing are gone, long gone (unless perhaps you are a famous author). For scholarly and critical editions, this means the recursive nature and interplay between print and digital are in full force. Digital archives push to present texts in new ways, ones that embody multimedia features that were not available in printed editions, whether they were critical or not. At the same time, the pull from traditional scholarly editors is wanting for its trusted critical apparatus. New forms of editions and hypermedia archives will continue to bring novel improvements, enhance accessibility and provide significant amounts of information. It is becoming more apparent that critical editors will also find new ways to incorporate their critical apparatuses, which may be a more difficult task in the digital realm than it used to be in print, as it requires more computational understanding, with deep layering. However, this approach has the potential to create its own novel type of digital edition.

\subsection{Hypertext Theory and Methodology in Digital Critical Editions}

Hypertext theory and methodology is at the heart of most digital editions. Here diverse sets of content from images to texts and audio are "linked through multiple paths, chains, or trails in open-ended, perpetually unfinished textuality" (Landow 3 qtd. in Schreibman, "Scholarly Editing" par. 23) Here "readers could navigate between inter- or extra-textual lexias and engage in multisequential readings" (Schreibman, "Text Ported" 78). This approach creates new ways of writing, editing (i.e. hyperediting), and reading that varies dramatically from the linearity of books. Hypertexts "obey a logic . . that is

not the dominantly sequential and horizontal one of reading and writing on paper . . but 
the dominantly nonsequential, vertical digital organization, with fields or headings, by association and by strata arranged in levels of depth. Hence we have the "pull-down menus,' 'tool bars,' and 'links' by which we gain access to these depths" (Régnier 64). As previously mentioned in "The Rationale of Hypertext," Jerome McGann stipulates that the methodology of hyperediting should comprise two goals: an ambitious project and modular design that allows for flexibility and adaption to changes in computing (58). These two guidelines governed his approach to the Rossetti Archive, on which he began conceptual and theoretical work in 1992. Its first installment was released in 2000 and its production was closed in 2008 with its fourth installment. The archive is image-based, contains a description of each item, and provides transcriptions of Rossetti's textual work as well as page images and scholarly commentary. Unfortunately, unlike the Blake Archive, one cannot compare multiple images or transcriptions simultaneously. A word search will provide all locations of a particular word in any one of the collections (collection intros, text intros, images records or text transcriptions), but there is no way to compare the results, aside from reading through all of them. The website is exceptionally well designed, clean, and uncluttered, and does link thumbnails with text transcriptions. However, the bulk of its editorial commentary is separated from the text or images, and there is no way to collate any of the works, except through the keyword searches. The user must jump from one page to the next. The Rossetti Archive is an informative hypermedia archive and, in my personal opinion, its website is more aesthetically pleasing than that of the Blake Archive; however, it lacks many of the functional elements found in the Blake Archive. The sleek design is likely the result of McGann's view that “one should not lock a front-end hypertext system prematurely" (McGann 58). 
McGann's argument that digital hypermedia, hypertext and digital editions and the design of such texts should have a modular structure in order to adapt to future innovations in hardware and software is echoed by Michael Spermberg-McQueen, who contends that an edition should not "limit its dependency on any single piece of software, and that the creators of editions plan for the obsolescence of their delivery systems" (34). While the goal of making digital editions transferable across software and hardware platforms is often accomplished using XML mark-up that conforms to the TEIs guidelines, which potentially allows any future editors to view the encoding and tagset used, there are those who hold an opposing view. Peter Robinson, one of the founding members of The Canterbury Tales Project, argues that "the greatest promise of the electronic editions, to me, is not that we will find new ways of storing vast amounts of information. It is that we will find new ways of presenting this to the readers" (50). Much of what the William Blake Archive and the Rossetti Archive do is provide techniques to store content in new ways, by presenting images and transcriptions. Thus, they do provide new reading practices. These projects offer diverse and new ways to look, read and use a text. They do not pretend to be critical editions, but I question how much scholarly information they add to the texts they represent. In contrast to these archives, The Canterbury Tales Project is closer to a digital critical edition that allows for new critical reading practices.

\subsection{The Lens Through Which Digital Editions Can Be Seen}

In "The Turn in Textual Scholarship," Odd Einar Haugen and Daniel Apollon point out three distinct ways of looking at digital editions: looking backwards, outward, and inward. 
Looking backwards means to search for the origin of the text and to trace its development through time. ... Looking outward means to view the text as a product situated in a sociohistorical context. This implies that its contents, its use, and its organic relationship to other texts and sociocultural realities is of greater interest than its origin and transmission. Third, looking inward implies viewing the text as an individual expression in its own right.

In light of these definitions both the Blake Archive and the Rossetti Archive, offer readers collections of an author's works, and do not focus on one particular text and its evolution. Hence, both these archives can be seen as fitting under the umbrella of looking outward at the sociocultural realities that surround their production, and at their relation to other works by the author. In contrast, in 1989-90 Peter Robinson, Elizabeth Solopova and Norman Blake conceived the idea for a hypertext version of the Canterbury Tales, and in 1992 began work on what would become the Canterbury Tales Project. To date the project has published eight CD-ROM editions, and in 2013 released the Multitext Edition, the first online edition as part of the The Norman Blake Editions of the Canterbury Tales (Stubbs, et al.). Though the entirety of The Canterbury Tales is a dispersed edition, the first edition, published in 1996 by Cambridge University Press, was The Wife of Bath's Prologue on CD-ROM, and is much more concise. The disc contains images of 1200 manuscript pages from fifty-eight pre-1500 witnesses of the text, as well as a transcription encoded in Standard Generalized Mark-up Language (SGML) that allow for the collation of any word using hypertext linking between the witnesses. It also contains a database that traces the spelling of every word across the witnesses using DynaText software, which produces each 
line of the witnesses with the same word (Blake, et al.; Robinson and Solopova, The Wife of Bath's Prologue). However, the edition did not offer critical commentary, and it is left up to readers to construct their own reading text. This left some critics to call the work an archive rather than an edition; however, this author disagrees with such a definition, as it implies that the formation of a reading text is the main goal of a critical edition, which only harkens back to attempts at reproducing what readers once had in a printed critical edition. Perhaps the The Wife of Bath's Prologue is not critical, but it is an edition of a single text though offered in many versions for comparison. It is unlike The Blake Archive and The Rossetti Archive. Robinson notes that in producing The Wife of Bath's Prologue the team's intention "was and is to recover the history of the making of the text, in order to find better ways to read it" ("What Text is Not" 48). This approach is more akin to looking backwards and tracing the development of the text through time. A method that is similar to the one applied to the DCE of $A$ General History, as it does not aim to construct a singular reading text; however, unlike the Wife of Bath's Prologue the DCE also offer critical commentary throughout each edition.

The DCE looks both backwards and outwards. It looks backwards in the same way as The Wife of Bath's Prologue, and tries to "trace the development from the first drafts made by the author until the end product, usually a printed edition" (Haugen and Apollon 35). In the case of the DCE for A General History there are no pre-print drafts, so the technique of looking backwards is slightly modified, as it examines the first through the fourth printed editions. But the DCE also looks outwards as an expression of the sociocultural milieu of eighteenth-century print culture by tracing the changes made to the text. The first chapter addresses questions of authorship and attribution to set the stage for 
looking outwards to the sociocultural environment the text was produced in. It does not offer definitive answers to who made the changes, be it Defoe or someone else, or why anyone would take the trouble to do so. Instead this glimpse into eighteenth-century print culture offers readers the seeds from which a sociocultural analysis could grow. The approach of the DCE can also be seen through the theoretical framework of one of the first models of born digital editing: a phylogenetic/cladistics methodology applied to textual editing. "The principle behind this theory is that text variation as present in scribal manuscripts behaves similarly to the genetic mutation of molecules of DNA in living creatures; therefore it is possible to apply phylogenetic algorithms and methodology to group witnesses around their similarities and then to reconstruct a text" (Pierazzo 23). Though this theory requires a high level of computational power in order to collate variants, it represents "the interdisciplinary vocation of the Digital Humanities, as it uses and adapts methods borrowed from computer science and biology, applying them to a typical humanities question" (Pierazzo 23). Though the DCE does not use automatic computational collation methods, but a rigorous tagging method, future iterations, as will be discussed in Section 4.7, do draw on the possibility of applying this technique. The discussion of this type of edition also brings up one of the biggest questions regarding digital editions: the division of content and its delivery or presentation.

Robinson acknowledges that because the Wife of Bath is on CD-ROM, it is unlikely that in a hundred years "anyone will be using the transcripts of the Canterbury Tales .... Our transcripts will be outdated and of no interest to anyone except the occasional digger into archives" (50). This is likely true and unfortunately the Wife of Bath's Prologue may become outdated in much less than a hundred years. Today, less than two decades after its 
publication, most computers do not contain a CD-ROM drive. In the article Death of the Computer Optical Drive, Mark Kyrnin writes, "[i]t is almost certain that the drives will be completely removed from most mobile computers in the near future. . . Desktops will still pack them for a while as the technology is so inexpensive to include and there aren't the space issues of mobile computers" ("Conclusion"). Robinson also notes that just because a text is encoded using the TEI guidelines, it does not mean that they are forever safeguarded against changes in technology (50). He states that in pursuit of the goal of making the texts of Chaucer come to life, TEI does offer a standardized method of encoding, but "any pretence that any encoding is for all time is a delusion. . . . In time this 'linguistic' community will change. And when it does, and it will, our encodings, the systems of signs which make up our edition, will be inappropriate and will have to be redone" (44). Therefore it can be said that the method of presentation and the content or encoding theory of current editions are in flux, but it could be argued that the content is coming into a more concrete state.

\subsection{What Text Encoding does to Digital Critical Editions}

TEI's guidelines will have to continue to adapt to the changing needs of editors and technological advances if they are to remain relevant; however, much in the same way that the dictionary includes new words, there is no reason to believe that TEI could not do the same, and also adapt to new methods of web-based presentation (i.e. new programming, style and mark-up languages). In "Evaluating Digital Scholarship: Suggestions and Strategies for the Text Encoding Intiative," Sarah Pfannenschmidt and Tanya Clement argue that as the state of digital scholarship becomes more stable, demands have been made 
for "[s]cholarly organization, including the Modern Language Association (MLA) . . . to provide suggestions as to general guidelines for evaluating digital scholarship" (MLA; Working Group on Evaluating Public History Scholarship qtd. in Pfannenschmidt and Clement par. 1). One suggestion has been that the TEI Consortium (hereafter TEI-C) should contribute "to the creation of evaluation criteria" in text encoding and digital scholarship in general (Pfannenschmidt and Clement par.7). When Sarah Pfannenschmidt and Tanya Clement published their article "Evaluating Digital Scholarship" for the Journal of the Text Encoding Initiative they examined the answers of participants who took place in a survey were about TEI-C's involvement in the evaluation of text encoding and digital scholarship, they identified the same problem facing "the general digital scholarly community as a whole namely, trying to define exactly what an evaluation would assess and why (Pfannenschmidt and Clement par.7). Participants also recognized that if there are "two different editorial methodologies ... it is not always possible to determine what is 'better' about one choice over another. . . . Therefore, there is no absolutely correct way to encode a text beyond what will validate for a given set of parameters" (Pfannenschmidt and Clement par.12).

Though all the above mentioned projects are the result of a team of editors, social editing takes this collaboration a step further. Here one finds two main types of projects: the social edition and the crowdsourced edition. The social edition allows readers/users to define and construct their own texts; whereas in the crowdsourced edition readers/users are active participants in the transcription and making of an edition. In the first case one finds editions such as the Shakespeare Quartos Archive. Though some may argue that, like the Wife of Bath's Prologue, this project is not an edition but an archive, this author takes the 
stance that because it focuses on a single text, the thirty-two editions of Hamlet from before 1642, it is an edition. Here readers/users can view page images of each edition, compare these images, and crop selections. One can also compare any two transcriptions of any two editions with variants shaded for ease of access, annotate the text, view the annotations and notes of others, and keep one's notes/annotations as public or private, as well as make exhibitions and publish them online through the archive. The archive was launched in 2004 and is "aimed at facilitating scholarly research, performance studies, and new pedagogical applications derived from detailed examination and comparison of the quartos" ("About the Archive"). Not only is the archive the result of the collaboration of the many people who made it, but it continues to grow as more people use it and publish their annotations, notes and exhibits. The idea of collaborative or social editions "are not a novelty: large editorial endeavours have always been a familiar concept in editing" (Pierazzo 24). The social edition aims "to change the role of the scholarly editor from the sole authority on the text to a facilitator who brings traditional and citizen scholars into collaboration through ongoing editorial conversation (Siemens et al. qtd. in Pierazzo 25). This is how the Shakespeare Quartos operate to some degree, as anyone can become part of the editorial practices of this project, but only after the fact of its production by scholarly editors. As such, users of the archive are not part of the "making" of the archive; they are rather part of using the archive in a productive way that adds to its collection.

In contrast to this approach, Transcribe Bentham is an editorial project that fully integrates the user/reader as part of the editorial - or rather the transcription - team. Established in 2010, Transcribe Bentham is an ongoing project that aims to transcribe 35,002 folios of the manuscripts of the philosopher Jeremy Bentham. To date the project 
is $41 \%$ complete with 14,419 folios transcribed (Seaward). Users who wish to participate need simply to register to be able to take part in the project. The project operates by providing users with page images of Bentham's handwritten works, and asking users to make diplomatic transcriptions using TEI compliant XML to tag elements of the manuscripts. It is a form of crowdsourcing which can be "defined as the use of social media tools to enable users to contribute to a specific project or platform with new content" (Pierazzo 26). Though the project is impressive in the amount of work it has produced, and transcription is the most tedious part of producing digital works, this editorial project is by no means a critical edition, nor does it aim to be. Furthermore, editors of crowdsourced transcription projects such as those involved with the "Papers of Abraham Lincoln" found that, when experimenting with using non-academic transcribers, they spent more time correcting errors than they would have had they carried out the transcriptions themselves (Pierazzo 28). Editorial members of Transcribe Bentham addressed this issue by evaluating "the quality of the transcription provided by volunteers" and once these contributions were reviewed and deemed to have a certain level of accuracy, the transcriptions were acceptable for further editorial work" (Pierazzo 28).

This is not to say that crowdsourcing is not a useful tool, quite the contrary. In the case of producing the DCE for A General History, it would be of tremendous benefit to crowdsource the transcription process because what would be required would be less arduous than the demands of the Bentham project. A General History is not in manuscript form and the only hurdle that a transcriber would have to overcome is deciphering the long "s" ( or $\left.\int\right)$, used in eighteenth-century literature. Furthermore, because the DCE uses the $V M 4.0$ and requires a particular type of TEI encoding, one that uses the location-referenced 
method of tagging variants, it would only be asked that transcribers use the $<$ choice $>$ tag around each variant. The rest of the transcription would simply involve typing out each page, or part thereof, in a word processor or a plain text editor, and retaining the spelling, capitalization, font, format and line breaks. The difficulty would lie more in getting people to participate in such a project. In the chapter "Traditional and Editorial Models" from Digital Scholarly Editing, Elan Pierazzo notes that "[T]he work of analysing readings, making sense of them and if necessary, correcting them seems still solidly in the hands of trained editors" (29). Though some scholars and editors lament the fact that text encoding involves a large amount of transcription, it may be for the best. This not to say that scholars engaged in digitizing texts have merely become transcriptionists, but that it is part of the work needed for digitization, and a part that has made this author/editor more aware of the subtle changes in the four editions of the DCE. For it is only when one knows the goals of a project, and has performed a substantial amount of the transcription, that one can use TEI's guidelines to meet those needs.

All the above mentioned texts make their XML files, which are TEI conformant, available for downloading, so users can produce or change the mark-up and make their own iteration of the text. Some critics, such as Julie Flanders have noted that " $[\mathrm{t}]$ he scholartechnician is not a producer but a reproducer of knowledge", I whole heartedly disagree with this argument (61). By encoding texts, editors do engage in a form of remediation and reproduction, and by adding notes and deliberately tagging specific aspects of a text, they also engage in the production of knowledge, not just the reproduction. Pfannenshmidt and Clement argue that, "[w]hen an editor marks up the text in a detailed, methodical way, the text encoding becomes both an implicit and explicit part of their theory of the text" and 
more importantly that the "editorial decisions about how to encode text affect the scholarly quality of the project" (26-8). Encoding takes one away from the assumption that the "best way to study a book is by looking at it" by suggesting that "if we can represent it powerfully and usefully enough, we might be able to study it in ways that are not otherwise possible" (Flanders 56). Encoding a text may be one of the most important aspects of making a digital edition because doing so attempts to find ways of representing the textual, physical and visual forms of a text. Encoding and mark-up often present a reductionist and quantitative impression of texts, but here I agree with Flanders that the analytic modelling of texts will likely create "[t]he most powerful editions of the electronic era ... using text encoding to create models to morph the text, to re-order words, align them with other versions, lemmatize them and so forth" (62). Encoding does not simply make it possible to count words or quantify aspects of a text, turning them into data, but it also adds information, which users/readers can use to create knowledge. Every time individuals add a note tag and insert their critical opinion or observation of a textual element, they are adding information and embedding their own knowledge into a text or texts. Additionally, encoding can affect the element presentation. Though electronic texts separate content and presentation, software like VM 4.0 brings these two elements back together by stipulating how the encoding of a text will be presented and transformed through the declarative statements of the Cascading Style Sheets (CSS), and the Extensible Stylesheet Language Transformations (XSLT).

Fraistat and Jones” article, "Editing Environment: The Architecture of Electronic Text", notes that the modern digital "editor [is] transformed into a hybrid literarylibrarian/literary-encoder whose goal is to create an edition that surmounts limitations 
imposed by print-based publication" or a "literary-encoder grappling with a logic more amenable to programmers than literary scholars" (10). In many ways the transformation of the editor into a literary-librarian/encoder who deals with the logic of programming is a truism felt by this author; however, to be removed from the field of literary scholarship seems contradictory when producing a literary text, even if it is an electronic version. Rather, this author feels that a nuanced understanding of literary, editorial/bibliographical practices and "programming" is needed to create the information architecture of a DCE. It should also be acknowledged that using the $V M 4.0$ at a primary level only entails an understanding of encoding in XML according to TEI's "Critical Apparatus" and parallel segmentation or location-referenced method, which is a metadata language, not a programming language. It is worth noting that in order to accomplish the desired rendering of the DCE of A General History, the author did have to make modifications to the XSLT and the CSS code of the VM 4.0. The author also had to possess the ability to produce an HTML webpage and have an understanding of server-side migration in order to make the edition available to the public.

As a preamble to the following chapter on methodology, I would by no means classify myself as a programmer. XML and HTML are mark-up languages, and CSS is a style sheet language. The modifications to the XSLT are actually the closest thing to programming performed in the making of this DCE, as XSLT does specify a computation that can be performed by a computer (i.e. a Turing-complete language), by transforming the XML into HTML for the web page that hosts the DCE. XML is more attuned to bibliographic codes, such as collation statements, and natural language that is interpreted by humans. And HTML and CSS are analogous to typesetting and book design. The bulk 
of the work done to produce this DCE was encoding. In this vein, Fraistat and Jones are correct in stating that "electronic textual editing currently is far more advanced in theorizing and producing the 'back-end' of editions - where the issues primarily involve rigorous structural mark-up - than it is in attending to issues relating to the 'front end' the interface through which editions make their knowledge available experientially to users" (10). The next chapter will explain the strategies, methodology and encoding issues grappled with while making the DCE as well as the transcription process that led up to this phase.

\section{Chapter 4: Making the Digital Critical Edition of $A$ General History of the Pyrates}

Making the DCE was a task envisioned long before this thesis was proposed, and previous work done at the University of Toronto while pursuing a Master of Information in Library and Information Science helped to lay the ground work for the project. Section One of this chapter begins with a short introduction about the conception of this project and the work necessary before engaging in the production of the DCE. Section Two examines other preliminary steps that familiarized this author with various editions of this work and some of the work done prior to the encoding phase. Section Three of this chapter explains how the texts were prepared for the encoding process, including the transcription process and other "preliminary" steps, such as running optical character recognition (hereafter OCR) on page images (be they photographs, page scans, or previously digitized facsimile images which took place just before each section of the book was encoded). The need to prepare the texts in this manner was determined by the choice to use Susan Schreibman's the $V M$ 4.0.This section also examines other software that was tested. 
Section Four discusses the TEI's encoding guidelines for the "Critical Apparatus" employed throughout this project, as well as the way certain tags are used in the DCE. After learning and testing various encoding techniques on my own and presenting at least two iterations of the "Title Page" and "The Preface" of the DCE through course work for the English Language and Literature Department and Collaborative program in the Digital Humanities, as well as discussions with Professor Brian Greenspan, I decided that a User Experience/Analysis Survey should be circulated to gain feedback on the presentation and functionality of the DCE. Section Five explains the goals and results of this survey along with the feedback participants provided. Section Six explains how this feedback impacted the encoding methodology used in the final project presented for this thesis. Finally, Section Seven, presents thoughts about possible future iterations of the DCE.

The current iteration of the DCE is not a completed edition, but a selection or sampling of each part of the book, including the "Title Page," "The Preface," parts of the contents, and the first page of each chapter, along with the back matter and illustrations. A complete transcription and production of the work would have involved transcribing, comparing and encoding 1,643 pages of text (326 pages from the first edition; 420 pages from the second edition; 445 pages from the third edition; and 452 pages from the fourth edition), a feat that would have exceeded the scope of the current study. One project that has accomplished such a feat using the VM 4.0, is Walden: fluid text, housed on the Digital Thoreau website (Digital Thoreau). The fluid text edition compares seven manuscript revisions of Walden, written between 1846 and 1854, which have been transcribed and encoded (Digital Thoreau). Ultimately, a project such as this is the goal of the DCE of $A$ General History, but the edition of Walden: fluid text is only one a part of Digital Thoreau, 
which houses other texts regarding Thoreau's works. It is a collaborative project with twenty-five members from the State University of New York at Geneseo, the Thoreau Society, and the Walden Woods Project. The edition of Walden: fluid text, represents a benchmark project using the same software as the DCE to produce to produce a critical edition in the same format, though with a completely different methodological approach.

\subsection{The Conception}

This author was first introduced to TEI while encoding Robert Burns's poem "Halloween" in the course The Future of the Book at the University of Toronto, which ultimately supplied the foundation for learning the tag sets needed for this thesis (Burns 208). During the same period, course work in rare books and a workshop on visual markup tools using the University of Victoria's Image Mark-up Tool was completed. The project for the workshop was well received because it produced a final useable project that examined a headpiece from a reprint of $A$ General History. This was my first introduction to marking up an edition of this book. For the course The History of Books and Printing, I compared six editions of A General History, spanning from 1724-1999, I examined the variations of the format, the presentation of ornaments, paper being used, the type of binding, and the material used for its covers. A more in depth comparison of the three editions from the eighteenth century was produced for a final project in descriptive bibliography, for the course Analytical and Historical Bibliography, a paper that has been used as a reference for the collation statements seen in the "Bibliographical Information" pane of the "Title Page." During this course, various different approaches to descriptive bibliography were addressed. At the end of the course, a discussion of critical and 
diplomatic editing and digital tools also reintroduced this author to the $V M$ 4.0. Another tool that was introduced was the McLeod Collator, a device that uses a mirror to superimpose two texts on top of each other to show variants. However, using this device would have required purchasing the machine, and having paper copies of each page photocopied and set precisely to the same position on single sheets. I did not have paper copies of the editions of A General History at my disposal, nor do many libraries allow one to make photocopies of rare books.

\subsection{Preliminary Steps}

While studying at the University of Toronto from 2010-2012 and in the year after, I became familiar with the evolution of this book and began to scan numerous pages of the eighteenth-century editions housed at the University of Toronto's Libraries. In the spring of 2013 while auditing a course on Analytical and Historical Bibliography, I began a more thorough scanning of the fourth edition, housed at the Thomas Fisher Rare Book Library, using their Book2Net Kiosk overhead scanner that generated the JPEG images used in this thesis. The number of pages scanned and the use of the scanner were both done with permission of the Thomas Fisher Library and within the limits of reproduction. I also began photographing the necessary pages of the first edition from the Baldwin Reading Room at the Toronto Reference Library, using my cellphone mounted on a tripod to capture a JPEG image of each page, including the pages used in this project. Again permission was obtain by the Toronto Reference Library. Both of these reproduction processes were completed in anticipation of this thesis, and took place over the course of five months, in intervals ranging from thirty minutes to two hours. Photographing and documenting the collation 
and contents of the first edition took place over the course of at least two weeks of almost full-time work at the Baldwin Room. Interestingly, a page scan of a single page would have cost twenty-five dollars, amounting to roughly six-hundred dollars for the reproduction of the whole book, but unlike most rare book collections, photography was allowed in the Baldwin Room and it was free. In contrast, the page scans of the fourth edition from the Thomas Fisher Library were free, but photography was strictly prohibited. During this time WorldCat was also used to locate born digital copies of the second and third editions, as it proved easier in some regards to use editions that had already been digitized. Paper copies of these two editions were, at their closest, located in Buffalo, Erie, and Ithaca in New York State. I did not have the time or money to spend several weeks in rare book libraries in upper New York State. The use of already digitized editions also meant one less step in the production line, or so I thought. However, while gaining access to digitized editions was easier than traveling, the quality of some of page images was not as good, which meant that running OCR on the selected pages resulted in a less accurate text for transcription. It also meant that more time was required to visually compare the results from the texts generated by OCR to the facsimile images in order to produce accurate transcriptions.

\subsection{Preparing the Texts}

The problem digitized texts presented was twofold: first, a copy of the second edition of $A$ General History found on the Internet Archive is improperly collated, in that the leaves of "The Contents" are not organized properly. Page ten ([10]) is in the position of page seven ([7]), when checked against other electronic editions from Project Gutenberg and Eighteenth Century Collections Online "The Contents" section was properly collated, 
This could be a mistake made by whoever collated the page images from the Boston Public Library, though it may be that this copy of the second edition was actually collated improperly in its print format. Without access to the copy of the Boston Public Library's print copy, it is impossible to ascertain whether it is the digital or print copy that is improperly collated.

The second problem with digitized editions is the poor quality of their page images. While the second edition from the Internet Archive provides very well-preserved images and a relatively high quality of accuracy when it is run through OCR software, the third edition, from ECCO, is in a black-and-white PDF format that had not previously been run through OCR technology and was therefore unsearchable. It produced very poor results when I ran it through OCR software. Small ink marks on the page and the poor quality of the black-and-white images required extensive human examination and visual comparison to the original to fix the errors made by the OCR. The OCR and transcription processes, otherwise known as preparing the text, were the lengthiest in making the DCE. Numerous open source OCR programs were tested, including Adobe Acrobat Professional, Free OCR and OnlineOCR, but none of them produced results that could be transcribed without enormous amounts of correction. All the above programs produced a five to ten page document for a single page from one edition of $A$ General History. The page produced by these OCR programs was often filled with random, non-text-based characters. Eventually, this meant using the licensed software ABBY FineReader, one of the best OCR software programs available. Even so, it did not produce text that was quickly transformed into usable transcriptions for a variety of reasons outlined below. 
The reason for converting the "original” images (JPEG's) or PDF files was that I needed text for transcription and comparison before I could proceed to encoding the editions. The long "s" was a troublesome character. There is no dictionary in ABBY FineReader for eighteenth-century English, and numerous random characters would be produced for portions of the text that the program did not recognize. There is, however, the option to "train" the software by tediously going through a document and entering the letter that corresponds to the unrecognized character. I did not use this function because it made reviewing each page a much longer process. Instead, I opted to use the "find and replace" function in Microsoft Word (hereafter MS word) as it was quicker. After converting the JPEGs or PDFs using ABBY, I could transfer the transcriptions into MS Word, and then go through the document I had and replaced every long s ( $\left(\right.$ and $\left.\int\right)$ which ABBY had converted to "f" instead of "s". I then ran a spell check and compared the MS Word document to the original texts visually. This approach proved to be relatively effective in producing accurately transcribed versions of texts.

There were two other problems encountered when converting the originals into searchable documents. One was that the only English language dictionary provided in ABBY is the American English Dictionary. In Microsoft Word, there are numerous English dictionaries, but there is not one for older forms of English that use different spellings of words such as "compleat" from the eighteenth-century, so these words are interpreted as errors, and MS Word wanted to correct them to the modern spelling of "complete", or as in the title of the work MS Word wanted to correct the word "pyrate," to "pirate". Other joined characters such as, 'æ' and 'œ’ were commonly used in the eighteenth-century. All such variations in spelling ABBY and MS Word view as errors. In such cases I had to skip 
these words when performing a spellcheck and double check them against the facsimile images. The other issue was the random capitalization of nouns in eighteenth-century English. For example, when running a section of text through the grammar/spellcheck in MS Word, I had to ignore all the grammatical cues to make sure sentences retained their original capitalization. The sentence "It is for this Reason we have subjoined to the Work, a short Abstract of the Laws now in Force against Pyrates, and made choice of some particular Cases..." is in fact printed with the above words capitalized (Johnson, ed.1: Preface 1). However, what complicated this issue (and is in fact one of the points of the digital edition) is that capitalization varied throughout the editions. In the sentence above, taken from "The Preface" of the first edition, the word "choice" is all lowercase, but in editions two through four it becomes "Choice." Paying attention, and ensuring that such minute details were correct, and comparing the pages from the four editions to check for such changes, was one of the goals of the DCE, all of which was done to prepare the text for encoding.

Documenting these changes and making them apparent to the readers/users without becoming interruptions to the text was another issue that had to be addressed when encoding the text. How these variants are documented and which ones are pertinent, was partially governed by the TEI's location-referenced method of the "Critical Apparatus" tag set, and partially by how I chose to use the tags of the "Critical Apparatus" in the DCE. Likewise, the manner in which I chose to present them was partially determined by the $V M$ 4.0 method of interpreting these tags, and partially by modifications I made to this open source software. 


\subsection{The Versioning Machine and TEI}

The decision to use the VM 4.0 to present the DCE to the public was made after a trial of encoding the "Title Page" using the UVic Image Mark-up Tool and the VM 4.0. During this one-page trial, the UVic Image Mark-up Tool was ruled out for two reasons. The first was that it required me to choose a single edition as a copy-text, which I would have had to mark-up and annotate, describing each of the changes in other editions that would not be visible to the reader. Though in theory one could annotate all four editions and present them on a single web page, this did not seem like a suitable way for readers to compare the changes in each edition: although my annotations could serve as a guide, readers would still have to visually compare each page of the four editions. Secondly, the UVic Image Mark-up Tool is (as its name implies) image based, meaning I had to mark-up the image of the page instead of the text.

The result was that, in this trial phase, I selected the first edition, and enclosed each part of the text with different coloured boxes that corresponded to four different types of changes:

- Additions in the 2nd ed.(1724), 3rd ed. (1725) \& 4th ed.-vol.1 (1726)

- Title changes in unnumbered edition (issue from 1725)

- $\quad$ Title in 4th ed. vol.1 (1726)

- Deletions

The illustration of result from the UVic Image Mark-up Tool can be found in Appendix A. These categories were further annotated and encoded using XML in which I used the paragraph tag $(<\mathrm{p}>)$ around the comments displayed in the "Annotations" box visible below the enclosed part of the image, the changes are located in. The one advantage of the 
UVic Image Mark-up Tool was that it provided a form of index for the changes. This approach was only a trial, and had I continued using the UVic Image Mark-up Tool, it would have been more logical to colour code the changes for each edition in a different colour and perhaps simply underline the text instead of boxing it off.

This image-based annotation proved quicker to encode than the method used to encode the texts in the $V M 4.0$, but did not allow for a visual comparison where readers had a textual transcription that pointed out the variants using the visual cues with inserted annotations for each edition that is found in the DCE made using the VM.4.0. Furthermore, when using the UVic Image Mark-up Tool, the page quickly became cluttered with multicoloured boxes, and appeared much less intuitive in illustrating the difference of each edition to the user/reader. This is mainly because one must scroll over different parts of the image to get the coloured boxes to appear, or click on the "Annotations" menu to make an index of the annotations appear and then click on the desired annotation. To view the functionality of this trial, one can go to "Legacy Trials: December 2014" by clicking on the link under "1b. UVIC Image Mark-up Tool" on the webpage that hosts the DCE (http://ingridreiche.com/Resume/Thesis.html).

After these two trial runs, the decision was made to use the $V M$ 4.0. The $V M 1.0$ made its debut in 2002 at the Association for Literary and Linguistics Computing/Association for Computers and the Humanities Conference in Tubingen, Germany, and was released as open source software in May 2003. Version 2 quickly followed in December of 2003 (Schreibman, "Credits"). The original team of developers comprised Susan Shreibman, Amit Kumar, Jarom McDonald, Lara Vetter, Eric White, Jose Chua and Michael Beddow. Both McDonald and Vetter were working on the Dickinson 
Electronic Archive at the time, and Vetter had encoded Dickinson's manuscripts, family papers and secondary works in "TEI-conformant XML" (Schreibman, "Credits"). Four years later, in July of 2007, Version 3.2 was released, and the development team expanded to include Ann Hanlon, Sean Daugherty, and Tony Ross. By this time McDonald, Vetter, White, Chua and Beddow had left the team, though their contributions were key to forming the initial launch of the software. The version used in this project is version 4.0, which was realised in May 2010. The development team added Tanya Clement and Robert Whalen, while Kumar and Ross moved on to other projects. This thesis and the accompanying DCE of A General History of the Pyrates is indebted to all of their contributions.

Through correspondence with the current $V M$ team members, it also came to my attention late in the summer of 2015 that the VM 4.0 was planning to release version 5.0 in the near future, and the project inquired about and requested permission to include $A$ General History for the section the "VM IN USE." In the beginning of February 2016 the release VM 5.0 went live, and does feature the version of the DCE used in the survey. With new participation from The Modernist Project at the University of Victoria, the VM 5.0 is also HTML5 compatible, and "can now incorporate sound-based, image based, and textbased versions" (Carter, "VM 4.0 for Audio 5.0"). The final version of the DCE does not use the updated $V M$ 5.0. A discussion of why I chose to continue working with the $V M 4.0$ and the possible changes to the DCE using the newly released version will appear at the end of this chapter.

The initial trial of encoding with the VM 4.0 did not produce the exact results desired for the DCE; nor does the final iteration presented with this project, in that the entirety of the editions are not encoded, and no single reading text is presented. These 
shortcomings will be discussed in the reflections section at the end of this chapter. However, the VM 4.0 was the best tool available to this author at the time, and does have numerous advantages. One of these is that it allows editors to add bibliographic and critical information to the text. The "Bibliographic Information" pane in the "Title Page" section outlines the physical location of the library from which the digital copies were made, as well as other elements of descriptive bibliography, such as the collation statements, which are important pieces of information for readers/users who wish to view the original works, or for future editors who might compare the particular copies used in the DCE to other copies. Recording the Bibliographic Information for the second edition posed a bit of dilemma, as the page scans are from the Internet Archive, which are sourced from a copy at the Boston Public Library that may have collated "The Contents" section out of order, as noted earlier. This copy has been cross-referenced against another version from Project Gutenberg which is also sourced from the Internet Archive, but "The Contents" have been transcribed to reflect the collation intended for the second print edition from 1724. The DCE reflects the "intended" collation that is seen in the Project Gutenberg edition, but uses the page images from the Internet Archive, as they are of better quality. Though the witness list names the Internet Archive scan as its source, the transcription does not reflect the collation of this digital copy, so it proves more informative to provide the edition and date as the primary description and the location of the source material as secondary description in the Witness List. Furthermore, the "Bibliographic Information" pane does indicate that the second edition is sourced from both the Internet Archive and Project Gutenberg in order to inform readers of the discrepancies between the two copies. The only way to know if the copy from the Boston Public Library is actually collated improperly would be to 
physically examine the copy. Recording the bibliographic information was the first step in creating the DCE. For the first and fourth editions, the collation statements and pagination had been done for a previous project while I was auditing a course on Analytical and Historical Bibliography in 2013; the descriptions for the second and third editions were done for this thesis.

The second step after deciding to use the VM 4.0 and recording the bibliographic information was to begin encoding the texts. The XML encoding was written with oXygen's XML editor, a piece of software that informs editors if their encoding is valid. It also allows one to apply transformations to the XML based on the XSLT indicated at the beginning of the XML document, which transforms the text into HTML display for the $V M$ 4. 0 platform where users/readers can view and interact with the text. The VM 4.0 uses TEI's "Critical Apparatus" tag set, with the parallel segmentation method, and provides the option of using the location-referenced method as an alternative to link sections of a text to show their variations or similarities across the version.

The parallel segmentation method allows one to encode multiple versions or, in the case of this DCE, multiple editions using a single XML file. Each witness must be declared in the Witness List. The example texts from the VM 4.0 indicate that it is useful to identify each witness by its source location, and provide a short bibliographic description, as proposed by TEI's "Critical Apparatus" section on the Witness List (TEI, 12.1.4.3). I chose to use the edition and date as primary identifiers, and the source material as secondary identifiers. The use of plain language as a primary identifier was picked because it seemed more relevant to ensure that readers understood the edition they were examining before presenting an obscure bibliographic code, which some readers might only understand after 
examining the bibliographic information pane. The Witness List for the DCE reads as follows:

$<$ listWit $>$

<witness xml:id="ed1-1724">1st ed.-1724, "GHP",(CaOTPH910.4J57C.1/TPL)</witness $>$

<witness xml:id="ed2-1724">2nd ed.-1724,"GHP",(Internet Archive/scans from BPL-Defoe21.G421724B) $</$ witness $>$

<witness xml:id="ed3-1725">3rd ed.-1725, "GHP" (ECCO/scans from LO/N37276.i.4) </witness $>$

<witness xml:id="ed4-1726v1">4th ed.(Vol.I)-1726, "GHP",(CaOTUTF

B1003067- Vol.1/TFL)</witness $>$

$</$ listWit $>$

First, the attribute given to the element describing the witness (i.e. $<$ witness $x m l: i d=" 1{ }^{\text {st }}$ ed.-1724">) appears as the text "1:1 $1^{\text {st }}$ ed.-1724, "GHP”, ",(CaOTPH-910.4J57C.1/TPL)" in the drop down menu for each reading. Considering that some of the editions came from digital editions, and not from any particular library, I felt it would be more intuitive to tag each reading by the edition and year first, so users could easily select a desired edition. Tagging in plain language as well as bibliographic code for source material allows those outside of the realm of bibliography to understand which reading they are examining. In addition, using only bibliographic code as a primary identifier for source material did not seem adequate to convey the desired information, and would possibly cause confusion, as it does not indicate the year or the edition. In this author's opinion these two piece of information are the most relevant for this particular project because it is looking at distinct 
printed editions. In contrast, many of the examples from the $V M 4.0$ are transcriptions of manuscripts, in which identifying the source of the material is much more important.

The Apparatus Entry $<$ app $>$ embedded within the head and title, near the beginning of the body of the XML file, identifies the title of each witness "and groups together all the readings constituting the variation. ... different editors may group readings differently. No rules are given as to how to group readings into the apparatus entries" (TEI 12.1.1). An editor can therefore choose to group the readings in the manner they find most useful; however, it is crucial to define the witnesses at the beginning in a manner that makes logical sense For the "Title Page" of DCE the apparatus entry reads:

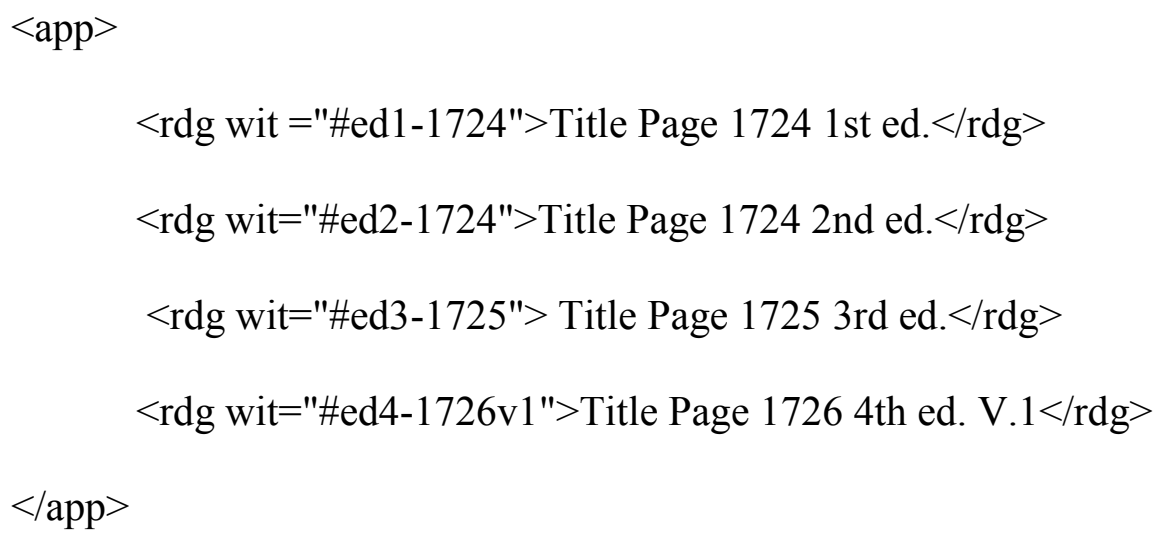

With the apparatus entry the $<\mathrm{rdg}>$ tag indicates a single reading of a text so each reading/witness/edition is denoted by a different attribute. Thus, the second edition is denoted by $<$ rdg wit=“\#ed2-1724" $>$. Whenever that value is used in the encoding it will be seen in the pane for the second edition. Likewise, one can also use the lemma tag $<$ lem $>$ to specify a reading that "contains a lemma, or base text, of textual variation" (TEI 12.1.2).

The parallel segmentation method was used while conducting the initial trial. In the parallel segmentation method "no two variations can overlap, although they may nest. The texts compared are divided into matching segments all synchronized with one another. This 
permits direct comparison of any span of text in any witness with that in any other witness" (TEI 12.2.3).At that time this author was not aware of the of the alternate style sheet developed by Tanya Clement that uses the location-referenced method, as seen in the sample text for "In Transition: Selected Poems by Elsa von Freytag-Loringhoven" (Clement). At the time of the trial I was using the default stylesheet, in which I could only produce a text that would highlight corresponding line numbers, instead of parts of a line or a single word across different lines. Once I discovered how to use Tanya Clement's stylesheet, the VM 4.0 proved to be much more adequate for the DCE of $A$ General History. The file for Tanya Clement's stylesheet is called evfl.xsl, and uses TEI's locationreferenced method from the "Critical Apparatus" tag set: "The location-referenced method of encoding apparatus provides a convenient method for encoding printed apparatus; in this method as in most printed editions, the apparatus is linked to the base text by indicating explicitly only the block of text on which there is a variant" (TEI 12.2.1). However, the method will work even if one decides not to choose a base text. For the production of the DCE of $A$ General History, the first edition acts as the basis of comparison, though not the base text, a distinction I draw based on the fact that the first edition also includes annotations and mark-up. If it were a base text, it would not include such features, but would be free of annotations and would be an unannotated, uninterrupted reading of the text. The decision to use the first edition as a basis of comparison, as opposed to a base text, was largely informed by the survey: “Digitizing the Pyrates: A user experience survey about a digital editing platform that allows for different methods of encoding and interacting with a digital critical edition and compares four digitized editions of Captain Charles Johnson's A General History of the Pyrates, 1724-1726," that was carried out for 
this thesis during the fall of 2015 (Reiche). In fact, much of the customisation done for the final iteration of the DCE is informed by that survey. Three major components that were affected by the results of the survey are the presentation of underlined sections of the text, the redundancy between underlined comments and notes, and the manner in which line numbers are presented in final product.

\subsection{The User Experience Survey-Its Goals and Results}

The goal of the user experience survey: "Digitizing the Pyrates: A user experience survey about a digital editing platform that allows for different methods of encoding and interacting with a digital critical edition and compares four digitized editions of Captain Charles Johnson's A General History of the Pyrates, 1724-1726" was to determine what method of encoding would provide the most user-friendly and intuitive method of presenting the DCE (Reiche). The survey was emailed out to roughly forty people from various disciplines including students and professors from Carleton's English and Digital Humanities programs; previous professors and librarians from my studies at the University of Toronto's Faculty of Information; and members of the general public (i.e. friends and family). The members of the general public included some people who had academic degrees from various backgrounds including English, History, Business, Sociology, and Art, and others who had no formal academic background. Most of this last group had very little exposure to digital humanities scholarship or digital scholarly editing. I received a total of fourteen completed surveys. The majority of respondents were from Carleton's English and Digital Humanities programs, though roughly a third of the respondents came from outside Carleton, including a rare book librarian, a teacher and former English 
student, a sociologist, a salesman, and a professor emeritus who was not familiar with such digital tools. All in all, it was a diverse group of respondents from various disciplines and age groups. Such diversity proved useful as they all had their respective views, though a majority answered in a similar fashion. This meant the survey produced general themes in its answers that informed the DCE's final iteration.

The survey presented users with six different methods of encoding for the "Title Page" and the eight pages of "The Preface" from four editions of $A$ General History of the Pyrates (see Appendix B for a copy of the survey). These six methods included one for the "Title Page" and five for "The Preface". All pages contained a thumbnail image that could be accessed by clicking on it. When one entered the "Title Page," there was a "Bibliographic Information" pane that appeared automatically, which contained information about the source of each edition, its collation and pagination statements. Additionally, there was a "Critical Introduction" pane, which the user viewed by clicking on a button in the headlined menu. It contained relevant information about historical criticism and about the different types of notes. The "Title Page" section also automatically loaded the first two of the four versions. To view the other two editions, one had to click on the "New Version" button from the overhead menu. The "Title Page" was encoded with notes in two forms: gloss notes (denoted by a superscript $g$ ), which refer to changes in spelling or wording; and general notes (denoted by a superscript $n$ ), which refer to general changes in the text. The notes would appear by scrolling over the superscript letters when the popup note function was enabled, or by activating the inline notes function, which would make all the notes appear on the right hand side of the page. The "Title Page" also included underlined words that provided visual references to where these changes 
appeared. When the user scrolled over these portions, a popup would appear that gave a brief explanation about the marked change. One could also click on both parts of the text that had similarities and variants, which would highlight the corresponding sections in all four editions. Finally, every line of the page was numbered, but if a line contained a variant from the first edition, a letter was added to the line number. Furthermore, where a line of text had been added in editions two through four, $\mathrm{a}+1$ was added to the line number (i.e. $29+1)$.

For the "Title Page" section, the survey asked questions about the overall understanding of the material and its presentation. The general reaction was that people understood what they encountered upon entering the "Title Page" section. The majority felt that the "Bibliographic Information" pane was useful and should be presented, though some felt it was cluttered or that it was difficult to read the size of the text. Interestingly, most wanted the "Critical Introduction" pane to be displayed at first glance as well, which was unexpected. Almost all understood how to access the additional two versions, though there were suggestions for a help function, or a user manual of sorts. Respondents generally wanted to be able to access more than one page image at a time, which unfortunately is not a function of the VM.4.0. Most found it difficult to compare all four editions at once. Many mentioned small screen size being an issue here. Most had a general desire to explore the functions even before they were asked to perform certain tasks.

Many respondents had contradictory opinions about line numbering. Some felt the line numbering was confusing, or cluttered the page, but many used it to guide them through the various editions of the text, and thought it was relatively clear. All but one respondent preferred the popup notes to the panel of inline notes that could be used. Almost 
all found that the underlining was useful in identifying where changes occurred, but thought the popups displayed by scrolling over the underlined text and the popups displayed with the notes (superscript letters $g$ and $n$ ) were redundant. However, all agreed that some notes were essential to the text's function as a critical edition. Many also liked the ability to hide the notes and have a "clean" version of a reading text. The ability to highlight all parts of the texts, including those that are similar and those with variants, was generally preferred, but many suggested that there be two different colours: one for the similarities, and one for the variants. The ability to highlight all parts of the text goes against the general encoding principles outline in "The Documentation" section of the VM.4.0 and by TEI, but was something I wanted to test.

"The Preface" contained six pages in the first edition and eight pages in editions two through four. It did not automatically display the "Bibliographic Information" pane that appeared when one first entered the "Title Page," nor did "The Preface" display the "Critical Introduction" pane when the page loaded. Three editions - the first, second and fourth - appeared. The non-chronological sequence of the editions was chosen based on the fact that these three editions showed the most variation. The pages of "The Preface" were encoded in five different methods to provide users with different experiences. The first page, much like the "Title Page," had notes and underlined text in all four editions, which could be activated in the same way. The one difference is that a third type of note was added. This was the physical note (denoted by a superscript $p$ ), which pointed out changes in formatting and the physical layout of the page, such as changes to line ends. The majority of notes in "The Preface" were either physical or gloss notes. This page also featured line numbers only for those line with changes. 
The second page of "The Preface" did not have any notes or underlined text in the first edition, so that it acted as a base text. This page had underlined text that contained explanations, but did not have any notes. One could also highlight all parts of the text for comparison, meaning both those with similarities and differences, but there were no line numbers. The third page did not contain any annotations for the first edition. It did provided notes, but did not contain underlined text. One could highlight all parts of the text, but line numbers were added only to those lines where there were changes. The fourth page contained annotations in the first edition and all other editions, but only contained underlined text without notes. One could only highlight those parts of the texts with variants. The parts that were similar would not highlight when clicked, and there were no line numbers. The fifth page contained notes in all editions, but had no underlined text, and again one could only highlight those parts of the texts with variants. There were no line numbers. Pages six through eight contained no notes or underlined text, but one could highlight all parts of the text, so one could only identify those places with changes by clicking on various parts of the text to make them highlight.

This section of the survey was designed to distinguish what particular functions were more user-friendly. Through the responses it became much more apparent whether users preferred notes, highlighting, underlining, or line numbers. Almost all participants wanted the "Critical Introduction" pane to be displayed when the page opened, though responses were equally divided about the "Bibliographic Information" pane being presented in this section. The majority of respondents felt the editions should be presented in chronological order, as opposed to those with the most variation. Most indicated that if the order of the edition was left in the current display — with editions one, two and four- 
that this should be explained. One thing that was unanticipated is that people wanted line numbers, or at least the ability to activate them, and have them throughout the pages. Because the pages of "The Preface" are unnumbered it seems likely that people need some way to reference their location in the text. Most participants also wanted the underlined text to mark the variant sections. Respondents were also deterred from the final section of "The Preface" where there are no notes or underlined text, and where one could only identify variants through exploration and clicking on different parts of the text to make section containing similarities and differences highlight.

\subsection{Final Production Methods}

After having conducted the initial trials and producing the edition of the "Title Page" and "The Preface" for the survey, which greatly informed the final methodology to be used in the DCE, it was time to play with some of the features of the VM 4.0 and decide on which were to be used in the final methodology for its production. Decisions regarding the methodology were carefully considered. In the end, the final iteration of the DCE for $A$ General History of the Pyrates (1724-1726) includes four editions of the text, not six as originally planned. These are the first, second, and third editions, and volume one of the fourth edition. This decision is based on the ability to compare the material in these editions. While it was originally anticipated that the DCE would include both volumes of the fourth edition, the second volume contains completely different material that is about a whole other set of pirates, meaning it is essentially all new material. Including it in the DCE would only show that there are no similarities between this volume and the previous three editions along with volume one of the fourth edition. 
The issue from 1725 was also taken out of the DCE for similar reasons. The material in the 1725 issue varies greatly from the four chosen editions: it is only one hundred and fifty-six pages long, approximately half the size and content of the first edition, meaning that its author made deletions and alterations to the text, making its contents considerably different from those of the four editions chosen. The 1725 issue does contain chapters about all the same pirates, but its utility in illustrating variations is too plentiful for comparison at the level of this project. However, it would prove very interesting to compare it in a larger project, as it does cover much of the same subject matter.

After establishing that these two texts were not to be used in the DCE, there were two other factors that needed to be considered. First, after examining "The Contents" section of the four editions chosen, it was determined that the amount of variants in this section of the book was extensive. Therefore "The Contents" were encoded last, to the best ability of this author, but would not include the entire ten pages of this section. The encoding methodology now became the main focus. After compiling the results of the survey and the associated comments, and playing with the code of the $V M 4.0$, the methodology for encoding the DCE was finalized.

Second, it was determined that both the "Bibliographic Information" and "Critical Introduction" panes would appear when the "Title Page" first loads, along with the first two editions. The decision to add the "Critical Introduction" pane to the initial presentation was based on the responses from the survey conducted, and it adds a further layer of critical matter to the DCE. Additionally, since the "Critical Introduction" pane explains the meaning of the different types of notes used by the $V M 4.0$, it helps explain the apparatus used within the DCE. 
Third, instead of having a popup appear for the underlined sections of texts which mark the variants, this function was disabled. This means that the CSS file associated with the VM 4.0 was modified for the styling associated with the $<$ choice $>$ tag, so that what previously were the underlined sections of text now appear in a very light blue/grey colour. Additionally, I modified the CSS so that no popup note would appear for the underlined (now coloured) sections. This was based on suggestions from the survey that these portions would benefit from being a different colour than those that have no variation, and that underlined text might indicate that the text was actually underlined in the originals. The choice to get rid of the popup note for the underlining was made based on the redundancy the participants felt when examining the popup that appeared with the underlined text and the popup for the notes. The notes, [physical $(p)$, gloss $(g)$, critical $(c)$, and general notes (n)] would remain as popups beside the portion of texts that is now coloured and would function as the sole explanatory and critical device within the DCE.

Fourth, line numbers were added at the interval of every fifth line, to aid readers in assessing their location on any given page. The choice to use this method of line numbering as opposed to numbering paragraphs was based on two premises. Numbering paragraphs did not seem sufficient as a method for location. In those sections, such as "The Preface" where there are no page numbers but page breaks it is a way to mark the location on each page. Unlike a digitally published web-based scholarly work that contains numbered paragraphs, it was difficult to decide whether numbering paragraphs continuously throughout the whole section would be intuitive, or whether it would be more user-friendly to number the paragraphs on each page. Furthermore, the VM 4.0 is largely constructed to deal with poetry, not prose, and there is no method to mark paragraph numbers. One can 
mark them in the XML document as an aid for future editors, but this will not appear in the HTML rendering. It also seemed excessive to number every line because this adds significant work to the encoding process; therefore, numbering every fifth line of text on each page presented a middle ground. This process allows readers to locate the position of a line, but it does not become invasive or clutter the page when this function is activated. It should also be noted that the choice was made not to present line numbers when the page for each section loads, but to allow users to activate the function by clicking on the box beside "Line numbers" in the menu.

\subsection{Future Iterations}

The VM 5.0 was released in early February 2016, too late for use in the present study. It is possible that in the future the DCE will be migrated to this new platform; however, thus far trials in migrating the DCE to the VM 5.0 pose both new possibilities and problems. The VM 5.0 automatically loads both the "Bibliographic Information" pane and the "Critical Introduction" pane in one panel on the left, which is both a positive and negative. Though this option can be modified using the CSS file, that file is also considerably larger and would take some time to figure out. Furthermore, the VM 5.0 integrates both Tanya Clement's stylesheet, which uses the location-referenced method, and the default stylesheet which uses the parallel segmentation method (that were two totally different sets of files in the VM 4.0) into one set of files (a XSLT, CSS, JS, and JSON), so that one can use either the parallel segmentation method or the locationreferenced method without having to choose a different XSLT and CSS file. Therefore, using the VM 5.0 would necessitate looking at and modifying much more code than before. 
There is a "settings" file which is supposed to help one through the process of modification, but it contains limited content, and upon a quick read, it does not explain how to implement the customization already made in the DCE using the VM 4.0. Additionally, the VM 5.0 is TEI P5 compliant, and contains a Document Type Description (DTD) and schema that are also associated with the XML file, if one chooses to use them. This adds another layer of complexity to customization and migration, as if one does use them the XML file must comply with both these external files. Initial trials at such migration have added extra spaces and additional line spacing, for reasons that are yet to be understood.

On the other hand, the VM 5.0 contains added features that the DCE would benefit from, many of which were requested by survey participants, whose responses have been shared with the $V M$ team. For example, one can open multiple images of digital facsimiles for comparison, something many participants suggested. Additionally, these images can be zoomed in or out by the readers/users to the desired size, which is also something that was suggested. Finally, when using the new VM 5.0, one can open different versions/witnesses and resize them to a desired width, as well as turn them on or off, as opposed to selecting "New Version" from the menu, or choosing a witness from the drop down menu as seen in the $V M$ 4.0. There are many other upgrades made to the $V M 5.0$ that I have not yet had time to become familiar with, such as the ability to encode images and sound. All these new functionalities would without a doubt make an improved version of the current DCE.

Another possibility for a future version would be to design my own software, or to create a database using MySQL that contains each edition and a table for all the changes in each edition. In this scenario, one could bring up all the editions for comparison as in the $V M$ software, but it would also possess the ability to create an index for the changes in 
each edition via its line number, and one could compare the changes in the index created for any two, three or four of the editions. Furthermore, I would like to write a script in PHP or Python script that would generate multiple reading texts: one that is free of any of the changes, and one that contains annotations and illustrates the changes. This is the phylogenetic approach discussed in Chapter Three, where the computation of PHP or Python would automatically collate the variants. An example of this type of reading text, and the collating of variants is somewhat comparable to that seen in Digital Thoreau's construction of each version of Walden: a fluid text. Though this project does use the Versioning Machine, it does so in a markedly different fashion than the DCE of $A$ General History. A future iteration of DCE, produced using the VM 5.0 would contain at least the entire transcriptions of all four editions, and would require learning how to use and customize this new version. On the other hand, producing an iteration using MySQL, and PHP or Python would require a better understanding of these languages and database design, but would resemble that of The Wife of Bath's Prologue on CD-ROM. Projects of this calibre would likely take place in the course of a doctoral program, and require examining the 1725 issue, and Volume II of the 1726(28) edition that were originally anticipated for inclusion in this thesis, as well some of the works studied by John Robert Moore, such as the account of John Gow's hanging.

\section{Conclusion}

Making the DCE and writing this thesis has attained the goal of producing a digital critical edition that was informed by a user experience survey, in order to design a final product that is user friendly, intuitive in its use, and critical of the four editions of $A$ General 
History of the Pyrates that it covers, from the first edition in 1724 to the first volume of the fourth edition published in 1726. In the course of producing the DCE much has been learned about what type of methodology should be employed to construct an edition designed to be of use to as wide a range of audience as possible. The DCE presents a text that is useful and informative to scholars and students interested in the production of eighteenth-century literature and the production of critical editions in a digital age, as well as to those interested in print culture and, eighteenth-century literature in general. By accounting for the numerous editions of this book that were printed beginning in 1724 , it informs the construction of historical accounts of pirates at the end of the so called "golden age of piracy," that ended in 1725.

By the end of the eighteenth century, eleven editions of the book had been published. The last of these was in 1788, under the title The History and Lives of All the most Notorious Pirates and their Crews, showing that while it may or may not have been a book that was in demand, it certainly was extensively reproduced (Duncan, 1788). A detailed examination and comparison of the first four editions found in the DCE identifies the variants between the editions scrupulously, documenting not only changes to the content of the texts, but also changes in spelling, capitalization and line-endings, to determine how digital editing can shed new light on print culture in the early eighteenth century. The methods used are informed not only by the responses in the survey, but also by two decades of digital editing that was pioneered by Peter Robinson, Jerome McGann and many others, and which continues on with collaborative projects such as NINES and the Versioning Machine. Ultimately, the bibliographic practices employed in our digital age are indebted to over a century of bibliographic scholarship; from the likes of W.W. 
Greg, Fredson Bowers, Thomas Tanselle and D.C Greetham. Yet, what was once a field that was predominantly exercised by lone scholars laboriously pouring over texts in the lebensraum of rare book libraries has today become a collaborative space that is growing by leaps and bounds, as digital tools are made by members from numerous disciplines. Literary scholars, historians, librarians, and computer programmers all make up this new terrain of digital editing and publishing, along with the broader landscape of the digital humanities.

Bibliographers and scholars such as J.R. Moore contributed greatly to the foundation and canonisation of the works of Daniel Defoe, and lived their lives behind the walls of libraries like the Bodleian and their cozy studies, from which they produced lengthy lists, catalogues and papers that asserted their beliefs about the breadth of Defoe's cannon. While Others like P.N. Furbank and W.R. Owens disputed Moore's claims, such contests and debates pushed the works of Defoe to and fro, and possibly exaggerated his role in eighteenth-century literature. It is possible that Defoe wrote $A$ General History of the Pyrates. But what seems less plausible is that Defoe was the mastermind of over fivehundred works Moore attributed to him. Moore's methods of attribution and his construction of Defoe as a literary genius are based on ideas that had their foundations in an ideology about writing rooted in concepts of highly contested notions of individualism that date back to the nineteenth century. This is not to say Moore's philosophy was wrong or unfounded, but that it came from the era and belief system of his time. But as time pushes forward the idea of the lone scholar, such Moore, whose claims are refuted fifty years later by P.N. Furbank and W.R Owens are gone. 
What digital editing and the digital humanities do to shed light on the production of literature is to accelerate the process and time in which literary criticism and the critique of critical editorial practice are disseminated. It can present a new lens from which scholars can investigate the same questions Moore was asking. In less than two years from the time that I began concrete work on the DCE of A General History of the Pyrates, my edition has already gone out to the world, thanks to the kindness and collaborative nature of the team at the Versioning Machine who decided to link the edition I released for my survey to their software. It will be critiqued, for it is not perfect. In fact, the version they released is not even complete. The edition created for my survey presents six different encoding methodologies in one edition. This is not an ideal example of how one should go about the process of constructing a critical edition. It lacks consistency in its use of the critical apparatus, and it employs TEI's tags from the "Critical Apparatus" in ways that they are not "meant" to be used. For example, the survey edition and the final product will use the $<$ choice $>$ tag not to present readers with the alternate readings, but solely to mark them off as variants. At its root, however, this is what the tag is meant to do, mark a variant, but it is also supposed to provide an alternate reading which it does not, as the decision was made to disable the functionality of the tag and use it only as a visual marker. However, the survey edition was a user-experience test and it was designed to be inconsistent, to ask questions about the presentation of the DCE in its making. However, in the final iteration of the DCE a consistent method of encoding is used. The notes, marked by the superscript letters $g, p, c$ and $n$, explain the variations in spelling, physical format, and critical material added or deleted. But as Peter Robinson said at one of the founding meetings of the TEI consortium: 
I am quite happy to use TEI encoding if it helps me ... if I find a better way, then I will use that better way. . . The great promise of electronic editions, to me [Robinson], is not that we will find new ways of storing vast amounts of information. It is that we will find new ways of presenting this to readers, so that they may be better readers. (50)

Ultimately one of the goals of making the DCE is to do just this; to present the text of the four editions of $A$ General History of the Pyrates in a new way that is nearly impossible in print. Giving users the chance to visualize the changes across all four editions and to interact with them by choosing whether to read the notes, be they in popup or inline display, or to hide the notes completely and simply see the changes through the colour coded variants. This methodology provides a new way of presenting a critical edition in a digital format. Furthermore, one can also view facsimile images of the page and compare them to the transcriptions. If the project is migrated to the VM 5.0 platform, users will be able to compare the facsimiles as well. The ability to present a parallel-text edition of the transcriptions, a facsimile edition, and a critical apparatus, effectively provides three different types of edition in one. Readers/users have a new way of interacting with a critical apparatus that in print format would have most likely been impossible. Documenting small changes, such as changes to line-endings and the format of the text, as well as changes to capitalization, is a tedious job that would be presented in a large number footnotes, in a printed edition. Such an edition would have taken numerous pages to present the same amount of information that can be accessed in the DCE. A print edition would not allow one to compare and highlight the similarities and differences seen in the digital edition. A reader would be flipping back and forth through multiple pages and to complete the tasks 
accomplished on a single screen of the DCE, where one can view the text in the above mentioned ways and open all four editions to compare similarities and variants across these texts. Readers of a print edition would also have to move from reading the text to looking at footnotes in order to have the variants explained, causing them to shift their attention from the texts to the notes. In the digital edition, readers can decide whether, when and how they decide to read such notes. The presentation of and versatile ways of interacting with the DCE of A General History of the Pyrates using the Versioning Machine 4.0 clearly offers readers advantages, and creates a new reading practice not possible in printed critical editions.

In contrast, the one thing that is lacking in the digital model is a singular reading text presented only with footnotes, as is found in traditional printed critical editions. This lack is both an advantage and a disadvantage. Eliminating a singular reading text, be it constructed by selecting a single base text or by creating a new text out of multiple editions, has two drastic effects. First, it does not provide readers a flowing text which they can read through and simply refer to the footnotes for a quick and easy reference guide to the changes made in a work. Second, by eliminating the singular text, and producing four parallel-readings, readers must engage with the work on more active level, to discover the variants, which may not be desirable to all. This singular reading text with a critical apparatus is something that I foresee being able to construct if I were to continue to work on this project. It would be possible in the previously described scenario of creating a database, and would also be possible to make as an additional open-source web-based edition. I have seen editions that create this singular text using JavaScript and a Flash player to make the variants change as one scrolls of them. This would prove an effective way of 
presenting a singular reading text with notes (be they footnotes, popup notes or inline notes), but would utilize a MySQL database, PHP or Python, along with JavaScript code that powered a Flash player and would change a word when one placed the pointer over various parts of the text.

There are numerous ways one can present a digital critical edition, but it is essential that it point out the variants and provide a critical apparatus with substantive notes. The current digital critical edition does all of the above, and in doing so provides readers with a new way to look at eighteenth-century print culture. It also begs the question, who decided to make such small changes to capitalization, or line-ending, and why such changes were made in formatting. Eighteenth-century print culture is one that changed rapidly, and standardized capitalization was not present. The spelling of words was also changing, as were printing technologies from the use of copper plates to the use of steel ones, to the types of ornaments printers used for headpieces and ornamented letters. Digital scholarly editing aids scholars interested in both the large and the small details that changed in the course of eighteenth century printing, using XML to encode different variants, and the $V M$ 4.0 to display them, forces editors to take note and record these changes in ways that makes them become clearer to the readers/users of such editions and tools. 
Reiche 117

\section{Appendix A}

A General History of the pyrates - Title।

A GENERAL

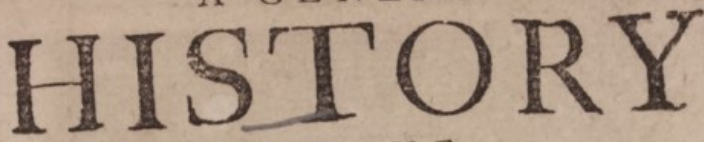
O F T H E Robberies and Murders

Of the moft nutorious

$\mathrm{X}$ only in 1725 issue

deleted everywhere excepted in unumber issue from 1725

\section{A N D A L S O}

TheirPolicies, Difcipline and Government, From their firft RISE and SeTrLEMENT in the Ifland of Providence, in 1717 , to the preleut Year 1724 .

$$
\text { W I } \mathrm{T} H
$$

The remarkable ACTIONS and ADVENTUREs of the two Female Pyrates, Mary Read and Anne. Bonny.

$$
\text { To which is prefix'd }
$$

An ACCOUNT of the famous Captain Avery and his Companions; with the Manner of his Death in England.

The Whole digefted into the following CHA P T ERS;

C VIII. Of Captain England.

II. The Rife of Pyrates.

II. The Rile $\quad$ X. Of Captain Roberts.

II. Of Captain Martel. J X. Of Captain Roberts.

IV. Of Captain Bonnet. 3 XII. Of Captain Lotutber.

V. Of Captain Tbatch. XIII. Of Captain Leqv.

VI. Of Captain Vane.

VII. Of Captain Rackam.

$$
\text { And their feveral Cre }
$$

A Thort ABSTRACT of the Statute and Civil Law, in Relation to $\mathrm{Px} a \Delta C \mathrm{x}$.

By Captain Ch A R LES JOH NSON.

LONDON, Printed for $C b$, Rivington at the Brown in St IOND Paul's Churcb-Tard, $\%$. Lacy at the Ship near the Temple-Gate, and
\%. Stone next the Crown Coffee-houfe the back of Greys-Inn, I724.
Annotations

Additions in 2nd ed(1724), 3rd ed (1725) \& 4th ed -vol.1 (1726)

Title changes

word change

All caps

word change2

added 1

abbreviated

added Capt. 1

Capt. Roberts moves

added Capt. 2

added Capt. 3

added Capt. 4

Title changes in unnumbered edition (issue from 1725)

Title changes

Title in 4th ed vol.1 (1726)

Title changes

Deletions

orignal/Delete1

\section{only in 1725 issue}

orignal/delete2

date1

date2

line change

case change

orignal/delete3

orignal/delete4wchange

orignal/delted5

Capt. orignal/moved

abbreviated

Printer for 1

Printer 1

Location of Printer 1

Printed for 2

Printer 2

Location of Printer 2

Printed for 3

Location of Printer 3 
Appendix B

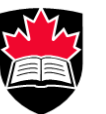

\section{Carleton}

U N I V E R I T Y

Digitizing the Pyrates: A user experience survey about a digital editing platform that allows for different methods of encoding and interacting with a digital critical edition and compares four digitized editions of Captain Charles Johnson's $\boldsymbol{A}$ General History of the Pyrates, 1724-1726, edited by Ingrid Reiche

\section{General Instructions:}

This is a user experience/user analysis survey about interacting with a digital critical edition of $A$ General History of the Pyrates, (1724-1726) by Captain Charles Johnson, which I am editing. The digital edition compares the $1^{\text {st }}, 2^{\text {nd }}, 3^{\text {rd }}$ and $4^{\text {th }}$ editions (Vol. I) of this book. Each edition is referred to as a witness in Versioning Machine V.4, which is the software used to produce this digital edition. The survey will ask a number of questions regarding your experience with the interface (i.e. the Versioning Machine V.4). If you do not want to answer any of the questions or explain your answers after responding "Yes" or "No", that is fine. Any and all input is appreciated.

\section{Please visit http://ingridreiche.com/Resume/Thesis.html}

Feel free to read, or not to read, the information above "The Contents" heading on the webpage displayed. This survey does not pertain to this preliminary material, though it may be of interest.

Section 1: Scroll down to "The Contents" heading and click on the "Title Page" link.

1.1

Upon opening this link three panes that appear: "Bibliographic Information", on the left hand side, and two "Witnesses" (which in this survey refer to different editions of the book). Please read the "Bibliographic Information" pane and briefly examine the two witnesses. Do you understand the information in each of these panes?

\begin{tabular}{|l|l|l|}
\hline Yes & & \multirow{2}{*}{ Please explain your response? } \\
\cline { 1 - 2 } No & & \\
\cline { 1 - 2 } & &
\end{tabular}

What is your first impression?

Response:

What could be improved to make it more appealing?

Response: 
1.2 There are 3 buttons on the menu, located at the top of the page:

\begin{tabular}{|l||l|l|}
\hline New Version & Bibliographic Info & Critical Introduction \\
\hline $\begin{array}{l}\text { Click on } \\
\text { containing the bibliographic information disappear. Click on the }\end{array}$ \\
$\begin{array}{l}\text { icon aibliographic Info } \\
\text { icon again to make the pane reappear. Do you think this information should be } \\
\text { displayed when the page first loads? }\end{array}$ \\
\hline Yes & Please explain your response: \\
\hline No & \\
\hline
\end{tabular}

1.3 Please click on the Bibliographic Info icon again to make this pane disappear. Before beginning these questions, please skim the $1^{\text {st }}$ and $2^{\text {nd }}$ editions of the title page and note the differences.

\begin{tabular}{|c|c|c|}
\hline A. & New Version & Click once. What is the outcome and is it obvious? \\
\hline \multicolumn{3}{|c|}{ Response: } \\
\hline B. & New Version & $\begin{array}{l}\text { Click one more time. What is the outcome and is it } \\
\text { obvious? }\end{array}$ \\
\hline \multicolumn{3}{|c|}{ Response: } \\
\hline \multicolumn{3}{|c|}{$\begin{array}{l}\text { C. Click on } \bar{X} \text { in the right hand corner of the last witness pane. What is the } \\
\text { outcome and is it obvious? }\end{array}$} \\
\hline & & \\
\hline
\end{tabular}

\section{4}

A. At the top of each witness is a menu pane that looks like Witness 1: 1st ed.: 1724, "GHP" - click on the downward facing arrow in the white section. Is it clear what the options here mean?

Yes, no Response:

B. Try picking another option from this drop down menu. What happens? Is It clear?

Response:

1.5

Click on the Critical Introduction icon from the menu and please read it. Do you think this information should be displayed when the page first loads?

\begin{tabular}{|l|l|l|}
\hline Yes & & Please explain your response: \\
\cline { 1 - 1 } & &
\end{tabular}


1.6 Close the "Critical Introduction" by clicking on $\mid$ Critical Introduction $\mid$ OR the $\bar{X}$ in the top right hand corner of the "Critical Introduction" pane. Now please click "New Version" once, so that all four witnesses are open. Please arrange them in chronological order (i.e. 1: $1^{\text {st }}$ ed.: 1724. “GHP"; 2: $2^{\text {nd }}$ ed.: 1724. “GHP"; 3: $3^{\text {rd }}$ ed.: 1725 "GHP"; 4: $4^{\text {th }}$ ed. (Vol. I): 1726, “). You can use the Witness 1: 1st ed.: 1724, "GHP" - icon to change the order, so they appear in the order displayed below.

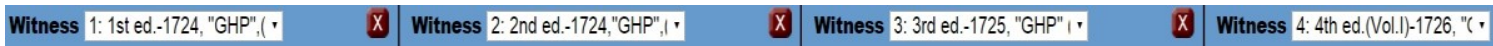

Click on the white box beside ${ }^{\text {Line Numbers: } O}$ (circled in red here), on the top menu, located after "Critical Introduction". Do you think the line numbers should be displayed when the page first loads?

\begin{tabular}{|l|l|l|}
\hline Yes & & Please explain your response: \\
\cline { 1 - 2 } No & & \\
\hline
\end{tabular}

1.6B

Does the line numbering in the different witnesses make sense?

\begin{tabular}{|l|l|l|}
\hline Yes & & Please explain your response: \\
\cline { 1 - 1 } & &
\end{tabular}

Leave the line numbers activated. If you have unclicked the box beside line numbers please click on it again so they appear.

\section{7}

In the $1^{\text {st }}$ edition click on the text where the names of "Captain Avery" and "Captain England" appear in line 18. This will highlight parts of the text in yellow throughout all the editions. Does the highlighting provide you with a clear understanding of what changes in the formatting of the title page were made in each of the editions?

\begin{tabular}{|l|l|l|}
\hline Yes & & Please explain your response: \\
\hline No & & \\
\hline
\end{tabular}

\subsection{B}

In the $1^{\text {st }}$ edition click on each name after the word "Captain" in lines 18-24. As you do this please compare the position of the names in each of the four editions. Does the highlighting provide you with a clear understanding of what changes in the formatting of the title pages were made in each of the editions?

\begin{tabular}{|l|l|l|}
\hline Yes & & Please explain your response: \\
\hline No & & \\
\hline
\end{tabular}


1.7C

Notes about the changes across the versions are denoted by the superscript letters $\mathrm{g}, \mathrm{n}$ or $\mathrm{p}\left(\mathrm{g}, \mathrm{n}\right.$ or $\left.{ }^{\mathrm{p}}\right)$. In the $2^{\text {nd }}$ edition scroll over the notes in lines 17-24.1, a popup will appear. Does the popup displayed provide a clear explanation of the change? \begin{tabular}{l|l|l} 
Yes & Please explain your response:
\end{tabular}

Please click on these names again to undo the highlighting

1.8

Click on the Popup notes $\mathbf{v}$ icon. Select "Inline notes". Do you prefer Inline notes or Popup notes?

\begin{tabular}{l|l|l} 
Yes & & Please explain your response:
\end{tabular}

1.8B

Click on the notes icon again. Select "Hide notes". Is the text more appealing without the superscript notes?

\begin{tabular}{l|l|l} 
Yes & Please explain your response:
\end{tabular}

1.9

In the $2^{\text {nd }}$ edition click on the first 8 places where you see underlined text (lines 117). This will highlight a portion of the text. Compare these sections. Does the highlighting provide a clear visualisation about the changes that are highlighted across the editions?

\begin{tabular}{l|l|l|} 
Yes & & Please explain your response: \\
\cline { 1 - 2 } & &
\end{tabular}

\subsection{B}

In the $2^{\text {nd }}$ edition scroll over an underlined portion of the text that you have highlighted. A popup will appear. Does the information in the popup provide a clear explanation about the change that is underlined?

\begin{tabular}{|l|l|l|} 
Yes & & Please explain your response:
\end{tabular}

1.10

Click on the thumbnail at the top right of the $1^{\text {st }}$ edition. It looks like this Now click on each thumbnail in all four editions. Do you think the thumbnails should be an image of the page itself (i.e. a mini preview of each page)? Currently it is a preview of the $2^{\text {nd }}$ edition's title page

Yes $\quad$ Please explain your response:


1.10B

Would it be helpful to see two images of the title page at once?

\begin{tabular}{|l|l|l|}
\hline Yes & & Please explain your response:
\end{tabular}

No

1.11

Do you have any additional comments/suggestions or questions?

Comments/ Suggestions/ Questions:

You Have Completed Section One - Thank You!

Section 2

Please go back to the website http://ingridreiche.com/Resume/Thesis.html and click on "The Preface" under The Contents.

The first six pages of "The Preface" are encoded in different ways. These sections ask for your feedback about the appearance of each of these pages.

2.1 General Questions

When "The Preface" opens, the "Bibliographic Information" pane is not visible. Please click on "Bibliographic Info". Do you think that the "Bibliographic Information" should or should not be presented when the page first opens?

\begin{tabular}{l|l|l} 
It Should be & & Please explain your response:
\end{tabular}

presented

It Should

NOT be

presented

Please click on "Bibliographic Info" again to close the pane.

\section{2}

When "The Preface" opens, the "Critical Introduction" pane is not visible. Please click on "Critical Introduction". Do you think that the "Critical Introduction" should or should not be presented when the page first opens?

\begin{tabular}{l|l|l} 
It Should be & & Please explain your response:
\end{tabular}

presented

It Should

NOT be

presented 
Please click on "Critical Introduction" again to close the pane.

\section{3}

When "The Preface" opens, three editions/witnesses are seen. They are the $1^{\text {st }}, 2^{\text {nd }}$ $\& 4^{\text {th }}$ (Vol. I.) editions. These were chosen based on the fact that they present the greatest amount of variation. Do you think this is a good choice?

\begin{tabular}{|l|l|l|}
\hline Yes, leave it & & Please explain your response: \\
\hline $\begin{array}{l}\text { No, change } \\
\text { it }\end{array}$ & & \\
\hline Indifferent & & \\
\hline
\end{tabular}

\subsection{B}

Do you think the first three witnesses/editions that appear should be in the order they were produced (i.e. showing the $1^{\text {st }}, 2^{\text {nd }} \& 3^{\text {rd }}$ editions)?

\begin{tabular}{|l|l|l|}
\hline Yes & & Please explain your response: \\
\hline No & &
\end{tabular}

\section{4}

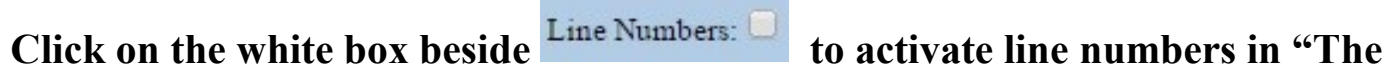
Preface". Only lines with changes have been numbered. Do you think all lines should be numbered?

\begin{tabular}{|l|l|l|}
\hline Yes & & Please explain your response: \\
\cline { 1 - 2 } No & &
\end{tabular}

\section{5}

The pages of "The Preface" in the printed editions are NOT numbered. Would numbering the pages be useful in this digital edition?

\begin{tabular}{|l|l|l|}
\hline Yes & & Please explain your response: \\
\hline No & & \\
\hline
\end{tabular}

3. Questions about page 1 of "The Preface". The first page is encoded in a similar way as the "Title Page". All parts can be highlighted and notes and underlining are present.

3.1

In any edition click on the first line of each paragraph until the majority of the text is highlighted. These are sections of the text that are the same. Does the highlighting provide you with a clear understanding of what sections are the same in each of the editions?

\begin{tabular}{|l|l|l|}
\hline Yes & & Please explain: \\
\hline No & & \\
\hline
\end{tabular}

Please click on the same sections of the text to undo the highlighting. 


\section{2}

In any edition click on all the underlined sections of the text in the $1^{\text {st }}$ paragraph, which will make sections of the text highlight. These are sections of the text where changes throughout the editions occur. Does the highlighting provide you with a clear understanding of what changes were made in each of the editions?

\begin{tabular}{|l|l|l|}
\hline Yes & & Explain: \\
\hline No & & \\
\hline
\end{tabular}

\subsection{B}

In any edition scroll over the underlined text. A popup will appear. Does the popup provide clear information about the change that is underlined? Repeat this as many times as you like.

\begin{tabular}{|l|l|l|}
\hline Yes & & Explain: \\
\cline { 1 - 1 } No & &
\end{tabular}

\subsection{C}

Does the underlining help identify the places where changes occur?

\begin{tabular}{|l|l|l|}
\hline Yes & & Explain: \\
\cline { 1 - 1 } No & & \\
\hline
\end{tabular}

\section{3}

Scroll over the superscript letters $\mathrm{g}, \mathrm{n}$ or $\mathbf{p}$ in the sections you have highlighted. A popup will appear. These are notes added to explain the changes in the text. Does the popup that appears provide a clear explanation of the change?

\begin{tabular}{|l|l|l|}
\hline Yes & & Please explain if the answer is "No": \\
\hline No & & \\
\hline
\end{tabular}

\section{4}

Click on the Popup Notes ( Popup notes v ) icon and select "Inline notes". Notice that the line numbers that appear are associated with the lines where a change occurs in the edition. Does having line numbers help you navigate the Inline notes?

\begin{tabular}{|l|l|l|}
\hline Yes & & Please explain your response: \\
\hline No & & \\
\hline
\end{tabular}

\section{5}

Do you prefer Inline notes or Popup notes?

\begin{tabular}{|l|l|l} 
Yes & & Please explain your response: \\
\cline { 1 - 2 } & &
\end{tabular}




\section{6}

Do you find that the notes and underlining are redundant and contain the same information?

\begin{tabular}{|l|l|l|}
\hline Yes & & Please explain your response: \\
\hline No & & \\
\hline $\begin{array}{l}\text { Indiffere } \\
\text { nt }\end{array}$ & & \\
\hline
\end{tabular}

In the notes menu at the top select "Popup notes" from the drop down menu.

4. Questions about page 2 of "The Preface". Please scroll down to the next page marked by the solid line, so that you are viewing the second page of "The Preface". On this page only underlining is present in the $2^{\text {nd }}$ edition onwards, notes are NOT.

\section{1}

In the $2^{\text {nd }}$ edition click on all the underlined sections of the text, which will make these sections of the text highlight. These are sections of the text where changes throughout the editions occur. Does the highlighting provide you with a clear understanding of what changes were made in each of the editions?

\begin{tabular}{|l|l|l|}
\hline Yes & & Explain: \\
\hline No & & \\
\hline
\end{tabular}

\section{2}

In the $2^{\text {nd }}$ edition scroll over the underlined text. A popup will appear. Does the popup provide a clear explanation about the change that is underlined and how it relates to other editions? Repeat this as many times as you like.

\begin{tabular}{|l|l|l|}
\hline Yes & & Please explain your response:
\end{tabular}

\section{3}

Does the fact that notes are NOT present appeal to you?

\begin{tabular}{|l|l|l|}
\hline Yes & & Please explain your response: \\
\cline { 1 - 1 } No & &
\end{tabular}

\section{4}

Is the underlining sufficient as an explanatory device, as opposed to notes?

\begin{tabular}{|l|l|l|}
\hline Yes & & Please explain your response: \\
\cline { 1 - 1 } & &
\end{tabular}

No

4.5

There is no underlining in the $\mathbf{1}^{\text {st }}$ edition. Does this appeal to you?

\begin{tabular}{|l|l|l|}
\hline Yes & & Please explain your response: \\
\cline { 1 - 1 } No & &
\end{tabular}


4.6

Does the underlining help identify the location of the changes?

\begin{tabular}{|l|l|l|}
\hline Yes & & Please explain your response:
\end{tabular}

5. Questions about page 3 of "The Preface". On this page only notes are present, underlining is NOT.

5.1

In the $1^{\text {st }}$ paragraph of the 2 nd edition click on the words next to the notes marked by the superscript letters $g$, $n$ or $p$. This will make the sections where changes occur highlight. Does the highlighting provide you with a clear understanding of what changes were made in each of the editions?

\begin{tabular}{|l|l|l|}
\hline Yes & & Please explain your response: \\
\cline { 1 - 2 } No & &
\end{tabular}

\subsection{B}

Scroll over the notes marked by the superscript letters $g, n$ or $p$ you see in the $1^{\text {st }}$ paragraph of the $2^{\text {nd }}$ edition. This will make a popup appear. Does the popup provide you with a clear explanation of the change in that line, which you might would not have not noticed when only the highlighting was present?

\begin{tabular}{|l|l|l|}
\hline Yes & & Please explain your response: \\
\cline { 1 - 1 } No & &
\end{tabular}

\section{2}

Are the notes sufficient as an explanatory device, as opposed to underlining?

\begin{tabular}{|l|l|l|}
\hline Yes & & Please explain your response: \\
\hline No & & \\
\hline
\end{tabular}

\section{3}

Does the lack of underlining make it difficult to find changes throughout the editions?

\begin{tabular}{|l|l|l|}
\hline Yes & & Please explain your response: \\
\cline { 1 - 2 } No & &
\end{tabular}

\section{4}

Thus far which page of "The Preface" do you find most appealing and informative?

\begin{tabular}{|l|l|l|}
\hline Pg.1 & & Please explain your response: \\
\cline { 1 - 1 } Pg.2 & &
\end{tabular}

Pg.2

Pg.3 
6. Questions about page 4 of "The Preface" - This page only allows the user to highlight the sections where changes occur and it uses underlining but does NOT contain notes.

6.1

In the $2^{\text {nd }}$ paragraph of any edition please click on all the parts of the text that are underlined. This will highlight these sections. Is highlighting only those sections with changes more appealing than being able to highlight all parts of the text, as one could do on page 1 ?

\begin{tabular}{|l|l|l|}
\hline Yes & & Please explain your response: \\
\cline { 1 - 1 } No & &
\end{tabular}

\section{2}

Scroll over the underlined text in the $2^{\text {nd }}$ paragraph. A popup will appear. Does the popup provide a clear explanation about the change that is underlined? Repeat this as many times as you like.

\begin{tabular}{|l|l|l|}
\hline Yes & & Please explain your response: \\
\hline No & & \\
\hline
\end{tabular}

\section{3}

Does the underlining help identify the location of the changes?

\begin{tabular}{|l|l|l|}
\hline Yes & & Please explain your response: \\
\cline { 1 - 1 } No & & \\
\hline
\end{tabular}

\section{4}

Does the fact that notes are NOT present appeal to you?

\begin{tabular}{|l|l|l|}
\hline Yes & & Please explain your response: \\
\cline { 1 - 1 } No & & \\
\hline
\end{tabular}

6.5

\begin{tabular}{|c|c|}
\hline \multicolumn{2}{|c|}{$\begin{array}{l}\text { Thus far which page of "The Preface" do you find most appealing and } \\
\text { informative? }\end{array}$} \\
\hline Pg.1 & \multirow[t]{4}{*}{ Please explain your response: } \\
\hline Pg.2 & \\
\hline Pg.3 & \\
\hline Pg.4 & \\
\hline
\end{tabular}


7. Questions about page 5 of "The Preface" - This page only highlights the sections where changes occur and it uses notes, but does NOT have underlining.

7.1

In the $3^{\text {rd }}$ paragraph of any edition, please click on all the words that have a superscript $g$, $n$ or $p$ beside them (most occur at the end of a line), which will highlight these sections. Now try clicking anywhere else in the paragraph. Is highlighting only those sections with changes more appealing than being able to highlight all sections of the text, as is possible on page 1 of "The Preface"?

\begin{tabular}{|l|l|l|}
\hline Yes & & Please explain your response:
\end{tabular}

7.2

Scroll over the superscript $g, n$ or $p$ in the $3^{\text {rd }}$ paragraph (most of them are a "p"). A popup will appear. Does the popup provide clear information about the change that occurs? Repeat this as many times as you like.

\begin{tabular}{|l|l|l|}
\hline Yes & & Please explain your response: \\
\hline No & & \\
\hline
\end{tabular}

7.3

Do you prefer notes, underlining, or both as a way to provide information about changes?

\begin{tabular}{|l|l|l|}
\hline Notes & & Please explain your response: \\
\cline { 1 - 1 } $\begin{array}{l}\text { Underli } \\
\text { ne }\end{array}$ & & \\
\cline { 1 - 1 } Both & & \\
\hline
\end{tabular}

7.4

Thus far which page do you find most appealing and informative?

\begin{tabular}{|l|l|l|}
\hline Pg.1 & & Please explain your response:
\end{tabular}

Pg.2

Pg.3

Pg.4

Pg.5

8. Questions about pages 6, 7 \& 8 of "The Preface". These pages highlight each paragraph in places where there are changes and where there are not (the text mostly remains the same, though some of the lines move down to the next page in certain editions). There are no notes or underlining.

8.1

In the $2^{\text {nd }}$ edition please click on each paragraph in pages $6,7 \& 8$ so that they highlight. Is the highlighting alone sufficient to locate the changes?

\begin{tabular}{|l|l|l}
\hline Yes & & Please explain your response:
\end{tabular}

No 


\section{2}

\begin{tabular}{|l|l|l|}
\hline \multicolumn{2}{|l|}{ Do you think this section would benefit from having notes? } \\
\hline Yes & Please explain your response: \\
\hline No & & \\
\hline
\end{tabular}

8.3

\begin{tabular}{|l} 
Do you think this section would benefit from having underlining? \\
\hline Yes
\end{tabular}

\begin{tabular}{|l|l|l|}
\hline Yes & & Please explain your response: \\
\hline No & & \\
\hline
\end{tabular}

8.4

Thus far which page do you find most appealing and informative?

\begin{tabular}{|l|l|l|}
\hline Pg.1 & & Please explain your response: \\
\hline Pg.2 & \\
\hline Pg.3 & \\
\hline Pg.4 & \\
\hline Pg.5 & \\
\hline Pg.6- & \\
\hline 8 & \\
\hline
\end{tabular}

\section{5}

Do you like being able to highlight all parts of the text, or only those parts that are similar, or only those parts that are different?

\begin{tabular}{|l|l|l}
\hline All & & Please explain your response:
\end{tabular}

Only the parts that are similar

Only the parts that are

different

Indifferent

THANK YOU FOR PATICIPATING - YOUR FEEDBACK IS APPRECIATED!

PLEASE SAVE THIS DOCUMENT WITH YOUR ANSWERS, THEN RETURN

IT TO THE RESEARCHER (Ingrid Reiche) BY EMAILING IT TO

ingrid.reiche@carleton.ca 


\section{Bibliography}

ABBYY FineReader 12 Professional Edition. Computer software. ABBYY. Vers. 12. ABBYY Software Ltd., 2013. Web. 12 Apr. 2015.

"About the Shakespeare Quartos Archive." The Shakespeare Quartos Archive. National Endowment for the Humanities and Joint Information Systems Committee, 2009. Web. 22 Nov. 2015.

Apollon, Daniel, Claire Belisle and Philippe Régnier, eds. Digital Critical Editions. Urbana, IL: University of Illinois Press, 2014. Google Books. 2014. Web. 19 Oct. 2015.

Apollon, Daniel and Claire Bélisle. "The Digital Fate of the Critical Apparatus.” Apollon, Belisle and Régnier 81-113.

Apollon, Daniel, Claire Belisle and Philippe Régnier. Preface. Appollon, Belisle and Régnier vii-viii.

Ayres, Philip. Classical Culture and the Idea of Rome in Eighteenth-Century England. Cambridge, UK: Cambridge University Press, 1997.

Bialuschewski, Arne. "Daniel Defoe, Nathaniel Mist, and the General History of the Pyrates." Papers of the Bibliographical Society of America 98 (2004): 21-38.

Blake, Norman, Dan Mosser, Stephen Partridge, Peter Robinson, Elizabeth Solopova "Chaucer: The Wife of Bath's Prologue on CD-ROM." Cambridge: Cambridge University Press, 2015. Web. 18 Nov. 2015. < http://www.cambridge.org/uk/catalo gue/catalogue.asp?isbn $=0521465931>$.

Blake, William. "Plan of the Archive" The William Blake Archive. Ed. Morris Eaves, Robert N. Essick, and Joseph Viscomi. 2012. Web 19 Nov. 2015. 
Bowers, Fredson. "Current Theories of Copy-Text." Essay in Bibliography, Text and Editing. Charlottesville, VA: University Press of Virginia, 1975. 277-288.

---. Principles of Bibliographic Description. New York, NY: Russell and Russell, 1962.

Burns, Robert. "Halloween.” The Works of Robert Burns. London: Henry G Bohn, 1844. 208-212. Google Books. Web 23 Nov. 2008.

Carter, Daniel. “The Versioning Machine for Audio: Introducing VM 5.0.” Research. The Modernist Versions Project. Victoria, BC: University of Victoria. 20 June 2014. Web. 16 Jan. 2015.

Classical Culture and the Idea of Rome in Eighteenth-Century England. Epigraph. Cambridge: Cambridge University Press, 1997.

Clement, Tanya. ed. In Transition: Selected Poems by the Baroness Elsa con FreytagLoringhoven. Digital Programs and Initiatives. University Libraries. University of Maryland. College Park, MD: Tanya Clement. Web. 8 Feb. 2016.

Cordingly, David. Under the Black Flag. 1996. New York, NY: Random House, 2006.

Coulter, Moureen. Property in Ideas: The Patent Question in Mid-Victorian Britain. Kirksville, MO: The Thomas Jefferson University Press, 1991.

“Critical Editions”. Yale College Writing Center. Yale University, 2015. Web. 1 March 2015. <http://writing.yalecollege.yale.edu/advice-students/using-sources/citingmiscellaneous-sources/critical-editions>.

David, Deirdre. "Making a Living as an Author." A Companion to the English Novel. Eds. Stephen Arata et al., Malden, MA: Wiley-Blackwell, 2015. 291-305.

Digital Thoreau. Walden: Fluid Text. Geneseo, NY: State University of New York at Geneseo. Web. 14 Oct. 2015. 
Duff, William. An Essay on Original Genius. London: Printed for Edward and Charles Dilly in the Poultry near the Mansion-House, 1767. New York, NY: Garland Facsimile Edition, 1970.

Flanders, Julia. "Data and Wisdom: Electronic Editing and the Quatification of Knowledge." Literary Linguistic Computing 24.1 (2009): 53-62. Oxford Journal Online. Web. 13 Mar. 2015.

Furbank, P. N. and W. R. Owens. The Canonisation of Daniel Defoe. New Haven, CT: Yale University Press, 1988.

---. A Critical Bibliography of Daniel Defoe. London: Pickering and Chatto, 1998.

Greetham, D.C. Foreword. A Critique of Modern Textual Criticism. By Jerome McGann. 1983. Charlottesville, VA: University Press of Virginia, 1992. ix-xix. Google Books. Web. 4 May 2016.

Greg, W. W. (Walter Wilson). Collected Papers by W. W. Greg; Edited by J. C. Maxwell. London: Oxford University Press, 1966.

Gosse, Philip. "The Pirates of North America." The History of Piracy. New York, NY: Tudor Publishing Company. 1934. 12 August 2013. Digitized by Google. E-book. 2 Feb. 2015. 175-213.

Griffin, Dustin. Authorship in the Long Eighteenth-Century. Newark, DE: University of Delaware Press, 2014.

--- . "Fictions of Eighteenth Century Authorship." Essays in Criticism 43.3 (1993): 181194. Scholars Portal Journals. 13 Jan. 2005. Web. 19 Sept. 2015.

Haugen, Odd Einar and Daniel Apollon. "The Digital Turn in Textual Scholarship." Apollon, Belisle and Régnier 35-57. 
Hayles, Katherine. "Print is Flat, Code is Deep: The Importance of Media Specific Analysis.” Poetics Today 25.1 (2004): 66-90. Project Muse. Web. 17 Nov. 2015.

Hillesund, Treje and Clair Bélisle. "What Digital Remediation Does to Critical Editions and Reading.” Apollon, Belisle and Régnier 114-154.

The History and Lives of All the most Notorious Pirates and their Crews. 11 ed. Glasgow: Printed by Robert Duncan, 1788. Eighteenth Century Collections Online. 6 Jan. 2004. Web. 12 Feb. 2016.

The History and Lives of All the Most Notorious Pirates, and Their Crews, From Capt. Avery, who First Settled at Madagascar, to Capt. John Gow, and James Williams, his Lieutenant, \&c. London: Printed for Edward Midwinter, at the Looking-Glass on London-Bridge, 1725. Eighteenth Century Collections Online. Web. 15 Oct. 2014.

"Introduction to the Archive." The Shakespeare Quartos Archive, National Endowment for the Humanities and Joint Information Systems Committee, 2009. Web. 1 March 2015 .

Johnson, Charles, Capt. A General History of the Lives and Adventures of the Most Notorious Highwaymen, Murderers, Street-Robbers, \&c. $2^{\text {nd }}$ ed. London: Printed for H. Slater, at the Golden Key, the Corner of Clare Court, Drury Lane; F. Noble, at Otway's Head, St. Martin's Court, near Leicester Fields ; and T. Wright, at the Bible, in Exeter Exchange, in the Strand. 1742.

---. A General History of the Pyrates, From Their First Rise and Settlement in the Island of Providence, to the Present Time. 2nd ed. Printed for, and Sold by T. Warner, at the Black-Boy in Pater-Noster Row, 1724. Internet Archive. Web. 15 Oct. 2014. 
---. A General History of the Pyrates, From Their First Rise and Settlement in the Island of Providence, to the Present Time. 2nd ed. Printed for, and Sold by T. Warner, at the Black-Boy in Pater-Noster Row, 1724. Produced by Jens Sadowski. Project Gutenberg. 25 Aug. 2012. Web. 3 Feb. 2015.

---. A General History of the Pyrates, From Their First Rise and Settlement in the Island of Providence, to the Present Time. 3rd ed. London: Printed and Sold by T. Warner at the Black-Boy in Noster-Row, 1725. Eighteenth Century Collections Online. Web. 15 Oct. 2014.

---. A General History of the Pyrates, From Their First Rise and Settlement in the Island of Providence, to the Present Time. 4th ed. Printed for, and Sold by T. Woodward, at the Half-Moon, over against St. Dunstan's Church, Fleet-Street. 2 vols. 1726.

---. A General History of the Robberies and Murders of the Most Notorious Pyrates, From Their First Rise and Settlement in the Island of Providence, in 1717 to the Present Year 1724. Printed for, Ch. Rivington at the Bible and Crown in St. Paul's ChurchYard, J. Lacy at the Ship near Temple-Gate and J. Stone at the Crown Coffee-house the back of Greys-Inn, 1724.

Kelley, James William. “Johnson, Charles (1679?-1748).” Oxford Dictionary of National Biography, edited by H. C. G. Matthew and Brian Harrison. Oxford: OUP, 2004. Online ed., edited by Lawrence Goldman. Jan. 2008. Web. 2 February 2015.

Kyrnin, Mark. "Death of the Computer Optical Drive: Why Most Future PCs Will Not Feature CD, DVD or Blu-ray Drives." About Tech. About.com, 16 Aug. 2015. Web. 22 Nov. 2015. 
Marshall, Ashley. "Fabricating Defoes: From Anonymous Hack to Master of Fictions" Eighteenth-Century Life 36.2 (2012): 1-35. Project Muse. Web. 17 Sept. 2015.

Maxwell, J.C. ed. The Prelude: A Parallel Text. By William Wordsworth. 1805-1850. Baltimore, MD: Penguin Books Ltd., 1971.

McGann, Jerome. A Critique of Modern Textual Criticism. 1983. Charlottesville, VA: University Press of Virginia, 1992. Google Books. Web. 4 May 2016.

---. Radiant Textuality: Literature after the World Wide Web. 2001. New York, NY: Palgrave Macmillan, 2004.

---. “Radiant Textuality.” Victorian Studies 39.9 (1996): 379-390. ProQuest. Web 8 Nov. 2015.

---. The Textual Condition. Princeton, NJ: Princeton University Press, 1991.

McKenzie, D. F. Bibliography and the Sociology of Texts. Cambridge, UK: Cambridge University Press. 1999.

McKerrow, Ronald B. An Introduction to Bibliography for Literary Students. London: Oxford University Press, 1928.

---. The Works of Thomas Nashe Edited from the Original Texts. Vol. 1. Forgotten Books, 2013. Web. 1 March 2015. Originally published London: The British Library, 1904. Moore, John Robert. Defoe in the Pillory and Other Studies. Bloomington, IN: Indiana University, 1932.

O’Donnell, Daniel Paul. "Back to the Future: What Digital Editors can Learn from Print Editorial Practice.” Literary Linguistic Computing 24.1 (2009): 113-125. Oxford Journals Online. Web. 7 Nov 2014. 
oXygen XML Editor. Computer software. Vers. 17.1. Syncro Soft SRL, 2015. Web. 23 Mar. 2015.

Pfannenschmidt, Sarah and Tanya Clement. "Evaluating Digital Scholarship: Suggestions and Strategies for the Text Encoding Intiative." Journal of the Text Encoding Initiative 7 (2014): n. pag. Web. 15 Nov. 2014.

Pierazzo, Elena. Digital Scholarly Editing: Theories Methods and Models. Hyper Articles en Ligne (HAL). 2014. Web. 17 Nov. 2015.

Régnier, Philippe. “Ongoing Challenges for Digital Critical Editions.” Apollon, Belisle and Régnier 58-80.

Reiche, Ingrid. Digitizing the Pyrates: A user experience survey about a digital editing platform that allows for different methods of encoding and interacting with a digital critical edition and compares four digitized editions of Captain Charles Johnson's A General History of the Pyrates, 1724-1726, edited by Ingrid Reiche. Ottawa: Research Ethics Board, Carleton University. 2015.

Robinson, Peter. "What text really is not, and why editors have to learn to swim." Literary and Linguistic Computing 24.1 (2009): 41-52. Oxford Journals Online. Web. 25 Mar. 2015.

Robinson, Peter, ed. The Wife of Bath's Prologue. By Geoffrey Chaucer. Cambridge, UK: Cambridge University Press, 1996. CD-ROM.

Robinson, Peter and Elizabeth Solopova. "The Wife of Bath's Prologue on CD-ROM: A Demonstration." Centre for Textual Studies. Web. 9 Nov. 2015. < http://chaucer.d mu.ac.uk/robinson+solopova/index.html>. 
Rogers, Pat. "Alexander Smith.” Oxford Dictionary of National Biography. Ed. H. C. G. Matthew and Brian Harrison. Oxford: OUP, 2004. Online ed. Ed. Lawrence Goldman. Web. 2 Feb. 2015.

Sahle, Patrick, Georg Vogeler, and IDE. "Preliminary Remarks." Criteria for Reviewing Scholarly Digital Editions, Version 1.1. Trans. Misha Broughton et. al., Institut Für Dokumentologie Und Editorik, Jan. 2014. Web. 14 Mar. 2016.

Schreibman, Susan. "Digital Scholarly Editing." Literary Studies in the Digital Age: An Evolving Anthology. Ed. Kenneth M. Price and Ray Siemens. New York, NY: Modern Language Association of America, 2013. 54 paragraphs. MLA International Bibliography. Web. 10 Nov. 2014.

---. “The Text Ported." Literary Linguistic Computing 17.1 (2002): 77-87. Oxford Journals Online. 26 Jul. 2002. Web. 21 Nov. 2015.

Schreibman, Susan et. al., eds. The Versioning Machine: A Tool for Displaying and Comparing Different Versions of Literary Texts. Computer software. A Digital Collections and Research Project. Vers. 4.0. 15 Nov. 2014.

---. "Credits." Schreibman, Susan et. al., eds. 19 May 2011. Web.15 Jan. 2016.

Seaward, Louise "Progress Update, 14 to 20 November 2015." Transcribe Bentham. London, UK: University College London. 20 Nov. 2015. Web. 22 Nov. 2015.

Snyder, Henry L. "Daniel Defoe, Arthur Maynwaring, Robert Walpole, and Abel Boyer: Some Considerations of Authorship." Huntington Library Quarterly 33.2 (Feb., 1970): 133-153. JSTOR. Web. 17 Sept. 2015. 
Statute of Anne. April 10, 1710. Lillian Goldman Law Library, Yale Law School, 2008. The Avalon Project. Web. 3 Oct 2015. http://avalon.law.yale.edu/18th_century lanne 1710.asp.

Stubbs, Estelle, Michael Pidd, Orietta Da Rold, Simon Horobin, Claire Thomson and Linda Cross, eds. The Multitext Edition. The Norman Blake Editions of The Canterbury Tales. University of Sheffield. 2013. Web. 19 Nov. 2015.

Tanselle, G. Thomas (Gregory Thomas). Textual Criticism and Scholarly Editing. Charlottesville, VA: University Press of Virginia, 1990.

Tedder, H. R. "Johnson, Charles (fl. 1724-1734)." Rev. David Cordingly. Oxford Dictionary of National Biography. Ed. H. C. G. Matthew and Brian Harrison. Oxford: OUP, 2004. Online ed. Ed. Lawrence Goldman. Web. 2 Feb. 2015.

TEI Consortium. Critical Apparatus. "P5: Guidelines for Electronic Text Encoding and Interchange.” Text Encoding Initiative. Ver. 2.9.1 15 Oct. 2015. Web. 8 Feb. 2016.

Temple, Kathryn. "Authors and other Criminals: Authorship in Eighteenth-Century Britain” Literature Compass 1.1 (2003): 1-5. Wiley Online Library. 15 Dec. 2005. Web. 17 Sept. 2015.

Text Encoding Initiative. "12 Critical Apparatus." P5: Guidelines for Electronic Text Encoding and Interchange. 15 Oct. 2015. Web. 16 Jan 2016.

---. 12.1.1 “The Apparatus Entry”.

“Types of Editions." Editions and Editing. Harvard isites, n.d. Web. 1 March 2015. $<$ http://isites.harvard.edu/fs/docs/icb.topic453618.files/Central/editions/edition_ty pes.html>. 
Warton, Joseph. An Ode to evening. Translated to Latin verse. London: Printed for W. Owens, at Homer's Head near Temple Bar.1749. Eighteenth Century Collections Online. 31 Dec. 2008. Web. 11 Oct. 2015.

Woodmansee, Martha. The Author, Art and the Market. Columbia University Press: New York, NY, 1994.

Young, Edward. Conjectures on Original Composition. $2^{\text {nd }}$ ed. London: Printed for A. Millar, in the Strand and R. and J. Dodsley in Pall-Mall, 1759. Eighteenth Century Collections Online. 1 Oct. 2003. Web. 19 Sept. 2015. 